UNIVERSIDADE DE SÃO PAULO

INSTITUTO DE PSICOLOGIA

NÁDIA BAGGIO BARRETO RODRIGUES

Aspectos do aprendizado motor em pacientes com Esclerose Múltipla Remitente Recorrente: implicações para a reabilitação 
UNIVERSIDADE DE SÃO PAULO

INSTITUTO DE PSICOLOGIA

NÁDIA BAGGIO BARRETO RODRIGUES

Aspectos do aprendizado motor em pacientes com Esclerose Múltipla Remitente Recorrente: implicações para a reabilitação

Dissertação apresentada ao Instituto de Psicologia da Universidade de São Paulo como parte dos requisitos para obtenção do título de Mestre em Neurociências e Comportamento.

Área de concentração: Neurociências e Comportamento

Orientadora: Prof. ${ }^{a}$ Dr. ${ }^{a}$ Michele Schultz Ramos

São Paulo 


\section{Aspectos do aprendizado motor em pacientes com Esclerose Múltipla Remitente Recorrente: implicações para a reabilitação}

Dissertação apresentada ao Instituto de Psicologia da Universidade de São Paulo como parte dos requisitos para obtenção do título de Mestre em Neurociências e Comportamento.

BANCA EXAMINADORA

Prof $^{\mathrm{a}}$. Dr ${ }^{\mathrm{a}}$. Luana Talita Diniz Ferreira

Hospital Israelita Albert Einsten

Prof. Dr. Flávio Henrique Bastos

Escola de Educação Física e Esportes-Universidade de São Paulo

Prof $^{\mathrm{a}}$. Dra ${ }^{\mathrm{a}}$. Cynthia Bedeschi

Instituto de Psicologia-Universidade de São Paulo

Prof $^{\mathrm{a}}$. Dra ${ }^{\mathrm{a}}$. Michele Schultz Ramos

Professor Orientador- Presidente da Banca Examinadora 
AUTORIZO A REPRODUÇÃO E DIVULGAÇÃO TOTAL OU PARCIAL DESTE TRABALHO, POR QUALQUER MEIO CONVENCIONAL OU ELETRÔNICO, PARA FINS DE ESTUDO E PESQUISA, DESDE QUE CITADA A FONTE.

Catalogação na publicação Biblioteca Dante Moreira Leite Instituto de Psicologia da Universidade de São Paulo Dados fornecidos pelo(a) autor(a)

Baggio Barreto Rodrigues, Nádia

Aspectos do aprendizado motor em pacientes com Esclerose Múltipla Remitente Recorrente: implicações para a reabilitação / Nádia Baggio Barreto Rodrigues; orientadora Michele Schultz Ramos. -- São Paulo, 2019.

$122 \mathrm{f}$.

Dissertação (Mestrado - Programa de Pós-Graduação em Neurociências e Comportamento) -- Instituto de Psicologia, Universidade de São Paulo, 2019.

1. Esclerose Múltipla. 2. Aprendizado Motor. 3. Reabilitação Física. I. Schultz Ramos, Michele, orient. II. Título. 
Dedico aos meus pais e à minha irmã, pois são minha inspiração e minha força para seguir adiante em todos os momentos da minha vida. 


\section{AGRADECIMENTOS}

Agradeço primeiramente a Deus por mais essa oportunidade de crescimento pessoal e profissional.

Agradeço à minha mãe e ao meu pai pelo amor e ensinamentos em todos os momentos da minha vida. Se hoje realizo mais este sonho, devo isso a vocês! Mãe, obrigada por me ajudar a seguir em frente e por não me deixar esmorecer!

Agradeço à Daniela, minha irmã, por me fazer acreditar que sou capaz de realizar meus desejos, por me fazer mais forte e me fazer desejar ser melhor a cada dia!

Agradeço ao Fabrizio, não apenas pelo auxílio imprescindível na construção e manutenção do aparelho utilizado nesta pesquisa, mas especialmente por acreditar nas minhas capacidades mais do que eu mesma!

Agradeço à minha orientadora, Michele Schultz, por ser compreensiva com as minhas limitações e dificuldades e por entender e me apoiar nos diversos processos que passei até a entrada no mestrado e especialmente por sua ética profissional!

Agradeço à ABEM por me aceitar em sua casa, especialmente à Dra . Ana Maria Canzonieri e ao psicólogo Lucas Ribeiro, que compartilharam seus conhecimentos e viveram essa experiência ao meu lado!

Agradeço aos voluntários desta pesquisa, sem os quais nada seria possível! Obrigada por sua paciência e dedicação! Sei o quanto o tempo de cada um é precioso e quão difícil é se colocar em posição de teste, por isso agradeço imensamente a participação de cada um!

Agradeço ao professor Mário Pedrazolli e sua aluna de pós-doutorado Pâmela, pela introdução nos domínios da genética e da biologia molecular!

Agradeço aos meus amigos, por seu carinho, compreensão e paciência nessa jornada! De forma especial à Ana Laura Ricci Victor, minha inspiração, e Martha Aguirre, companheira de jornada!

Agradeço ao financiamento da $\mathrm{CNPq}$, sem o qual eu não teria recursos para realizar esta pesquisa.

Por fim, agradeço a todos que me auxiliaram neste processo das mais diversas formas! 


\section{LISTA DE ILUSTRAÇÕES}

Figura 1. Foto do aparelho de teste de aprendizado motor.

Figura 2. Foto do aparelho de teste de aprendizado motor.

Figura 3. Foto do detalhe do aparelho utilizado para o teste de AM. Enfase no encaixe da barra na caixa.

Figura 4. Delineamento do teste de aprendizado motor.

Figura 5. Fluxograma de inclusão dos participantes do GE.

Figura 6. Frequência da EDSS.

Figura 7. Gráfico das médias e intervalo de confiança de T1 em cada bloco da fase AQ para cada grupo.

Figura 8. Gráfico das médias e intervalo de confiança de $\mathrm{T} 1$ em cada tentativa do primeiro bloco da fase AQ para cada grupo.

Figura 9. Gráfico das médias e intervalo de confiança de $\mathrm{T} 1$ em cada bloco da fase RET 1 para cada grupo.

Figura 10. Gráfico das médias e intervalo de confiança de T1 em cada bloco da fase RET 2 para cada grupo.

Figura 11. Gráfico das médias e intervalo de confiança de T1 em cada bloco da fase TR para cada grupo.

Figura 12. Gráfico das médias e intervalo de confiança de T1 nas fases AQ e TR para cada grupo. Transferência de aprendizado.

Figura 13. Gráfico de comparação das médias e intervalo de confiança de T1 ao longo das fases AQ, RET 1 e RET 2 para cada grupo.

Figura 14. Gráfico das médias e intervalo de confiança de T2 em cada bloco da fase AQ para cada grupo.

Figura 15. Gráfico das médias e intervalo de confiança de T2 em cada bloco da fase RET 1 para cada grupo. 
Figura 16. Gráfico das médias e intervalo de confiança de T2 em cada bloco da fase RET 2 para cada grupo.

Figura 17. Gráfico das médias e intervalo de confiança de T2 em cada bloco da fase TR para cada grupo.

Figura 18. Gráfico das médias e intervalo de confiança de T1 nas fases AQ e TR para cada grupo. Transferência de aprendizado.

Figura 19. Gráfico de comparação das médias e intervalo de confiança de T2 ao longo das fases AQ, RET 1 e RET 2 para cada grupo.

Figura 20. Gráfico das médias e intervalo de confiança de T3 em cada bloco da fase AQ para cada grupo.

Figura 21. Gráfico das médias e intervalo de confiança de T3 em cada bloco da fase RET1 para cada grupo.

Figura 22. Gráfico das médias e intervalo de confiança de T3 em cada bloco da fase RET 2 para cada grupo.

Figura 23. Gráfico das médias e intervalo de confiança de T3 em cada bloco da fase TR para cada grupo.

Figura 24. Gráfico das médias e intervalo de confiança de T3 nas fases AQ e TR para cada grupo. Transferência de aprendizado.

Figura 25. Gráfico de comparação das médias e intervalo de confiança de T3 ao longo das fases AQ, RET 1 e RET 2 para cada grupo.

Figura 26. Gráfico das médias e intervalo de confiança de T4 em cada bloco da fase AQ para cada grupo.

Figura 27. Gráfico das médias e intervalo de confiança de T4 em cada bloco da fase RET1 para cada grupo.

Figura 28. Gráfico das médias e intervalo de confiança de T4 em cada bloco da fase RET 2 para cada grupo.

Figura 29. Gráfico das médias e intervalo de confiança de T4 em cada bloco da fase TR para cada grupo. 
Figura 30. Gráfico de comparação das médias e intervalo de confiança de T4 ao longo das fases AQ e TR para cada grupo.

Figura 31. Gráfico de comparação das médias e intervalo de confiança de T4 ao longo das fases AQ, RET 1 e RET 2 para cada grupo.

Figura 32. Gráfico das médias e intervalo de confiança de T5 em cada bloco da fase AQ para cada grupo.

Figura 33. Gráfico das médias e intervalo de confiança de T5 em cada bloco da fase RET1 para cada grupo.

Figura 34. Gráfico das médias e intervalo de confiança de T5 em cada bloco da fase RET 2 para cada grupo.

Figura 35. Gráfico das médias e intervalo de confiança de T5 em cada bloco da fase TR para cada grupo.

Figura 36. Gráfico de comparação das médias e intervalo de confiança de T5 ao longo das fases AQ e TR para cada grupo.

Figura 37. Gráfico de comparação das médias e intervalo de confiança de T5 ao longo das fases AQ, RET 1 e RET 2 para cada grupo.

Figura 38. Gráfico das médias e intervalo de confiança de "Erros" em cada bloco da fase AQ para cada grupo.

Figura 39. Gráfico das médias e intervalo de confiança de "Erros" em cada bloco da fase RET 1 para cada grupo.

Figura 40. Gráfico das médias e intervalo de confiança de "Erros" em cada bloco da fase RET 2 para cada grupo.

Figura 41. Gráfico das médias e intervalo de confiança de "Erros" em cada bloco da fase TR para cada grupo.

Figura 42. Gráfico das médias e intervalo de confiança de "Erros" nas fases AQ e TR para cada grupo. Transferência de aprendizado.

Figura 43. Gráfico de comparação das médias e intervalo de confiança de "Erros" ao longo das fases AQ, RET 1 e RET 2 para cada grupo. 
Figura 44. Gráfico das médias e intervalo de confiança de "RETIRADA ANTECIPADA DA MÃO” em cada bloco da fase AQ para cada grupo.

Figura 45. Gráfico das médias e intervalo de confiança de "RETIRADA ANTECIPADA DA MÃO” em cada bloco da fase RET1 para cada grupo.

Figura 46. Gráfico das médias e intervalo de confiança de "RETIRADA ANTECIPADA DA MÃO” em cada bloco da fase RET2 para cada grupo.

Figura 47. Gráfico das médias e intervalo de confiança de "RETIRADA ANTECIPADA DA MÃO” em cada bloco da fase TR para cada grupo.

Figura 48. Gráfico das médias e intervalo de confiança de "RETIRADA ANTECIPADA DA MÃO” nas fases AQ e TR para cada grupo. Transferência de aprendizado.

Figura 49. Gráfico de comparação das médias e intervalo de confiança de “RETIRADA ANTECIPADA DA MÃO” ao longo das fases AQ, RET 1 e RET 2 para cada grupo. 
LISTA DE TABELAS

Tabela 1- Caracterização da amostra 


\section{LISTA DE ABREVIATURAS E SIGLAS}

EM: esclerose múltipla

SNC: sistema nervoso central

AM: aprendizagem motora/ aprendizado motor

BDNF: brain-derived neurotrophic factor

AVE: acidente vascular encefálico

EMRR: esclerose múltipla remitente recorrente

EMSP: esclerose múltipla secundária progressiva

EMPP: esclerose múltipla primária progressiva

GE: grupo experimental

GC: grupo controle

ABEM: Associação brasileira de esclerose múltipla

EDSS: Escala Expandida do Estado de Incapacidade

MEEM: Mini-exame do estado mental

AQ: fase de aquisição

RET 1: fase de retenção a curto prazo

TR: fase de transferência

RET 2: fase de retenção a longo prazo

GLM: modelo linear generalizado

IC: intervalo de confiança 


\section{RESUMO}

A Esclerose Múltipla (EM) é uma doença autoimune, inflamatória e desmielinizante, a qual afeta o sistema nervoso central (SNC) podendo ocasionar disfunções sensoriais, cognitivas e/ou motoras. Até o momento não há cura, entretanto, os indivíduos acometidos podem apresentar expectativa de vida prolongada e de boa qualidade utilizando-se da terapêutica medicamentosa correta e se envolvendo nos programas de reabilitação física e cognitiva, os quais se relacionam diretamente à aprendizagem motora (AM). Entende-se AM como um fenômeno que compreende mudanças no SNC, advindas de experiências e práticas prévias, relacionadas à capacidade de realizar tarefas motoras específicas, resultado de processos de neuroplasticidade. O objetivo desta pesquisa foi avaliar aspectos do AM na EM. O estudo foi aprovado pelo Comitê de Ética em Pesquisa com Humanos da Escola de Artes, Ciências e Humanidades da Universidade de São Paulo - EACH/USP - através do parecer número 1.947.155; CAAE 60189716.6.0000.5390. A amostra foi composta por 36 indivíduos, sendo 18 com Esclerose Múltipla Remitente Recorrente (EMRR) e 18 sem a doença, os quais foram submetidos a testes que avaliaram aspectos do AM: aquisição, retenção a curto e a longo prazo e transferência, através da realização de uma tarefa de função manual avaliada por um sistema computadorizado. Os testes foram filmados nos planos sagital e transversal durante a execução da tarefa, sendo estes vídeos avaliados posteriormente de forma qualitativa. Os resultados encontrados neste estudo foram semelhantes entre os grupos na maioria das variáveis estudadas, demonstrando que os indivíduos com EMRR, de baixa incapacidade motora e com até 10 anos de diagnóstico, apresentam a mesma curva de AM que indivíduos sem a doença. Apesar da capacidade de AM deste indivíduos estar íntegra, algumas particularidades encontradas nesta população indicam a necessidade de repensar as estratégias terapêuticas utilizadas neste grupo, a fim de potencializar as capacidades de aprendizagem motora.

Palavras-chave: esclerose múltipla; aprendizado motor; reabilitação física 


\begin{abstract}
Multiple Sclerosis (MS) is an autoimmune, inflammatory and demyelinating disease, which affects the central nervous system (CNS) and can cause sensory, cognitive and / or motor dysfunctions. At the moment there is no cure, however, the affected individuals can present long life expectancy and good quality by using the correct drug therapy and becoming involved in physical and cognitive rehabilitation programs, which are directly related to motor learning (ML). ML is understood as a phenomenon that includes changes in the CNS, arising from previous experiences and practices related to the capacity to perform specific motor tasks, the result of neuroplasticity processes. The aim of this study was to evaluate aspects of ML in MS. The research was approved by the Committee of Ethics in Research with Humans of Escola de artes, ciências e humanidades- Universidade de São Paulo - EACH / USP number 1,947,155; CAAE 60189716.6.0000.5390. The sample consisted of 36 individuals, 18 of them with RRMS and 18 without the disease, who underwent tests that evaluated aspects of ML: acquisition, short and long term retention and transfer, by performing a function task manual evaluated by a computerized system. The tests were filmed in the sagittal and transversal planes during the execution of the task, these videos being evaluated later in a qualitative way. The results found in this study were similar between the groups in most of the variables, demonstrating that the individuals with RRMS, with low motor incapacity and with up to 10 years of diagnosis, present the same motor learning curve as individuals without the disease. Although the motor learning ability of these individuals is suitable, some particularities found in the MS population indicate the need to rethink the therapeutic strategies used in this group, in order to potentiate the motor learning abilities
\end{abstract}

Keywords: Multiple sclerosis; motor learning; physical rehabilitation 


\section{SUMÁRIO}

1 INTRODUÇÃO. .19

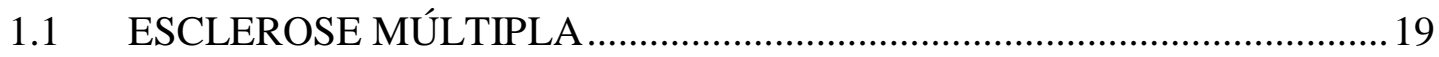

1.1.1 INCIDÊNCIA E PREVALÊNCIA ......................................................... 20

1.1.2 FORMAS CLÍNICAS, SINTOMATOLOGIA E TRATAMENTO ...........20

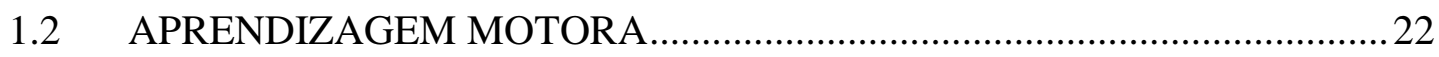

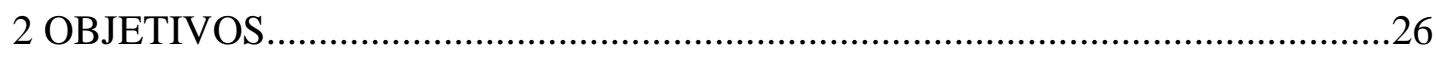

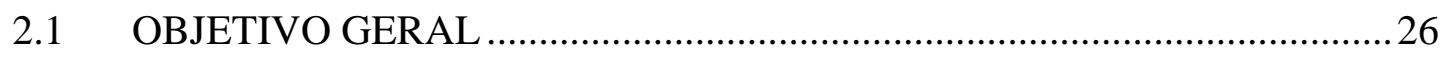

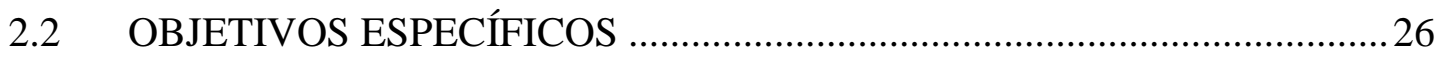

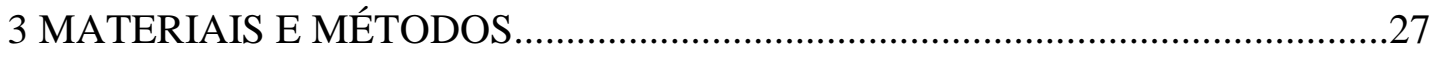

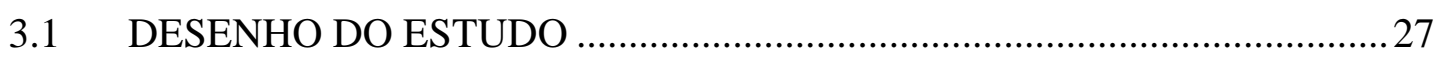

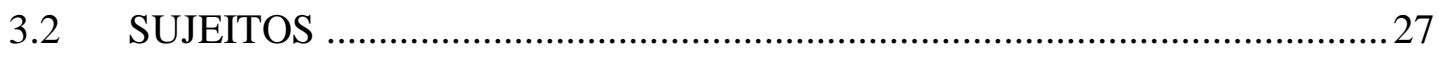

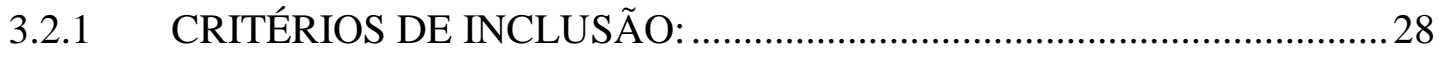

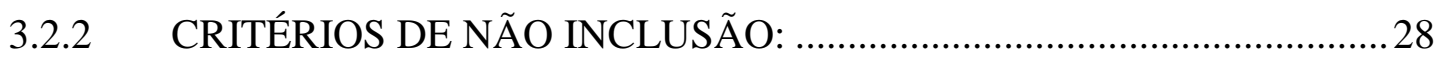

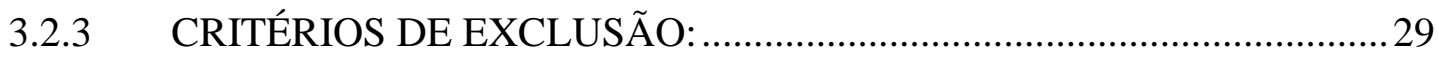

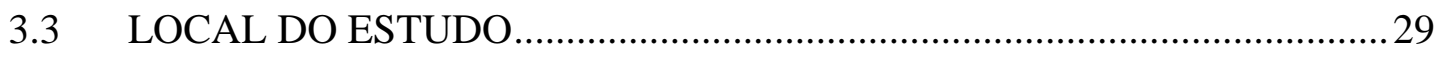

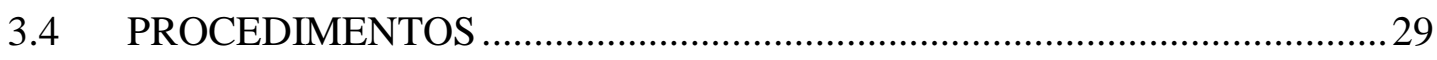

3.4.1 SELEÇÃO E AGENDAMENTO DOS SUJEITOS …………………….......2 29

3.4.2 AVALIAÇÃO DO APRENDIZADO MOTOR ………………………........30

3.4.2.1 Variáveis Dependentes ........................................................................ 34

3.4.2.2 Avaliação do Aprendizado Motor - Análise Qualitativa........................35

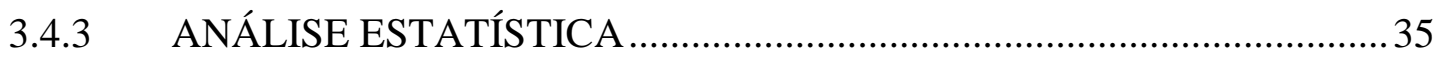

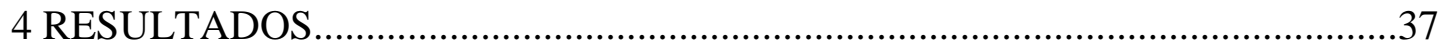

4.1 CARACTERIZAÇÃO DOS GRUPOS …………………………………....... 37 


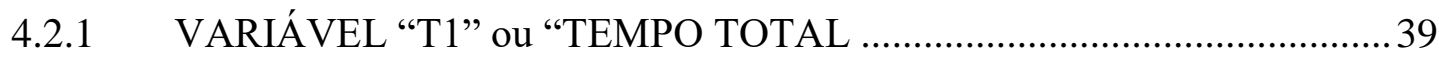

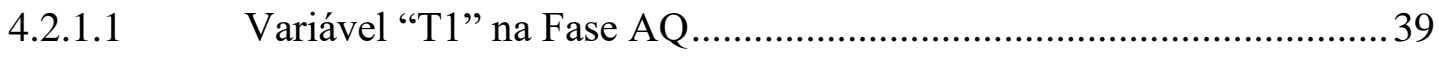

4.2.1.2 Variável "T1” na Fase RET 1 (memória motora de curto prazo)........41

4.2.1.3 Variável "T1" na Fase RET 2 (memória motora de longo prazo) .......4 42

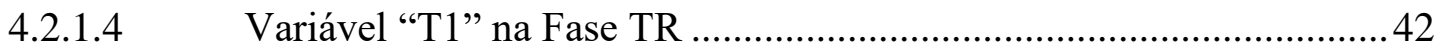

4.2.1.5 Variável “T1” - Comparação entre as Fases AQ e TR ........................ 43

4.2.1.6 Variável “T1” - Comparação entre as Fases AQ, RET 1 e RET 2 .....44

4.2.2 VARIÁVEL “T2” ou “TEMPO DE REAÇÃO” ........................................ 45

4.2.2.1 Variável “T2” na Fase AQ.......................................................... 45

4.2.2.2 Variável “T2” na Fase RET 1 (memória motora de curto prazo)........46

4.2.2.3 Variável “T2” na Fase RET 2 (memória motora de longo prazo) ....... 47

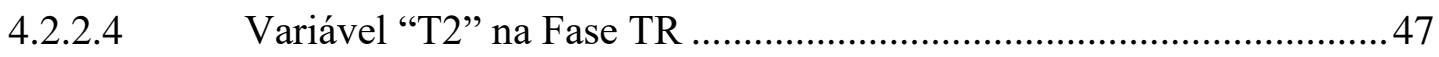

4.2.2.5 Variável “T2” - Comparação entre as Fases AQ e TR ..........................48

4.2.2.6 Variável “T2” - Comparação entre as Fases AQ, RET 1 e RET 2 ......49

4.2.3 VARIÁVEL “T3” ou “TEMPO DE INICIAÇÃO”..................................50

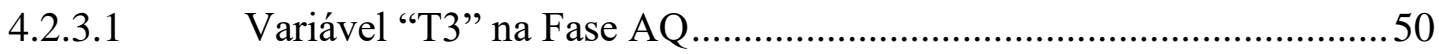

4.2.3.2 Variável "T3" na Fase RET 1 (memória motora de curto prazo).........51

4.2.3.3 Variável “T3” na Fase RET 2 (memória motora de longo prazo) .......52

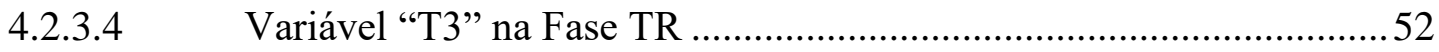

4.2.3.5 Variável “T3” - Comparação entre as Fases AQ e TR .........................53

4.2.3.6 Variável “T3” -Comparação entre as Fases AQ, RET 1 e RET 2 ......54

4.2.4 VARIÁVEL “T4” ou “TEMPO MÃO-BARRA” ......................................55

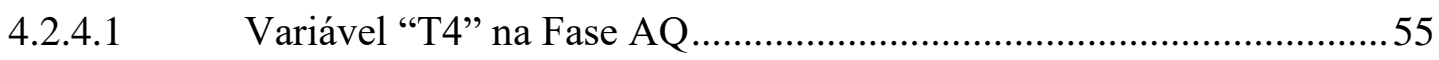


4.2.4.2 Variável "T4” na Fase RET 1 (memória motora de curto prazo).........56

4.2.4.3 Variável “T4” na Fase RET 2 (memória de longo prazo) ....................57

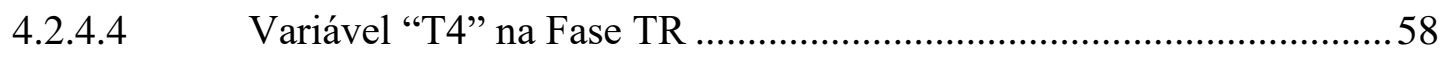

4.2.4.5 Variável “T4” - Comparação entre as Fases AQ e TR .......................59

4.2.4.6 Variável "T4" - Comparação entre as Fases AQ, RET 1 e RET 2 .....60

4.2.5 VARIÁVEL “T5” ou “TEMPO DE FINALIZAÇÃO”..............................61

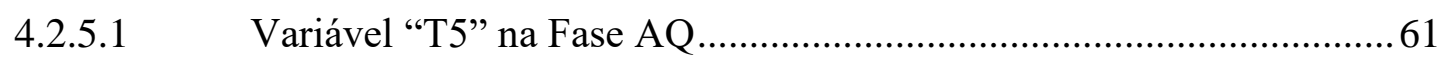

4.2.5.2 Variável “T5” na Fase RET 1 (memória motora de curto prazo)........6 62

4.2.5.3 Variável "T5” na Fase RET 2 (memória motora de longo prazo) ........63

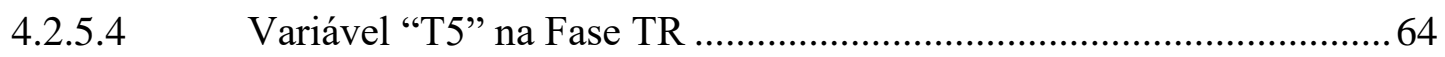

4.2.5.5 Variável “T5” - Comparação entre as Fases AQ e TR .........................6 64

4.2.5.6 Variável “T5” - Comparação entre as Fases AQ, RET 1 e RET 2 .....65

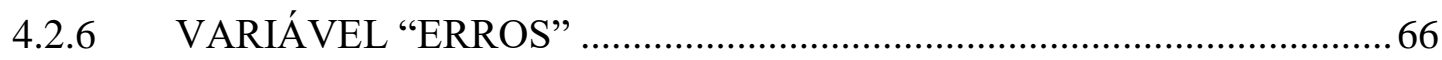

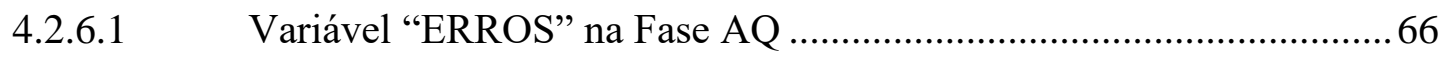

4.2.6.2 Variável "ERROS” na Fase RET 1 (memória motora de curto prazo)67

4.2.6.3 Variável “ERROS” na Fase RET 2 (memória de longo prazo)............68

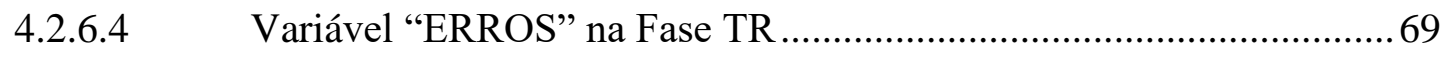

4.2.6.5 Variável "ERROS” - Comparação entre as Fases AQ e TR.................69

4.2.6.6 Variável “ERROS”-Comparação entre AQ, RET 1 e RET 2 ..............70

4.2.7 Variável "RETIRADA ANTECIPADA DA MÃO” .................................. 71

4.2.7.1 Variável "RETIRADA ANTECIPADA DA MÃO” na Fase AQ .......71

4.2.7.2 Variável "RETIRADA ANTECIPADA DA MÃO” na Fase RET 1...72

4.2.7.3 Variável "RETIRADA ANTECIPADA DA MÃO” na Fase RET 2...73

4.2.7.4 Variável "RETIRADA ANTECIPADA DA MÃO” na Fase TR ........ 74 
4.2.7.5 Variável “RETIRADA ANTECIPADA DA MÃO”-Comparação entre AQ e TR 75

4.2.7.6 Variável "RETIRADA ANTECIPADA DA MÃO” - Comparação

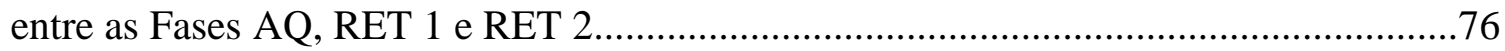

4.2.8 ANÁLISE POR TAXA DE APRENDIZAGEM …............................... 77

4.3 ANÁLISE QUALITATIVA DOS VÍDEOS...............................................78

5 DISCUSSÃO

6 CONCLUSÃO

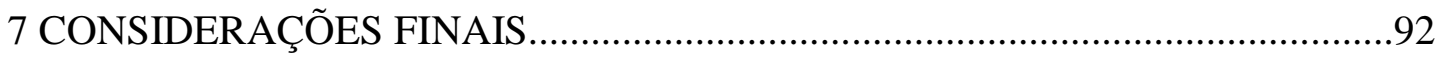

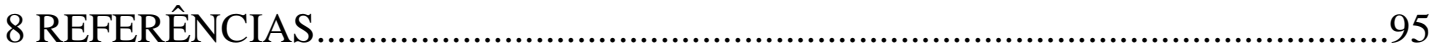

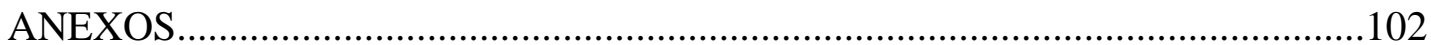





\section{INTRODUÇÃO}

\subsection{ESCLEROSE MÚLTIPLA}

A esclerose múltipla (EM) é uma doença autoimune, inflamatória e desmielinizante, a qual afeta o encéfalo e/ou a medula espinhal uni ou bilateralmente (HELDNER et al., 2014) podendo ocasionar disfunções sensoriais, cognitivas e/ou motoras (SOCIE e SOSNOFF, 2013), as quais podem ser agudas e transitórias ou se acumular, ocasionando deficiências (FILIPPI et al.; 2017). Caracteriza-se por infiltrados inflamatórios perivasculares, desmielinização, perda axonal e gliose de variados graus (REJDAK et al., 2010), os quais ocorrem especialmente na substância branca, formando múltiplas placas características da doença no SNC (MILO e KAHANA, 2010). Tais placas configuram a aparência de uma cicatriz no tecido nervoso e ocorrem devido à perda focal da mielina com relativa preservação de axônios, sendo estas lesões divididas em agudas ativas, crônicas ativas e crônicas inativas (REJDAK et al., 2010).

Trata-se da principal causadora de deficiência neurológica não traumática em adultos jovens, sendo que o início dos sintomas ocorre em torno dos 30 anos, entre os 20 e 40 anos em 70\% dos pacientes acometidos (REJDAK et al., 2010).

A causa exata da doença não está definida, entretanto, observam-se relações com fatores genéticos, infecciosos, inflamatórios e ambientais que podem estar envolvidos com o curso da mesma (IWANOWSKI e LOSY, 2015). Desse modo, indivíduos geneticamente suscetíveis, quando expostos a agentes ambientais, sofrem um ataque autoimune na bainha de mielina e outros componentes axonais, desenvolvendo a EM (COMPSTON e COLES, 2002). Corroborando com a hipótese de relação da doença com fatores genéticos, observa-se incidência vinte vezes mais alta entre parentes de primeiro grau, e sabe-se da correlação entre alterações no gene HLA do cromossomo 6 (DYMENT et al., 2004) e de polimorfismos em 5p13 e 10p15 (HAFLER et al., 2007) com o desenvolvimento da EM. Fatores infecciosos também se relacionam com o desenvolvimento da EM; a literatura apresenta correlações com a infecção pelo vírus Epstein-Barr (LEVIN et al., 2003), vírus da Herpes (HHV-6) e Chlamydophila pneumoniae (REJDAK et al., 2010). Fatores ambientais relacionados às baixas taxas de vitamina D decorrentes da baixa exposição aos raios solares, questões dietéticas, 
tabagismo, classe social e atividade laboral também foram apresentados como fatores ligados à doença (CORREALE et al., 2009; REJDAK et al., 2010).

\subsubsection{INCIDÊNCIA E PREVALÊNCIA}

A prevalência média mundial de pacientes com EM é de 33/100.000 habitantes, o que corresponde a cerca de 2,3 milhões, variando conforme as regiões, sendo que o Hemisfério Norte apresenta as mais altas prevalências enquanto a América do Sul é considerada de baixa prevalência, apresentando 5 a 20/100.000 habitantes (BROWNE et al., 2014). Segundo a Associação Brasileira de Esclerose Múltipla (ABEM), estima-se que existam mais de 35.000 brasileiros com EM (ABEM, 2018). Possivelmente as diferenças na distribuição da doença devam-se à ancestralidade, assim, a ocorrência entre descendentes do oeste europeu é significativa, enquanto que entre descendentes da Nova Zelândia e do Canadá Ocidental parece menor, mesmo com os descendentes vivendo em locais de alta prevalência (REJDAK et al., 2010). Essa distribuição pouco uniforme também pode ser relacionada à redução da síntese de vitamina $\mathrm{D}$, uma vez que, quanto maior a distância da linha do Equador, menor a incidência de raios solares, sendo a síntese desta vitamina dependente da incidência solar (JAGANNATH et al., 2010).

\subsubsection{FORMAS CLÍNICAS, SINTOMATOLOGIA E TRATAMENTO}

Os indivíduos acometidos pela EM podem apresentar diversos sintomas dependendo das regiões acometidas do SNC e podem ocasionar restrições funcionais e piora da qualidade de vida (MOTL e MCAULEY, 2010). Alguns se relacionam a questões motoras como fraqueza muscular, fadiga (LATIMER-CHEUNG et al., 2013), alterações da marcha (LAROCCA, 2011), do controle postural, equilíbrio (MATSUDA et al., 2011), dor, espasticidade e tremores (RICHARDS et al., 2002). Outras alterações comuns são depressão, disfunções urinárias, sexuais e intestinais, vertigens, convulsões (RICHARDS et al., 2002), alterações cognitivas, visuais e de fala (MOTL e MCAULEY, 2010).

A EM se apresenta em duas formas clínicas, a saber: esclerose múltipla remitente recorrente (EMRR) e esclerose múltipla primária progressiva (EMPP). A EMRR a forma 
mais comum da doença, correspondendo a cerca de $85 \%$ a $90 \%$ dos casos totais de EM; ocorre entre os 20 e 30 anos de idade, em proporção 2:1 para as mulheres em relação aos homens. Caracteriza-se por episódios de surto com piora clínica, seguidos de recuperação total ou parcial e intercalados por períodos de estabilidade (MILO e KAHANA, 2010; IWANOWSKI e LOSY, 2015). Após dez anos do início dos sintomas, 40\% dos casos desta forma clínica evoluem para a esclerose múltipla secundária progressiva (EMSP), cujos sintomas são os mesmos da EMRR, porém com característica de piora progressiva, sem que haja remissão dos sintomas (IWANOWSKI e LOSY, 2015). A forma EMPP inicia-se mais tarde, ao redor dos 40 anos de idade e acomete os sexos igualmente. Corresponde a cerca de $10 \%$ a $15 \%$ dos casos totais de EM e se caracteriza por disfunção neurológica progressiva que pode ou não apresentar exacerbação (IWANOWSKI e LOSY, 2015). Existe ainda uma forma pediátrica da doença, ou seja, antes dos 18 anos de idade, a qual corresponde a cerca de 3 a $10 \%$ dos diagnósticos totais e, aparentemente, cursa com maior inflamação (BENSON et al., 2014).

Como dito acima, a doença apresenta caráter progressivo, sendo essa progressão direta no caso da EMPP e da EMSP ou através dos surtos na EMRR. Aproximadamente 15 anos após o diagnóstico há probabilidade de 40\% dos pacientes com EM apresentarem dificuldade para realizar a marcha, sendo necessária a utilização de algum tipo de dispositivo auxiliar e cerca de $25 \%$ necessitam de cadeira de rodas (ZWIBEL, 2009).

Visando o controle destes sintomas, a redução das internações e a diminuição das taxas de recidiva são empregadas algumas terapêuticas medicamentosas, sendo os principais medicamentos o interferon beta e o acetato de glatirâmero, além da suplementação de vitamina $\mathrm{D}$, a qual muitas vezes é empregada como auxiliar (REJDAK et al., 2010). Novos estudos têm demonstrado a ligação entre baixos níveis de colesterol e a dificuldade de reorganização da mielina a partir de precursores dos oligodendrócitos. Assim, parece que a suplementação dietética de colesterol poderia melhorar esse metabolismo e, consequentemente, o quadro clínico, como demonstrado em animais, entretanto essa terapêutica é controversa uma vez que o aumento do colesterol pode também influenciar negativamente a inflamação (BERGHOFF et al., 2017).

No mais, é imprescindível o acompanhamento interdisciplinar dos diversos profissionais da saúde, entre eles fisioterapeutas e psicólogos, visando à manutenção da qualidade de vida dos pacientes com EM (LATIMER-CHEUNG et al., 2013). A fisioterapia objetiva melhorar as funções motoras, interferindo positivamente em aspectos 
físicos como força e flexibilidade muscular, condicionamento cardiorrespiratório e mobilidade (DALGAS et al, 2008).

\subsection{APRENDIZAGEM MOTORA}

Um dos principais objetivos da fisioterapia na reabilitação de indivíduos com lesões neurológicas é promover aprendizagem motora (AM). Entende-se AM como sendo um fenômeno que compreende mudanças no SNC relativamente permanentes, advindas de experiências prévias e práticas, relacionadas à capacidade de realizar tarefas motoras específicas (MAGILL, 2000; SHUMWAY-COOK e WOOLLACOTT, 2003). São conceituadas duas formas de AM, sendo o aprendizado explícito ou declarativo e o aprendizado implícito ou processual. No primeiro ocorre a recordação consciente de experiências prévias, pode ser rápido e ocorrer após uma única tentativa, enquanto no aprendizado implícito se faz necessária a repetição da tarefa em diversas tentativas (KARNI et al., 1998). O aprendizado explícito parece se relacionar a processos de planejamento motor e o implícito, podendo também ser considerado como aprendizado lento, reflete mudanças estruturais ou de planejamento a longo prazo e ocorre através do fortalecimento de conexões neurais (KARNI et al., 1998).

Outra teoria divide o processo de AM em aprendizado on line, consolidação e retenção (ABE et al., 2011). No aprendizado on line haveria melhora do desempenho ao longo de apenas uma sessão de treinamento até que o desempenho atinja níveis estáveis (REIS et al., 2009). A etapa de consolidação está relacionada à estabilização e aprimoramento, sendo que, na estabilização a memória se torna pouco sujeita a alterações na tarefa ou ambiente (MAGGIL, 2000; ROBERTSON e COHEN, 2006) e no aprimoramento podem ocorrer mudanças no desempenho motor entre as sessões de treinamento, ou seja, sem prática adicional e geralmente dependentes do sono, o que é chamado de aprendizado off line (ROBERTSON et al., 2004; REIS et al., 2009; WITT et al., 2010). A retenção permite resgatar as memórias motoras sem que haja novo treino da tarefa após determinados períodos (ABE et al., 2011), podendo ser retidas em diversos graus ao longo de semanas ou meses após o término do treinamento (REIS et al., 2009).

Durante a realização de uma tarefa motora há o armazenamento de informações relacionadas às condições iniciais, utilizadas no programa motor generalizado, consequências sensoriais do movimento e dos efeitos do movimento em relação aos 
resultados (SHERWOOD e LEE, 2003; SHUMWAY-COOK e WOOLLACOTT, 2003). Assim, a AM se baseia na construção de maior quantidade de programas motores de melhor qualidade, permitindo o desenvolvimento de amplo repertório motor (NEWELL, 2003). Dessa forma segundo a Teoria do Esquema de Schmidt (1975), a extensão e a variabilidade da prática favorecem o aprendizado, pois fortalecem a generalização do programa motor (SHERWOOD e LEE, 2003; SHUMWAY-COOK e WOOLLACOTT; 2003).

Diante do exposto, no momento em que um indivíduo se depara com a necessidade de realização de uma determinada tarefa, inicialmente há o planejamento da ação a ser realizada e, em seguida, a execução do movimento, o qual geralmente não é perfeito nas primeiras tentativas havendo a necessidade de correção de parâmetros dos movimentos de forma a deixá-los mais coordenados e efetivos nas tentativas subsequentes. Dessa forma observa-se melhora no desempenho, maior constância e fluidez de movimento, diminuição dos erros e diminuição no tempo de execução da tarefa (TEIXEIRA, 2004). Assim, pode-se inferir que houve aprendizado motor através da melhora do desempenho da tarefa (TEIXEIRA, 2004) e a fim de verificar a solidez do AM utilizam-se testes de retenção e/ou transferência. Nos testes de retenção verifica-se a permanência do comportamento motor adquirido após um período sem prática e, nos de transferência, verifica-se a capacidade de adequar um dado comportamento motor em um contexto diferente (MALHEIROS et al., 2015), podendo ser uma tarefa distinta porém com características semelhantes a treinada, na qual o indivíduo reproduz o mesmo movimento em outra circunstância (generalização próxima), ou há alteração de uma tarefa para outra em situação muito diferente da treinada (transferência para longe) ou ainda ocorre a realização da mesma tarefa com o outro membro (transferência inter membros) (VAN MIER e PETERSEN, 2006; SCHMIDT e WRISBERG, 2001).

A AM se dá através da prática do ato motor, o qual ocorre por meio da integração de diversos sistemas e diversas regiões encefálicas a partir de um modelo de processamento integrativo, o qual envolve o SNC e sistema osteomuscular, resultando na construção ou aperfeiçoamento dos comandos direcionados à execução (SHUMWAYCOOK e WOOLLACOTT, 2003). Por exemplo, para realizar um dado ato motor, há necessidade de aferências sensoriais indicando a posição ou o movimento do corpo e do alvo, há ativação das áreas de associação do córtex de forma a planejar o movimento, ativação do córtex motor primário para enviar os comandos do movimento e ativação dos núcleos da base e do cerebelo para modulá-lo (KANDEL et al., 1997). Dessa forma, a 
atividade das células nervosas que compõem o sistema motor está interligada ao processo de AM, por exemplo, a atividade das fibras trepadeiras do cerebelo pode se modificar durante a AM (KANDEL et al., 1997).

Este processo ocorre por meio da neuroplasticidade, definida como a forma que o SNC remodela a si próprio em função de mudanças ambientais tais como lesões, modificando suas conexões e funções neuronais (HALLETT, 2005; HENNIGAN et al., 2007; JOHNSTON, 2009), ou seja, a neuroplasticidade é a reorganização do SNC em sua estrutura e/ou função e inclui mecanismos de modificações neuronais, de vias neuronais, das sinapses, proliferação da glia, angiogênese e neurogênese (ZATORRE et al., 2012). Em casos de lesões, ocorre ipsi ou contralateralmente à lesão (NOWAK et al, 2009) e depende do tipo, tempo, extensão e localização da mesma (YOUNG e TOLENTINO, 2011). A mediação molecular dos processos de neuroplasticidade é feita por diversos fatores de crescimento neuronais, com destaque para o brain-derived neurotrophic factor (BDNF).

Uma vez que a reabilitação dos indivíduos com EM é dependente de sua capacidade de reaprender habilidades motoras perdidas devido às lesões neurológicas se faz necessária a compreensão deste fenômeno nestes indivíduos, neste sentido alguns pesquisadores têm conduzido pesquisas com este objetivo.

Parte destes estudos se dedicou a investigar se há melhora da função manual através de treinamentos a curto e a longo prazo, utilizando-se de tarefas virtuais e demonstraram que houve aprendizagem da tarefa sendo que os resultados encontrados se aproximaram dos resultados dos controles (CARPINELLA et al., 2012; ZAHIRI et al., 2017; TACHINNO et al., 2014) e outro foi além e verificou que o AM ocorre independente do grau de incapacidade motora (TOMASSINI et al., 2011). Embora todos estes estudos tenham encontrado bons resultados no que se refere ao aprendizado motor manual nessa população, uma pesquisa demonstrou resultados piores no grupo com EM do que no grupo controle, especialmente em tarefas de profundidade no treinamento de curto prazo (LEOCANI et al., 2010).

Outras pesquisas se dedicaram à investigação do aprendizado dos controles posturais e encontraram que apesar das performances dos grupos EM serem inicialmente piores em relação aos controles, após treinos de longo prazo houveram melhoras (CATTANEO et al., 2005; FLING et al., 2015). Além disso, demonstrou-se através de ressonância magnética funcional que possivelmente os indivíduos com EM dependem mais da ativação das vias córtico-estriatais do que das vias córtico-cerebelares para a 
aquisição e retenção motoras (FLING et al., 2015) e que os indivíduos com menor integridade do corpo caloso apresentam maior dificuldade de aprendizado do controle postural (GERA et al., 2016; PETERSON et al., 2017).

Ao avaliar o aprendizado visuomotor durante a marcha demonstrou-se adaptação semelhante nos grupos experimental e controle ao longo do treino de 1 dia e na retenção após uma semana (MCGOWAN et al., 2017).

Utilizando-se a estimulação transcraniana (TDCS) pós-treino a fim de verificar seus efeitos na consolidação motora, verificou-se que apesar da performance motora do grupo com EM ser pior do que a do controle, a velocidade e a magnitude do aprendizado foram superiores neste grupo, porém a TDCS foi eficiente para a consolidação dos resultados do grupo controle diferentemente do ocorrido com o grupo EM (RUMPF et al., 2018).

Embora haja diversos estudos investigando a AM na EM, observa-se que nenhum deles estudou especificamente cada fase deste processo tão complexo, baseando seus resultados exclusivamente na quantidade de erros e reduzindo os aspectos temporais exclusivamente ao tempo de reação. Além disso, a maioria dos estudos não realizou a investigação isolando os tipos clínicos da doença e teve sua amostra composta por indivíduos acima dos 40 anos, com incapacidade física moderada a alta e elevado tempo de curso da doença. No mais, não foram encontrados estudos na população brasileira com diagnóstico de EM.

Dada a importância do aprendizado motor para a melhora funcional dos indivíduos com EM e as limitações dos estudos encontrados nesta área, se faz necessária maior investigação deste fenômeno em sua plenitude bem como os aspectos biológicos da neuroplasticidade, sem a qual não há a aprendizagem. 


\section{OBJETIVOS}

\subsection{OBJETIVO GERAL}

Avaliar aspectos do aprendizado motor em indivíduos com diagnóstico de esclerose múltipla remitente recorrente e compará-los com indivíduos sem a doença.

\subsection{OBJETIVOS ESPECÍFICOS}

- Avaliar componentes motores do membro superior dominante;

- Avaliar a retenção motora a curto e a longo prazo;

- Avaliar as capacidades de transferência da habilidade motora. 


\section{MATERIAIS E MÉTODOS}

\subsection{DESENHO DO ESTUDO}

Trata-se de estudo caso controle, tendo sido aprovado pelo Comitê de Ética em Pesquisa com Humanos da Escola de Artes, Ciências e Humanidades da Universidade de São Paulo - EACH/USP - através do parecer número 1.947.155; CAAE 60189716.6.0000.5390, em 03/03/2017, conforme Anexo I.

\subsection{SUJEITOS}

Participaram do estudo indivíduos de ambos os sexos, divididos em grupo estudo (GE) e grupo controle (GC).

O cálculo da amostra foi feito com base no estudo de Tomassini e colaboradores (2010). Considerando-se diferença nos resultados dos testes de aprendizado motor para garantir um poder de teste de $80 \%$, nível de significância de 5\%, em um teste de hipótese bicaudal, foram necessários 16 indivíduos para o GE.

O GE é composto por 18 pacientes com diagnóstico de esclerose múltipla remitente recorrente em processo de reabilitação na Associação Brasileira de Esclerose Múltipla (ABEM) e o GC é composto 18 por indivíduos residentes na cidade de São Paulo que não apresentam EM ou qualquer outra patologia do SNC, semelhantes em sexo, idade, escolaridade e raça e em mesmo número que o GE.

Os indivíduos do GE foram selecionados de acordo com o grau de incapacidade motora segundo a Escala Expandida do Estado de Incapacidade (EDSS) - Anexo II, aplicada exclusivamente por avaliadores da ABEM, os quais são devidamente capacitados para a realização da mesma. Esta escala foi expandida em 1983, e tem por objetivo mensurar a máxima função dos indivíduos com EM. Trata-se de um método para quantificar as incapacidades ocorridas no decorrer da evolução da doença utilizando oito sistemas funcionais, a saber: funções piramidais, funções cerebelares, funções do tronco cerebral, funções sensitivas, funções vesicais, funções intestinais, funções visuais e funções mentais (KURTZKE, 1983). 
A fim de verificar as habilidades cognitivas necessárias para elegibilidade no estudo, todos os indivíduos do GE e GC foram avaliados através do Mini-Exame do Estado Mental (MEEM, Anexo III) por avaliador único e devidamente capacitado para a aplicação do instrumento. Trata-se de um teste de rastreamento e avaliação da função cognitiva o qual permite avaliar a orientação espacial e temporal, memória imediata e de evocação, cálculo, linguagem-nomeação, repetição, compreensão, escrita e cópia de desenho (DUNCAN et al., 2004).

\subsubsection{CRITÉRIOS DE INCLUSÃO:}

Para o GE foram incluídos indivíduos portadores de esclerose múltipla remitente recorrente cadastrados na ABEM, independente de sexo, de idade entre 18 e 65 anos e com classificação segundo a EDSS entre os níveis 0 e 5,5, com no máximo dez anos de diagnóstico da EM, sem limitações na amplitude de movimento do membro superior dominante e com força muscular suficiente para a realização da tarefa utilizada neste estudo. Tais critérios foram definidos com objetivo de garantir que não houvesse acometimento importante de membros superiores, grande limitação funcional e alterações decorrentes do envelhecimento.

Para o GC foram recrutados indivíduos saudáveis residentes em São Paulo de sexo, idade e raça semelhantes ao GE.

\subsubsection{CRITÉRIOS DE NÃO INCLUSÃO:}

- Surto no último mês;

- Apresentação de outras doenças de caráter neurológico concomitantes;

-Apresentação de alterações visuais que impedissem a realização das atividades propostas;

- Indivíduos com escore menor que 24 no MEEM (FOLSTEIN et al., 1975);

- Doenças ósseas pré-existentes, lesões articulares ou deformidades que afetassem o membro dominante para a execução das atividades propostas;

- Período pós-cirúrgico de correções ortopédicas no membro testado ou no tronco. 


\subsubsection{CRITÉRIOS DE EXCLUSÃO:}

- Apresentação de indisposição ou mal-estar durante a realização das atividades;

- Não comparecimento a qualquer dos dias previamente agendados para as avaliações protocolares, sem a possibilidade de remarcação;

- Por solicitação do paciente.

\subsection{LOCAL DO ESTUDO}

Os indivíduos foram avaliados na Associação Brasileira de Esclerose MúltiplaABEM, localizada na cidade de São Paulo-SP. A supervisora técnica e responsável pela equipe de pesquisa da ABEM, Dra Ana Maria Canzonieri e o psicólogo da ABEM, Lucas Felipe Ribeiro dos Santos, foram responsáveis pela liberação do espaço físico para as avaliações, análise dos prontuários, seleção e convite aos sujeitos e aplicação dos testes de avaliação cognitiva de todos os indivíduos.

\subsection{PROCEDIMENTOS}

\subsubsection{SELEÇÃO E AGENDAMENTO DOS SUJEITOS}

Primeiramente foi realizada triagem inicial dos indivíduos com EM através dos prontuários da ABEM de acordo com os critérios de inclusão previamente descritos; estes foram contatados via telefone e convidados a comparecer a ABEM em duas ocasiões, sendo os dias e horários agendados de acordo com a disponibilidade dos indivíduos e dos pesquisadores.

Inicialmente, os indivíduos foram apresentados à equipe de avaliadores, receberam as informações relacionadas aos procedimentos e foram convidados a ler e assinar o Termo de Consentimento Livre e Esclarecido (TCLE, Anexo IV)

Posteriormente, os indivíduos foram submetidos à avaliação cognitiva de acordo com o MEEM e à avaliação funcional do membro superior dominante, sendo incluídos ou não na pesquisa de acordo com critérios previamente descritos. No mesmo dia foram submetidos à primeira parte do teste de aprendizado motor, a saber: fases de aquisição 
(AQ), retenção a curto prazo (RET 1) e transferência (TR), conforme descrito a seguir. Em um segundo momento, realizado uma semana após o primeiro encontro, foram realizados os testes da fase de retenção a longo prazo (RET 2) do teste de aprendizado motor.

Os indivíduos do GC foram recrutados da comunidade, a partir das redes de contato acadêmicas e sociais e foram submetidos aos mesmos procedimentos do GE.

\subsubsection{AVALIAÇÃO DO APRENDIZADO MOTOR - TAREFA ESPECÍFICA}

Os indivíduos foram avaliados quanto aos aspectos de aquisição, retenção a curto e longo prazo e transferência através de uma tarefa manual que consistiu na inserção de uma barra de madeira em um orifício, a qual contempla os componentes de preensão, transporte e inserção (TORRIANI-PASIN, 2010), conforme ilustrado na figura 1. Trata-se de tarefa com alta demanda de planejamento, seriada, em meio estável e previsível, com controle por circuito fechado (SCHIMIDT e WRISBERG, 2001).

O instrumento utilizado para este estudo foi semelhante ao utilizado por TorrianiPasin (2010) conforme ilustram as figuras 2 e 3 , sendo composto por:

- Caixa de madeira com as dimensões $13 \mathrm{~cm} \mathrm{X} 15 \mathrm{~cm}$ X 4,5 cm com orifício na tampa em formato de cruz, para inserção de barra e sensores elétricos que são acionados nos momentos de toques da barra na tampa e no fundo da caixa;

- Lâmpada a qual indica o momento do início da tarefa;

- Placa de madeira para apoio inicial da mão com sensor de retirada da mão;

- 1 barra de madeira em formato de cruz, com duas extremidades de 1,5 cm e duas extremidades de $1 \mathrm{~cm}$;

- Suporte para a barra com altura de $6,5 \mathrm{~cm}$ no ponto de tangência com a barra com sensor para detecção do momento de retirada da barra do suporte. 


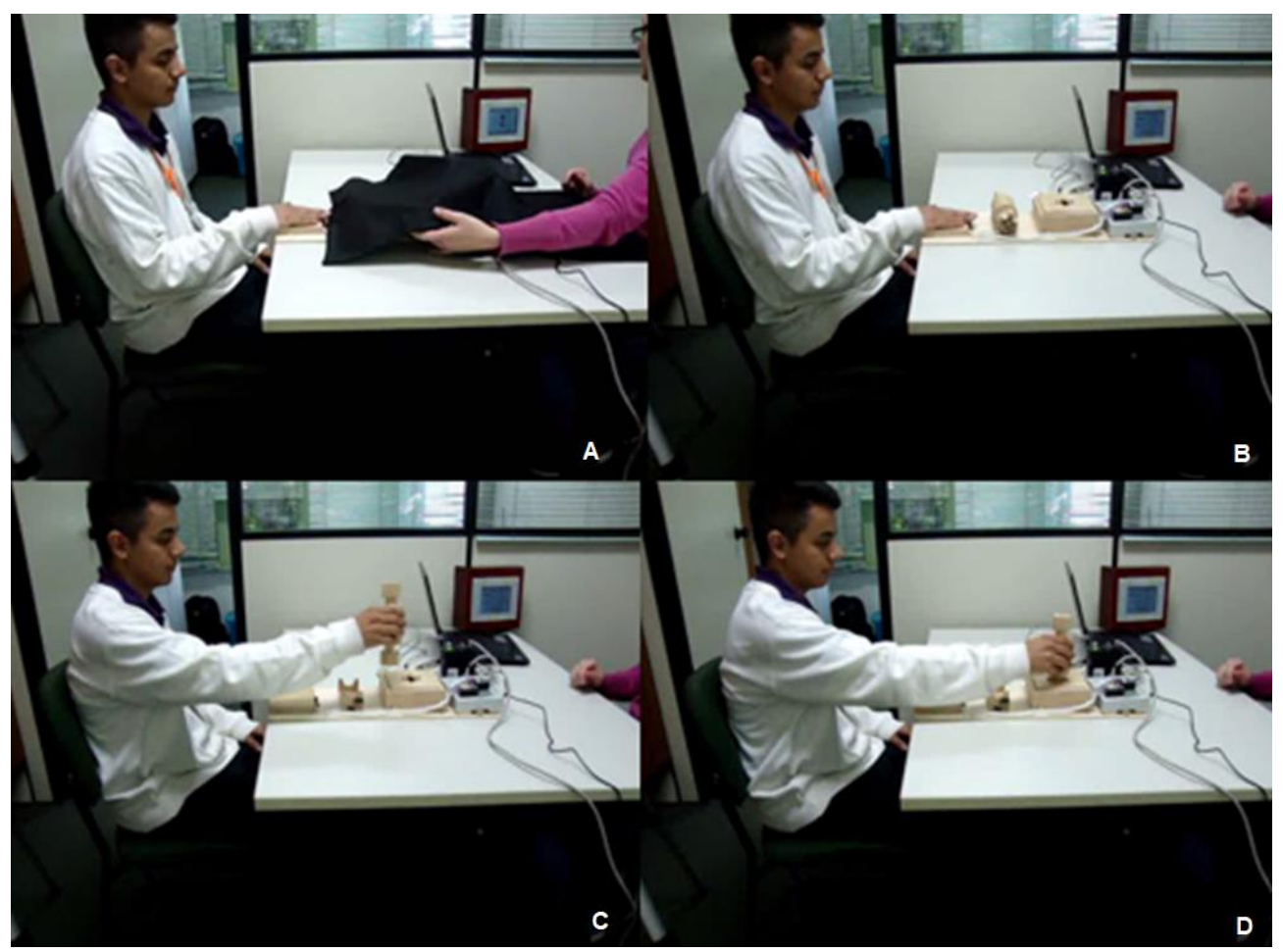

Figura 1. Foto do aparelho de teste de aprendizado motor. A-Retirada da cortina. B-Acendimento da luz e retirada da mão. C- Retirada da barra. D-Encaixe da barra.

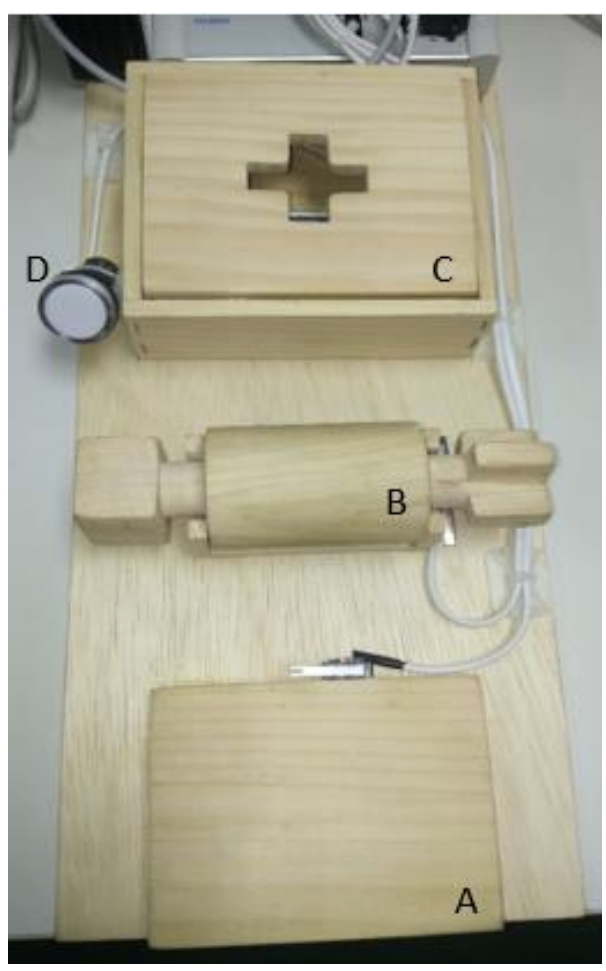

Figura 2. Foto do aparelho de teste de aprendizado motor. A- Apoio da mão. B- Barra de madeira. C- Caixa de encaixe com sensores. D-Lâmpada indicadora de iniciação da tarefa. 


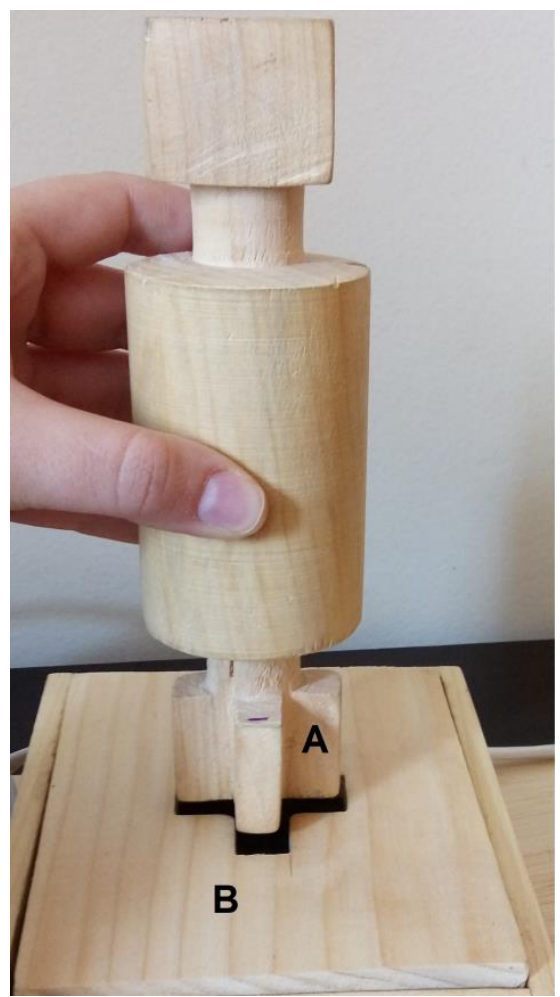

Figura 3. Foto do detalhe do aparelho utilizado para o teste de AM. Ênfase no encaixe da barra na caixa. AEncaixe da barra. B- Superfície de encaixe na tampa da caixa.

Para os testes, os indivíduos foram posicionados sentados diante do instrumento de avaliação localizado sobre uma mesa. A tarefa foi realizada com a mão dominante tanto nos indivíduos do GE quanto do GC. A figura 4 demonstra a sequência da realização do teste; as tentativas e blocos de todas as fases ocorreram sem intervalos pré-definidos. Os intervalos ocorriam apenas nos casos em que o indivíduo se sentisse fadigado, não excedendo 2 minutos de repouso. Entre as fases AQ e RET 1 foi dado intervalo de 10 minutos, não houve intervalo entre as fases RET 1 e TR e entre as fases TR e RET 2 se passou uma semana. Para as fases AQ, RET 1 e RET 2 a face da barra destinada ao encaixe, ou seja, a face com formato de cruz foi posicionada do lado direito do indivíduo, enquanto na fase TR a mesma foi invertida, ficando, portanto, do lado esquerdo do indivíduo.

Um tecido preto cobriu o instrumento antes do início dos testes, de forma a impedir a visualização do aparato pelo indivíduo, impedindo o planejamento motor prévio à realização da tarefa. Após cada tentativa, a cortina e a barra foram reposicionadas e ao final de cada bloco repetia-se a instrução da tarefa.

Os dados relativos aos momentos de acendimento da lâmpada, retirada da mão da placa sinalizadora, retirada da barra do suporte, contato da barra na tampa da caixa e contato da barra no fundo da caixa foram automaticamente enviados a um computador 
portátil através de interface que permitiu comunicação com o sistema de aquisição de dados.

O sistema de aquisição de dados por sua vez compõe-se por um Controlador Lógico programável (PLC), modelo FEC-660 fabricado pela empresa Festo, onde foram utilizadas: entradas digitais para a conexão dos sensores de detecção dos movimentos, saída digital para acionamento do LED indicativo de início do teste, comunicação serial com a Interface Homem Máquina (IHM) modelo FED-120 também fabricado pela Festo, e interface Ethernet para comunicação com o computador portátil através de DDE (Dynamic Data Exchange).

O PLC teve sua programação desenvolvida através do software FST 4.21 (do próprio fabricante), em linguagem STL, e teve como principal objetivo acompanhar a correta sequência de movimento executada pelo indivíduo, medindo o intervalo de tempo e a quantidade de tentativas (quando necessário) entre cada movimento em cada um dos blocos de cada fase.

A IHM, com sua programação desenvolvida através do software FED-Designer (do próprio fabricante), serviu para a entrada de informações como: identificação do indivíduo (nome), sinal de início do teste pelo avaliador, exibição dos resultados da avaliação (tempo e erros), permitindo ao avaliador salvar as informações, ou descartá-las quando necessário.

Através das comunicação DDE, os dados adquiridos foram enviados diretamente à uma planilha do Microsoft Excel que, através da programação em VBA (Visual Basic for Applications), fez o armazenamento automático dos dados dos testes, de forma que nenhum dado do teste foi inserido manualmente, o que poderia incorrer em erros (digitação, por exemplo).

Previamente ao teste, o indivíduo recebeu a seguinte instrução para a realização do teste:

"Você deverá permanecer sentado em frente a esta mesa, com a mão posicionada sobre este apoio de madeira. Embaixo do tecido preto existe uma barra que deverá ser retirada do apoio e introduzida em um orifício existente em uma caixa de madeira. Após a retirada do tecido você visualizará o acendimento de uma luz à sua esquerda, então deverá introduzir a barra no orifício, até que a barra encoste no final da caixa. Faça isso o mais rápido possível!"

As tentativas foram realizadas de acordo com o delineamento proposto por Torriani-Pasin (2010) a saber: 


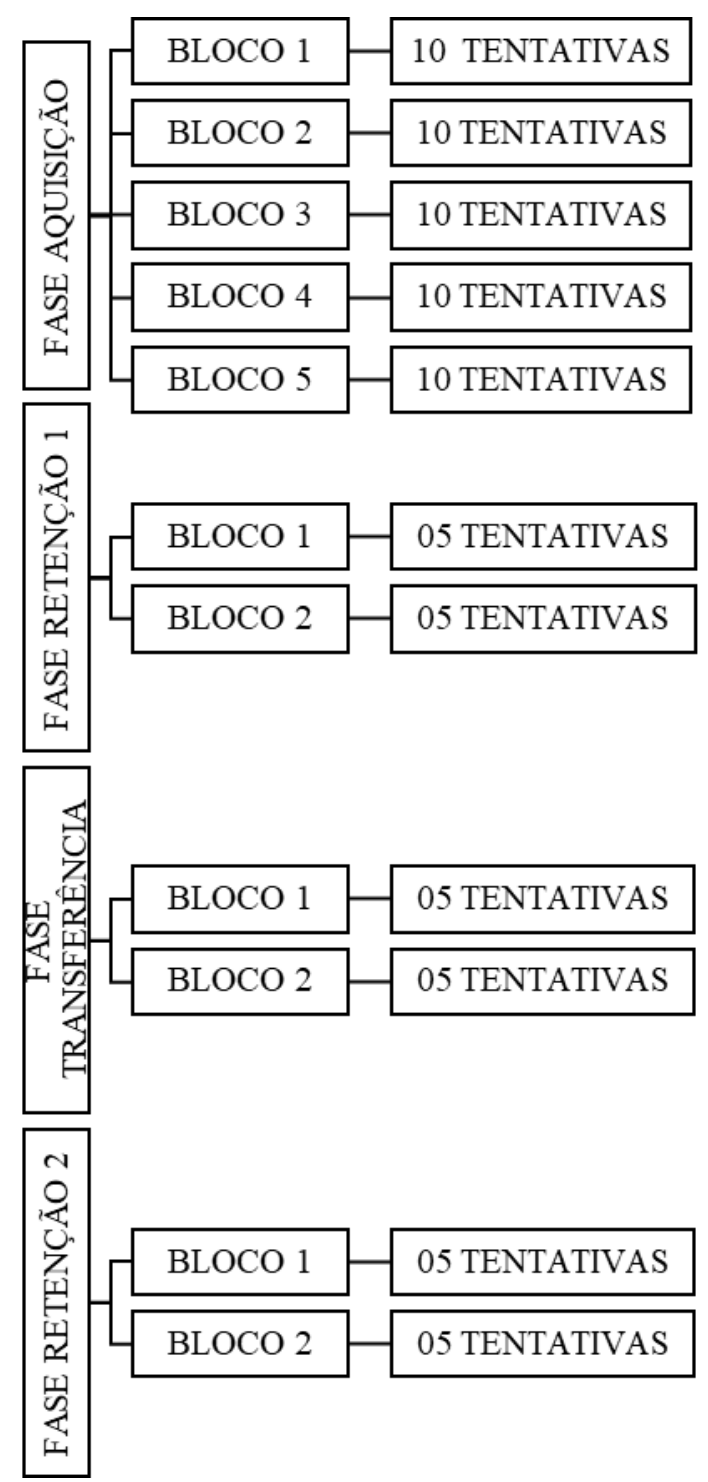

Figura 4. Delineamento do teste de aprendizado motor. Fase aquisição: corresponde a fase de treinamento da tarefa. Fase retenção 1: corresponde a memória motora de curto prazo. Fase transferência: corresponde a capacidade de realizar tarefa semelhante à treinada

\subsubsection{Variáveis Dependentes}

As medidas que foram utilizadas para avaliação do aprendizado motor são quantitativas e foram obtidas através de sensores elétricos; referem-se ao planejamento e execução da tarefa de inserção da barra no orifício. Foram coletados os seguintes dados:

- Variável "T1" ou "TEMPO TOTAL": Tempo de acendimento da luz (início do teste) até a inserção total da barra e o contato com o fundo da caixa; corresponde ao tempo total de execução da tarefa. 
- Variável "T2" ou "TEMPO DE REAÇÃO”: Tempo de acendimento da luz até a retirada da mão do posicionamento inicial; corresponde ao tempo de reação ou a percepção do indivíduo de que ele deve dar início a tarefa e faz parte do planejamento da ação.

- Variável “T3” ou "TEMPO DE INICIAÇÃO”: Tempo de acendimento da luz até a retirada da barra do suporte; corresponde ao tempo de realização da primeira parte da tarefa e faz parte do planejamento da ação.

- Variável "T4" ou "TEMPO MÃO-BARRA": Tempo de retirada da mão até a retirada da barra do suporte.

- Variável “T5” ou "TEMPO DE FINALIZAÇÃO”: Tempo de retirada da barra do suporte até o contato com o fundo da caixa; corresponde ao tempo de realização da segunda parte da tarefa e reflete o tempo necessário para o transporte da barra e para os ajustes necessários à inserção da barra.

- Variável "ERROS": Quantidade de toques da barra na tampa da caixa; corresponde ao número de tentativas sem sucesso.

- Variável "RETIRADA ANTECIPADA DA MÃO": Quantidade de vezes que a mão foi retirada do suporte antecipadamente, ou seja, antes do sinal luminoso que dá início à tarefa.

\subsubsection{Avaliação do Aprendizado Motor - Análise Qualitativa da Tarefa Específica}

Durante a realização da tarefa descrita no item anterior foram coletados vídeos nos planos frontal e transversal de modo a verificar as estratégias utilizadas pelo indivíduo através da movimentação do seu corpo e do assento.

Para facilitar a visualização foram posicionados marcadores de isopor em pontos específicos do corpo dos indivíduos, a saber: acrômio, olécrano e processo estiloide da ulna do membro dominante.

\subsubsection{ANÁLISE ESTATÍSTICA}

Os dados referentes ao teste de aprendizado motor foram analisados através do pacote estatístico SPSS, versão 22.0. 
As variáveis do teste de aprendizado motor (T1 a T5 e Erros) foram analisadas de duas formas, considerando as médias dos resultados e a taxa de variação do aprendizado.

Na primeira forma de análise dos dados optou-se pelo modelo linear generalizado (GLM) com função de Identidade Normal, função de ligação log Gama ou função de ligação log Tweedle, conforme especificado em cada um dos resultados a seguir.

A segunda forma de análise considera características individuais, dado que o ponto de início do teste, ou seja, os resultados encontrados na primeira tentativa, difere entre os participantes bem como a evolução do comportamento a partir deste resultado inicial e ao longo do processo de aprendizagem. Para isso, para cada indivíduo, os tempos finais foram divididos pelos tempos iniciais de cada momento investigado. Posteriormente foi calculada a média dessas taxas para cada grupo e por fim tais médias foram comparadas entre os grupos utilizando-se os testes estatísticos conforme a normalidade dos dados. Essa forma de análise foi denominada taxa de variação de aprendizado.

A normalidade dos dados foi testada e, para casos de dados paramétricos, foi utilizado o teste T de Student, enquanto para os não paramétricos utilizou-se o teste MannWhitney. Considerou-se o intervalo de confiança de $95 \%(\mathrm{p} \leq 0,05)$.

Considerando-se os conceitos da AM, momentos específicos foram escolhidos para as comparações entre as fases. Assim, para a comparação entre as fases AQ e TR utilizou-se apenas o último bloco da fase AQ e para a comparação entre AQ, RET 1 e RET 2 utilizou-se apenas o último bloco da fase AQ e o primeiro bloco das fases RET 1 e RET 2. Esta escolha deve-se ao fato de que a fase AQ corresponde à fase de treinamento, sendo em teoria, o último bloco o melhor em termos de desempenho após o treino da habilidade, sendo, portanto, selecionado como parâmetro de comparação entre os testes de retenção e transferência. Por sua vez, o primeiro bloco das fases RET 1, RET 2 e TR reflete com maior precisão a memória e a capacidade de transferência da habilidade do que os blocos seguintes, os quais passam a sofrer a influência de um novo treinamento, o que justifica a escolha do primeiro bloco destas fases para a análise da aprendizagem motora. 


\section{RESULTADOS}

\subsection{CARACTERIZAÇÃO DOS GRUPOS}

Para compor o GE foram convidados a participar da pesquisa todos os indivíduos portadores de EMRR cadastrados na ABEM e residentes em São Paulo que contemplavam os critérios de inclusão, dessa forma foram convidados 64 indivíduos, entretanto houveram perdas de voluntários no decorrer do processo, conforme a figura 5.

Para compor o GC foram convidados a participar da pesquisa indivíduos residentes em São Paulo e com características de sexo, idade, raça e escolaridade que se assemelhavam ao GE. Assim, foram convidados 21 indivíduos, porém 1 voluntário não retornou para o segundo dia de avaliação e 2 voluntários foram perdidos devido a intercorrências com o sistema.

Desse modo foram avaliados 18 indivíduos com EMRR e 18 indivíduos saudáveis, com características sócio demográficas demonstradas na tabela 1.

- 64 EMRR convidados

- 36 não aceitaram

- 1 faltou na primeira avaliação

- 6 faltaram na segunda avaliação

- 1 não incluído devido à pontuação no MEEM

- 1 não incluído devido à surto no dia da primeira avaliação

- 1 excluído por erro do sistema

- 18 EMRR concluíram todo o protocolo

Figura 5. Fluxograma de inclusão dos participantes do GE 
Tabela 1- Caracterização da amostra

\begin{tabular}{cccc}
\hline Variável & Níveis & GE & GC \\
\hline $\begin{array}{c}\text { Idade (anos) } \\
\text { média +/- dpm }\end{array}$ & - & $36,8+/-9,78$ & $34,6+/-7,65$ \\
\hline Sexo & Masculino & 08 & 08 \\
& Feminino & 10 & 10 \\
\hline Escolaridade & Médio & 01 & 01 \\
& Superior & 17 & 17 \\
Etnia & Branco & 12 & 01 \\
& Negro & 01 & 05 \\
\hline Dominância Lateral & Pardo & 05 & 0 \\
\hline MEEM & Destro & 17 & - \\
média +/- dpm & Canhoto & 01 & \\
\hline EDSS & - & $28,3+/-1,71$ & \\
média +/- dpm & & & \\
\hline Tempo diagnóstico (meses) & - & $1,72+/-1,30$ & 1,29 \\
\hline mpm & & & \\
\hline
\end{tabular}

A EDSS variou entre 0 e 4,5 para o GE e não foi avaliada no GC por tratar-se de escala desenvolvida para avaliação da incapacidade motora na EM. A frequência das pontuações na EDSS está demonstrada na figura 6; observa-se maior incidência na pontuação 1 (6 indivíduos), seguida das pontuações $0,1,5$ e 2 ( 2 indivíduos cada) e todas as demais apresentaram apenas 1 indivíduo. 


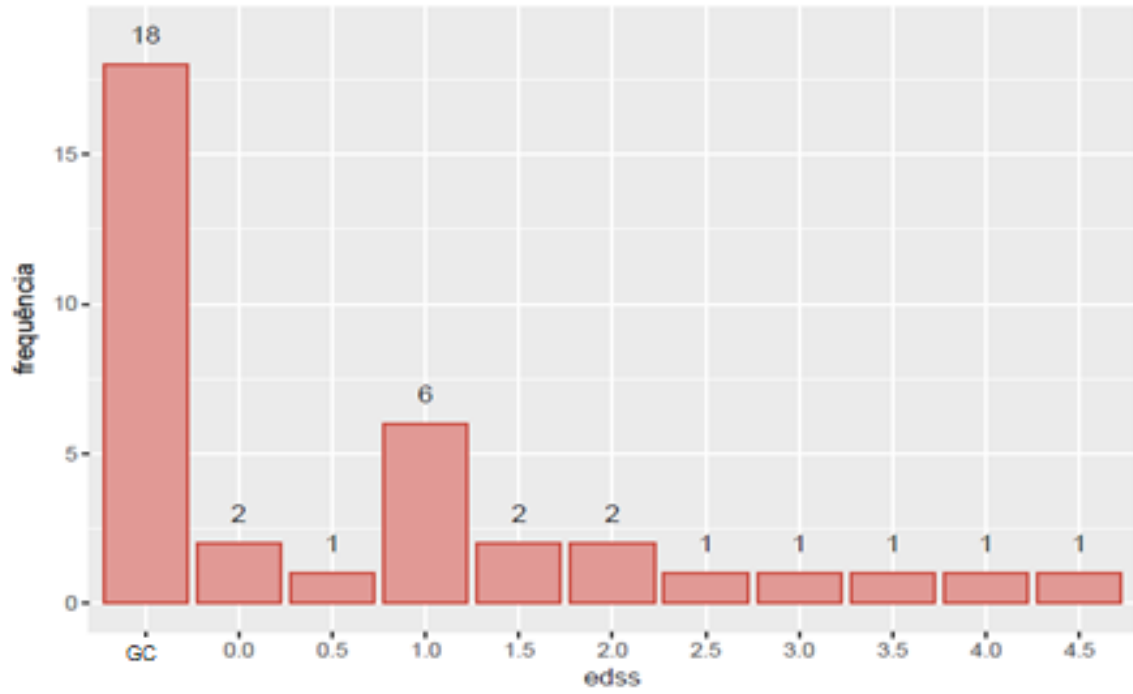

Figura 6. Frequência da EDSS. A EDSS é uma escala que varia de 0 a 10; para esta pesquisa foram incluídos indivíduos com EDSS o a 5,5.

\subsection{TESTE DE APRENDIZADO MOTOR}

A seguir serão apresentados os resultados das variáveis coletadas durante o teste de aprendizado motor, a saber: T1, T2, T3, T4, T5, "Erro" e "Retirada antecipada da mão", conforme descrito no item materiais e métodos.

Em um primeiro momento serão apresentados os resultados analisados pelas médias dos grupos e intervalo de confiança (IC). Ao final serão apresentadas as análises que consideraram as taxas de variação do aprendizado.

\subsubsection{VARIÁVEL “T1” OU “TEMPO TOTAL}

A variável T1 corresponde ao tempo total de execução da tarefa, desde o acendimento da luz até o contato da barra com o fundo da caixa, conforme descrito no item materiais e métodos. Esta variável foi computada a cada tentativa realizada pelo indivíduo.

\subsubsection{Variável "T1” na Fase $A Q$}

Houve diferença entre os grupos em todos os blocos da fase AQ ( $p=0,009)$, bem como entre os blocos desta fase $(\mathrm{p}<0,001)$. Aplicando-se o pós-teste de Bonferroni 
verificou-se que a diferença ocorre somente entre o bloco 1 em relação aos demais blocos para os dois grupos $(\mathrm{p}<0,001)$. Não houve diferença entre os grupos com relação à curva de desempenho ao longo de toda a fase AQ ( $\mathrm{p}=0,242)$.

Assim, pode-se dizer que houve melhora do desempenho entre os blocos 1 e 2 da fase AQ, seguida por estabilização do desempenho em ambos os grupos. Entretanto, o GE foi mais lento que o GC em todos os blocos da fase AQ, como demonstra a figura 7.

Uma vez considerados os dados acima, buscou-se investigar se a estabilização ocorreu no mesmo momento para ambos os grupos e em qual tentativa isso se deu. Não foram encontradas diferenças entre os grupos e, segundo pós teste de Bonferroni, verificou-se que a tentativa 1 , do bloco 1 , da fase AQ difere de todas as demais tentativas deste bloco ( $\mathrm{p}<0,001)$. Já a tentativa 2 deste bloco difere de algumas tentativas dentro do bloco e, a partir da terceira tentativa deste bloco, não houve diferença em relação às demais tentativas $(p>0,613)$. Assim, infere-se que houve estabilização da habilidade a partir da terceira tentativa do bloco 1 da fase AQ para GE e GC, como demonstra a figura 8.

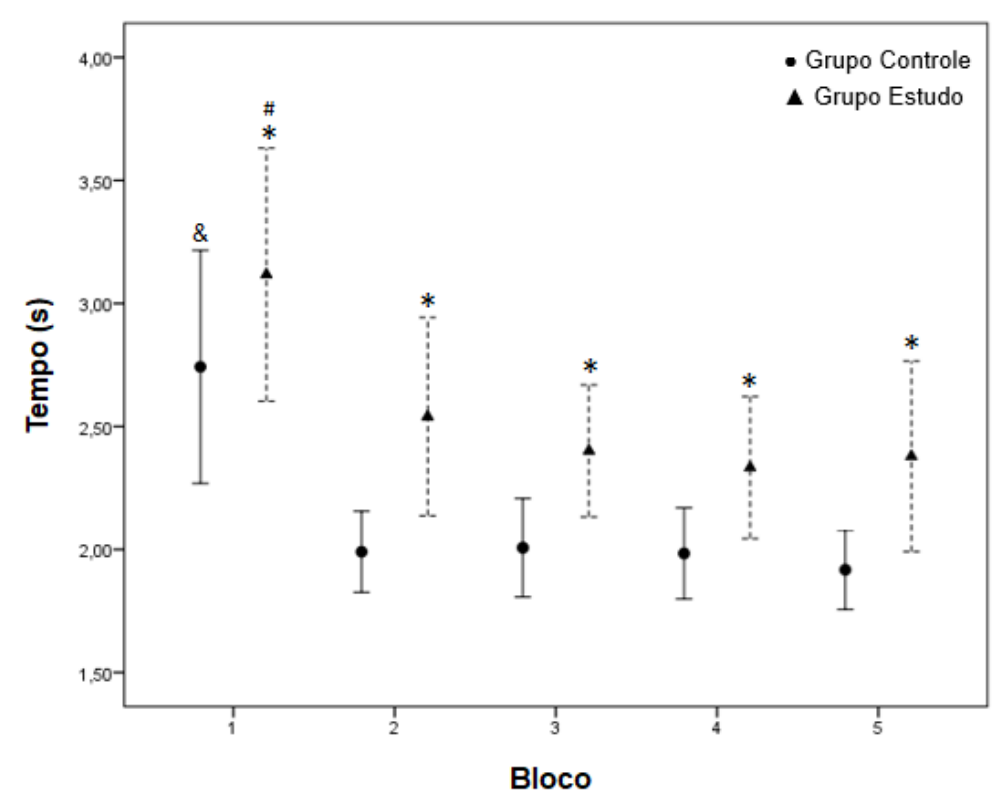

Figura 7. Gráfico das médias e intervalo de confiança de T1 em cada bloco da fase AQ para cada grupo. $\mathrm{P}<0,05: *$ vs. Grupo Controle; \& vs. Blocos 2-5 Grupo Controle; \# vs. Blocos 2-5 Grupo Estudo (GLM com função de ligação log Gama). 


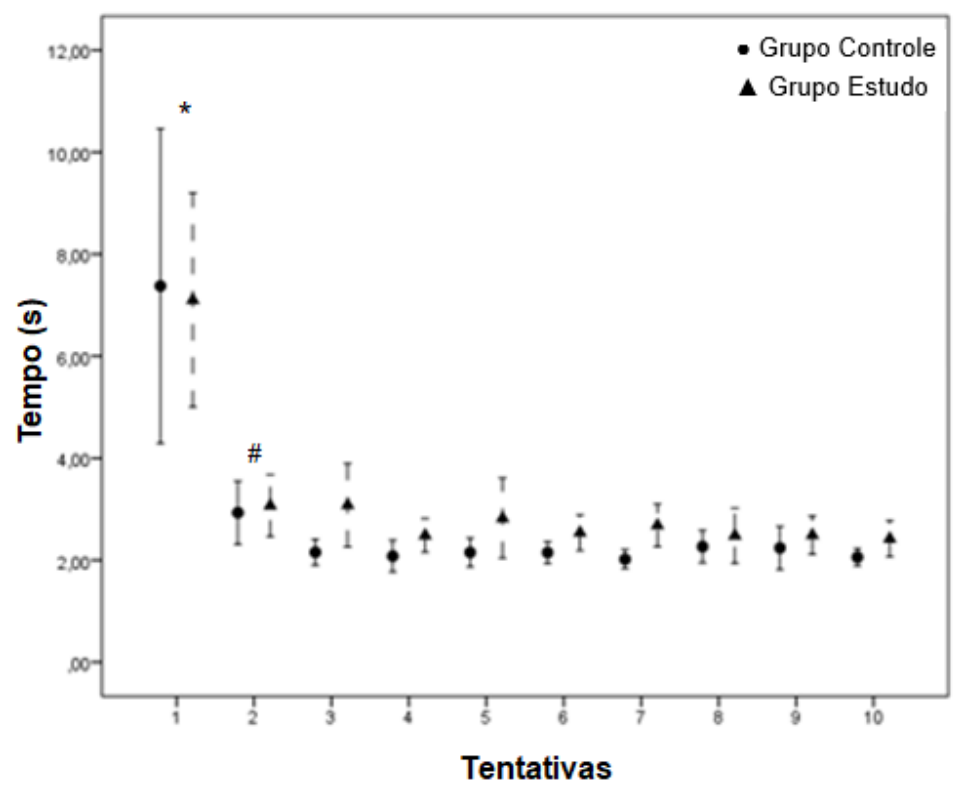

Figura 8. Gráfico das médias e intervalo de confiança de T1 em cada tentativa do primeiro bloco da fase AQ para cada grupo. P<0,05: * vs. Tentativas 2 -10 de ambos os grupos; \# vs. Tentativas 4, 7 e 10 de ambos os grupos (GLM com função de ligação log Gama).

\subsubsection{Variável “T1” na Fase RET 1 (memória motora de curto prazo)}

Não houve diferença entre os grupos no tempo total ao longo da fase RET 1 $(\mathrm{p}=0,067)$, assim como entre os dois blocos desta fase $(\mathrm{p}=0,995)$ e entre os grupos com relação à curva de desempenho ao longo de toda a fase RET $1(\mathrm{p}=0,078)$.

Assim, pode-se dizer que não houve melhora do desempenho ao longo desta fase e não houve diferença no desempenho entre os grupos, como demonstra a figura 9.

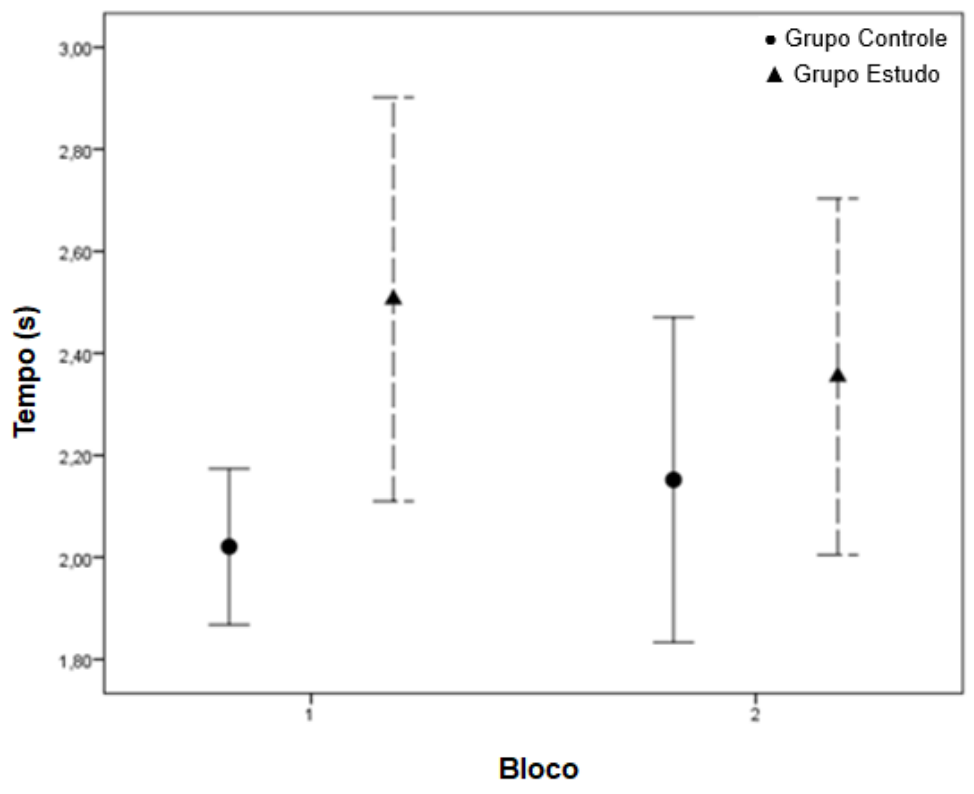


Figura 9. Gráfico das médias e intervalo de confiança de T1 em cada bloco da fase RET 1 para cada grupo. Não foram encontradas diferenças estatisticamente significativas (GLM com função de ligação log Gama).

\subsubsection{Variável “T1” na Fase RET 2 (memória motora de longo prazo)}

Houve diferença entre os grupos nos dois blocos da fase RET $2(\mathrm{p}=0,002)$ e entre os blocos desta fase $(\mathrm{p}<0,001)$, porém não houve diferença entre os grupos com relação à curva de desempenho ao longo de toda a fase RET 2 ( $\mathrm{p}=0,804)$.

Houve melhora do desempenho entre os blocos da fase RET 2 para ambos os grupos, entretanto o GE foi mais lento que o GC, como demonstra a figura 10.

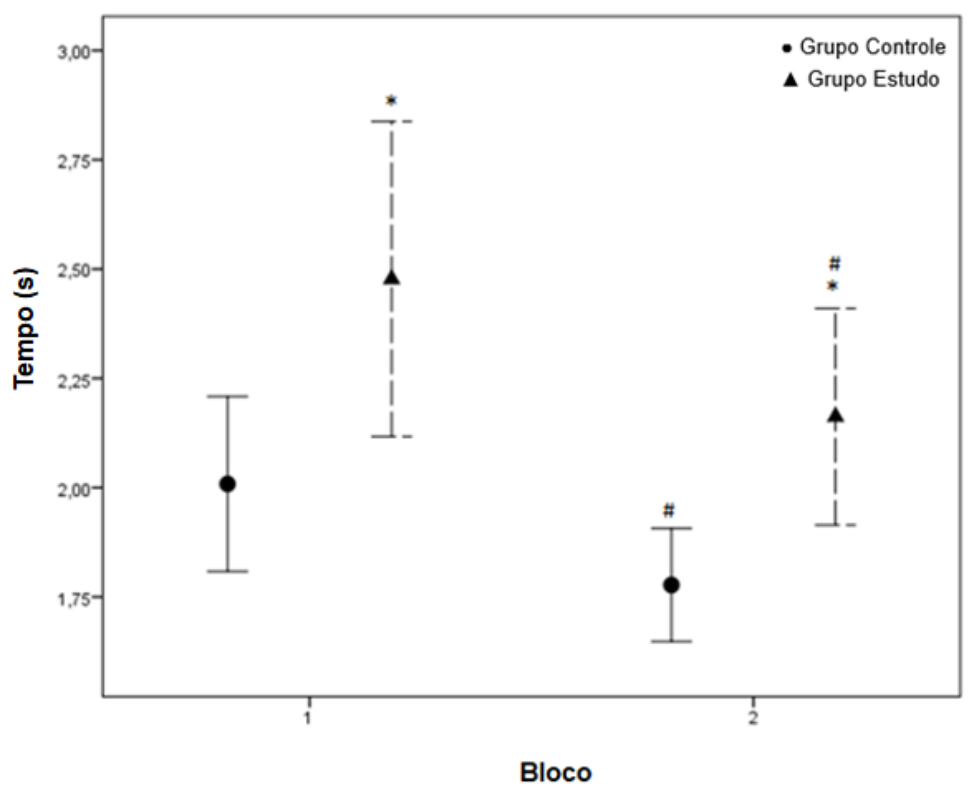

Figura 10. Gráfico das médias e intervalo de confiança de T1 em cada bloco da fase RET 2 para cada grupo. P<0,05: * vs. Grupo Controle; \# vs. Bloco 1 (GLM com função de ligação log Gama).

\subsubsection{Variável "T1" na Fase TR}

Houve diferença entre os grupos nos dois blocos da fase TR $(\mathrm{p}=0,012)$ e entre os dois blocos desta fase para os dois grupos $(\mathrm{p}=0,002)$, entretanto não houve diferença entre os grupos com relação à curva de desempenho ao longo de toda a fase TR $(\mathrm{p}=0,572)$.

Assim, pode-se dizer que houve melhora do desempenho entre os blocos da fase TR para ambos os grupos, mas GE foi mais lento que o GC, como demonstra a figura 11. 


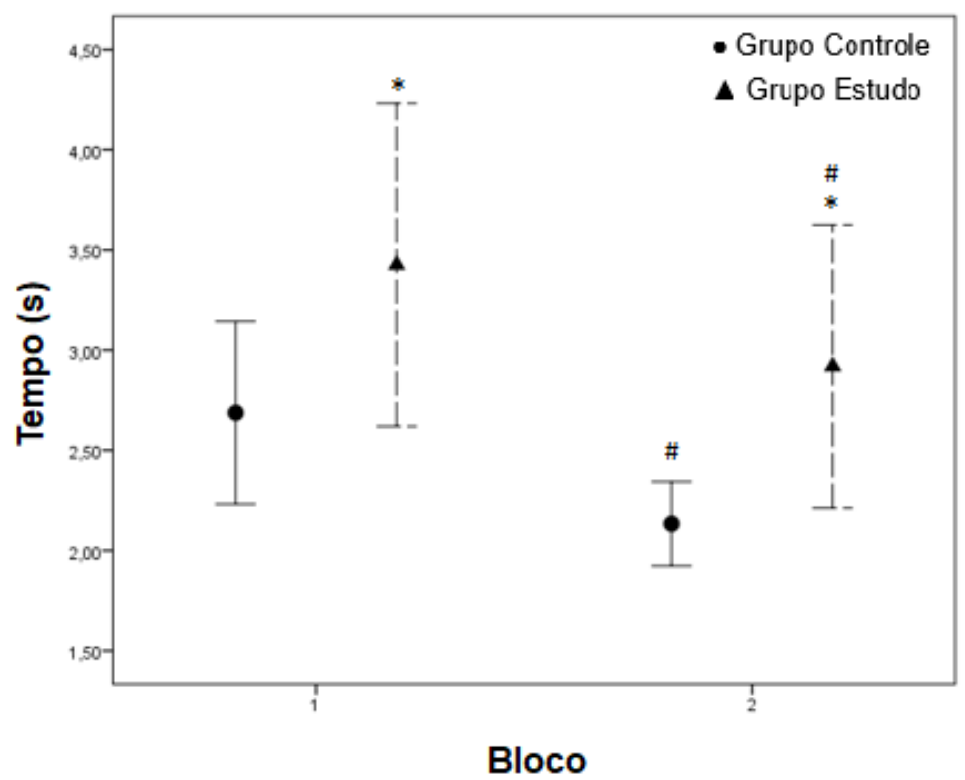

Figura 11. Gráfico das médias e intervalo de confiança de T1 em cada bloco da fase TR para cada grupo. $\mathrm{P}<0,05: *$ vs. Grupo Controle; \# vs. Bloco 1 (GLM com função de ligação log Gama).

\subsubsection{Variável "T1” - Comparação entre as Fases AQ e TR}

Para esta comparação utilizou-se apenas o último bloco da fase AQ, conforme explicado no item materiais e métodos.

Houve diferença entre o último bloco da fase AQ e o primeiro bloco da fase TR ( $\mathrm{p}<0,001)$ e entre o último bloco da fase AQ e o segundo bloco da fase TR $(\mathrm{p}=0,003)$, segundo pós teste de Bonferroni. Houve diferença entre os grupos $(p=0,007)$, sendo GE mais lento que GC e não houve diferença entre os grupos com relação à curva de desempenho ao longo do tempo $(\mathrm{p}=0,543)$, como demonstra a figura 12.

O desempenho obtido na fase TR foi inferior ao desempenho estabilizado na fase $\mathrm{AQ}$, inferindo que não houve transferência do aprendizado em nenhum dos grupos. Além disso, com o treino da nova tarefa na fase TR houve melhora do desempenho (diferenças entre os blocos da fase TR), entretanto, ainda assim, o desempenho do último bloco de TR foi inferior ao desempenho do último bloco da fase AQ nos dois grupos. 


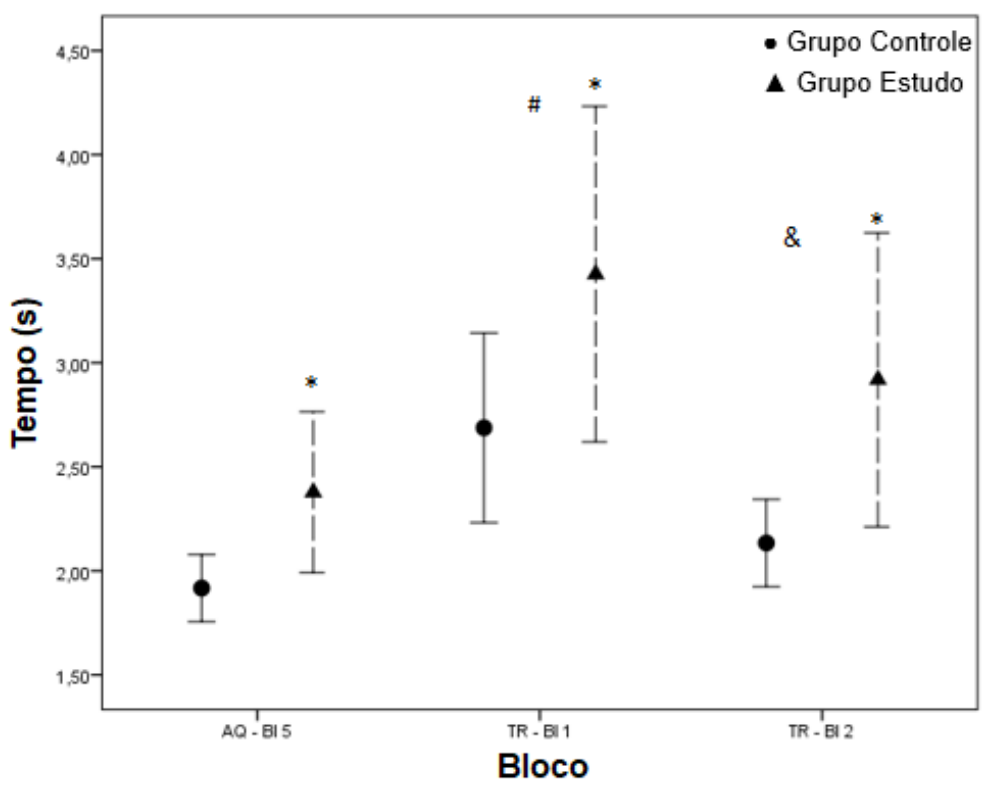

Figura 12. Gráfico das médias e intervalo de confiança de T1 nas fases AQ e TR para cada grupo. Transferência de aprendizado. P<0,05: * vs. Grupo Controle; \# vs. Aq-B15 de ambos os grupos; \& vs. AqB15 de ambos os grupos (GLM com função de ligação log Gama).

\subsubsection{Variável "T1” - Comparação entre as Fases AQ, RET 1 e RET 2}

Para esta comparação utilizou-se apenas o último bloco da fase AQ e o primeiro bloco das fases RET 1 e RET 2, conforme demonstrado no item 3.4.3.

Não houve diferença entre os blocos $(\mathrm{p}=0,102)$ ou entre os grupos com relação à curva de desempenho ao longo do tempo $(\mathrm{p}=0,993)$, entretanto, houve diferença entre os grupos $(\mathrm{p}=0,004)$, como demonstra a figura 13.

Assim, pode-se dizer que o desempenho obtido na fase AQ foi mantido nas demais fases, inferindo que houve retenção do aprendizado à curto e à longo prazo para os dois grupos, embora o desempenho de GE tenha sido inferior ao de GC. 


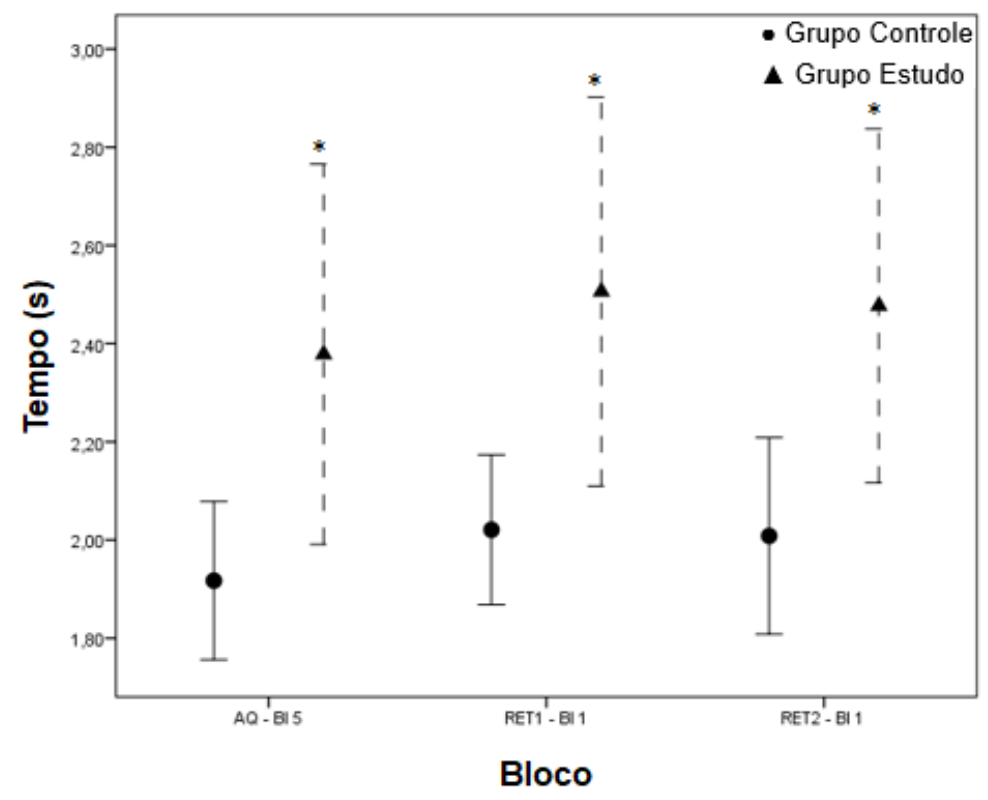

Figura 13. Gráfico de comparação das médias e intervalo de confiança de T1 ao longo das fases AQ, RET 1 e RET 2 para cada grupo. P<0,05: * vs. Grupo Controle (GLM com função de ligação log Gama).

\subsubsection{VARIÁVEL “T2” OU “TEMPO DE REAÇÃO”}

A variável T2 corresponde ao tempo decorrido desde o acendimento da luz até a retirada da mão do apoio, ou seja, o tempo que o indivíduo necessita para perceber que deve dar início ao movimento, conforme descrito no item materiais e métodos. Esta variável foi computada a cada tentativa realizada pelo indivíduo.

\subsubsection{Variável "T2” na Fase $A Q$}

Não houve diferença entre os grupos em nenhum bloco da fase AQ ( $\mathrm{p}=0,268)$ ou entre os grupos com relação à curva de desempenho ao longo de toda a fase AQ $(\mathrm{p}=0,179)$. Porém houve diferença entre os blocos desta fase $(\mathrm{p}<0,001)$ e, a partir do pós teste de Bonferroni verificou-se que a diferença ocorre somente entre o bloco 1 em relação aos demais blocos para os dois grupos $(\mathrm{p}<0,001)$.

Portanto, houve diminuição do tempo de reação entre os blocos 1 e 2 da fase AQ seguida por estabilização deste tempo em ambos os grupos, sendo o resultado semelhante entre os grupos, como demonstra a figura 14. 


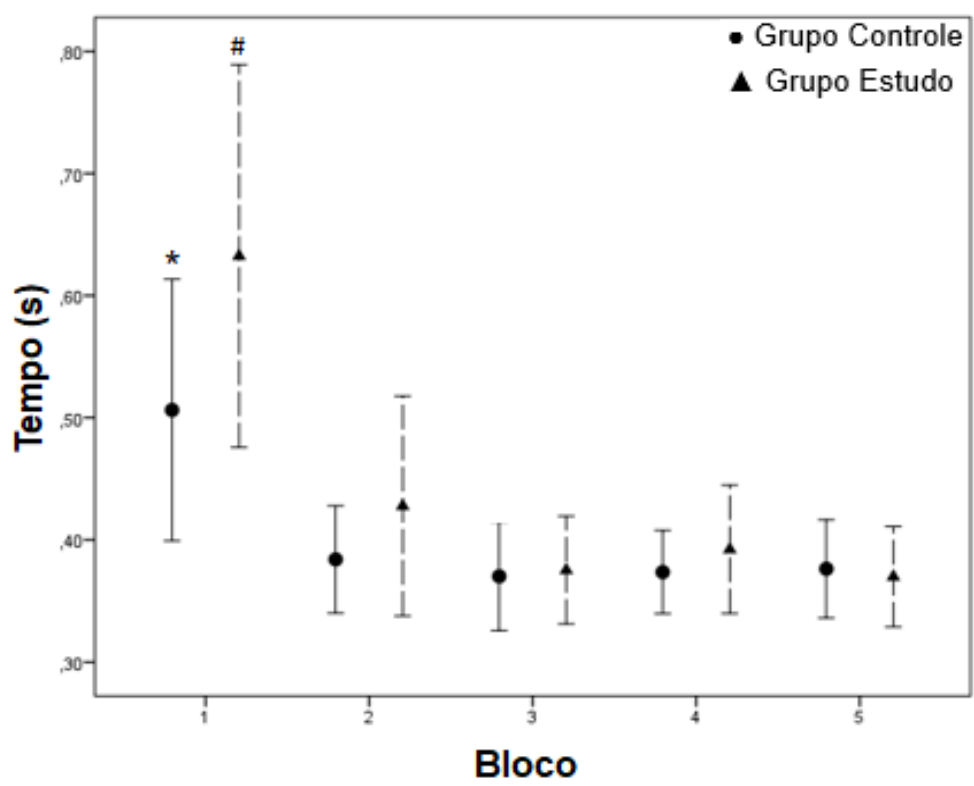

Figura 14. Gráfico das médias e intervalo de confiança de T2 em cada bloco da fase AQ para cada grupo. P<0,05: *vs. Blocos 2-5 Grupo Controle; \#vs. Blocos 2-5 Grupo Estudo (GLM com função de ligação Identidade Normal).

\subsubsection{Variável "T2" na Fase RET 1 (memória motora de curto prazo)}

Não houve diferença entre os grupos ao longo da fase RET $1(\mathrm{p}=0,118)$, entre os dois blocos desta fase $(\mathrm{p}=0,207)$ e entre os grupos com relação à curva de desempenho ao longo de toda a fase RET $1(\mathrm{p}=0,263)$.

Assim, pode-se dizer que não houve melhora do tempo de reação ao longo da fase RET 1 em nenhum grupo, como demonstra a figura 15.

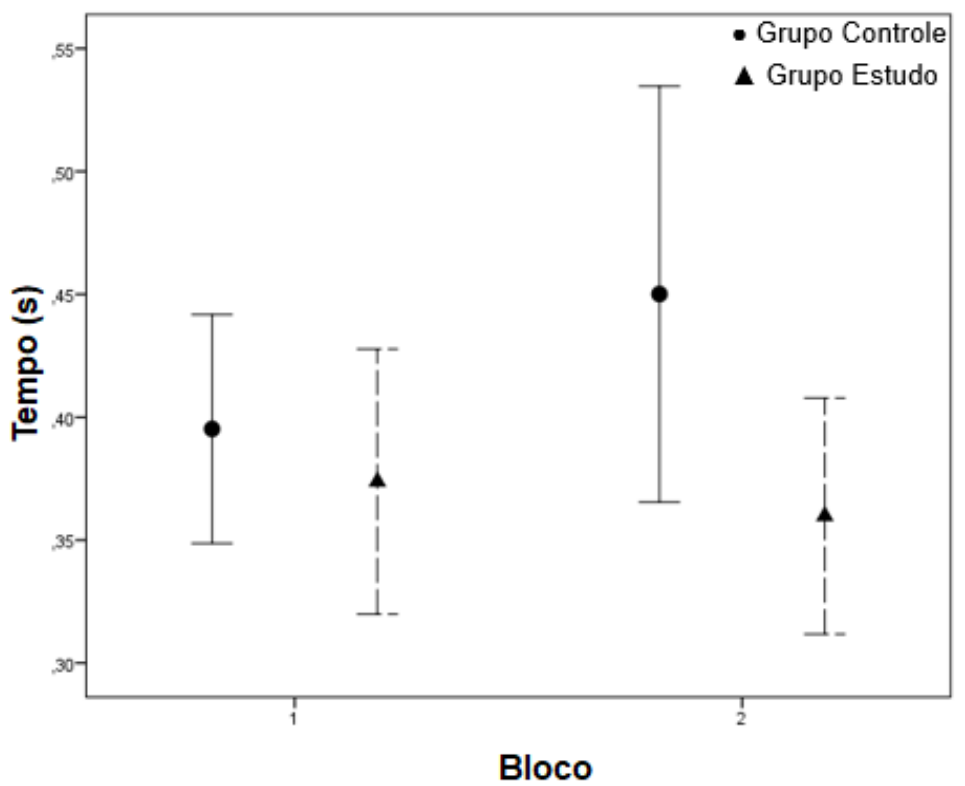


Figura 15. Gráfico das médias e intervalo de confiança de T2 em cada bloco da fase RET 1 para cada grupo. Não foram encontradas diferenças estatisticamente significativas (GLM com função de ligação Identidade Normal).

\subsubsection{Variável “T2” na Fase RET 2 (memória motora de longo prazo)}

Não houve diferença entre os grupos nos dois blocos da fase RET $2(p=0,736)$ e entre os grupos com relação à curva de desempenho ao longo de toda a fase RET 2 $(\mathrm{p}=0,206)$. Entretanto, houve diferença entre os blocos desta fase para ambos os grupos $(\mathrm{p}<0,011)$

Os dados apontam melhora do tempo de reação entre os blocos da fase RET 2 para ambos os grupos, sendo o desempenho dos grupos semelhante como demonstra a figura 16.

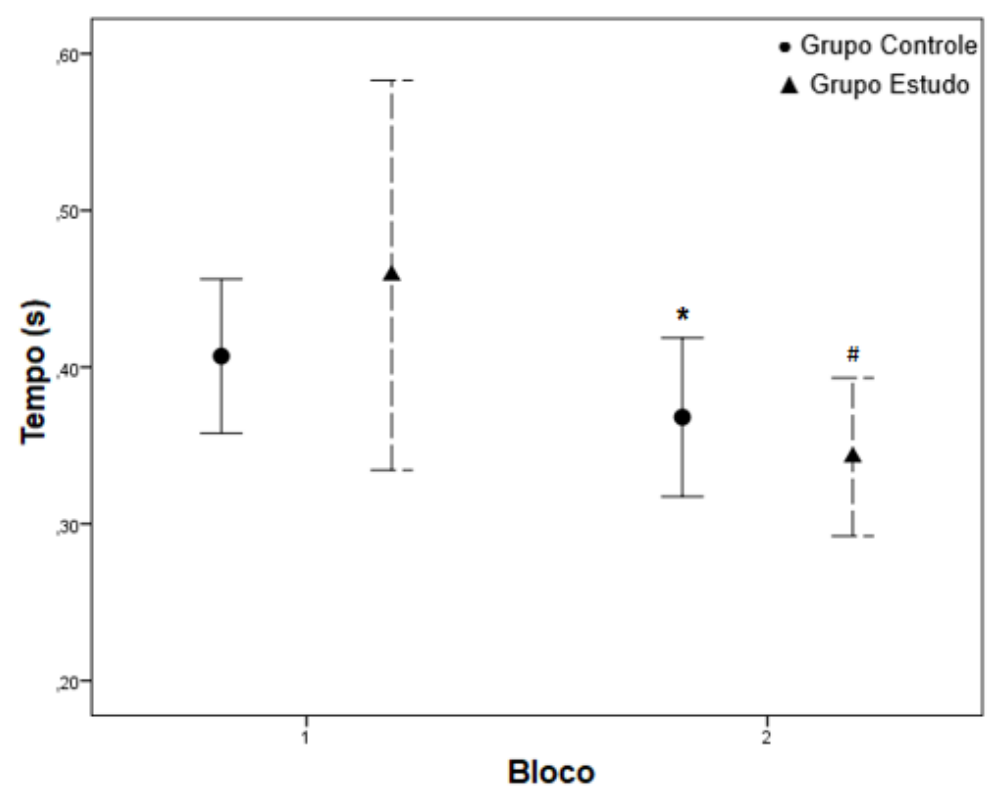

Figura 16. Gráfico das médias e intervalo de confiança de T2 em cada bloco da fase RET 2 para cada grupo. P<0,05: *vs. Bloco 1 Grupo Controle; \#vs. Bloco 1 Grupo Estudo (GLM com função de ligação Identidade Normal).

\subsubsection{Variável “T2” na Fase TR}

Não houve diferença entre os grupos nos dois blocos da fase TR $(\mathrm{p}=0,842)$ e entre os grupos com relação à curva de desempenho ao longo de toda a fase $\mathrm{TR}(\mathrm{p}=0,322)$. Porém, houve diferença entre os dois blocos desta fase $(\mathrm{p}=0,001)$ 
O desempenho dos grupos foi semelhante, como demonstra a figura 17, e houve redução do tempo de reação entre os blocos da fase TR para ambos os grupos.

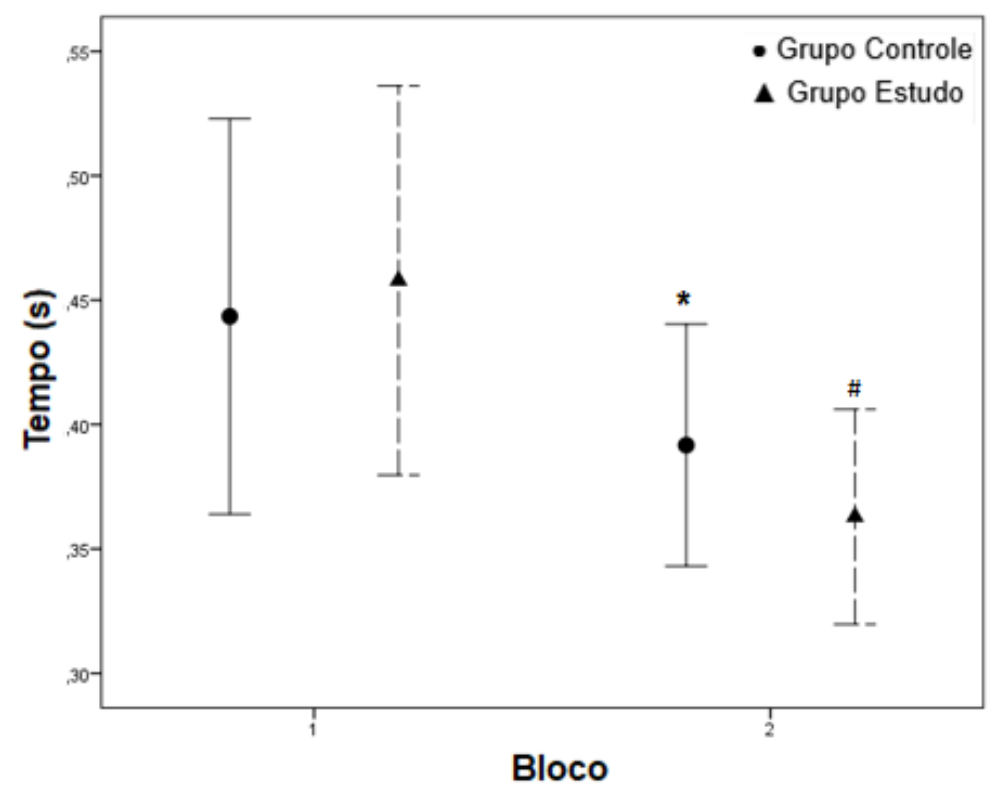

Figura 17. Gráfico das médias e intervalo de confiança de T2 em cada bloco da fase TR para cada grupo. P<0,05: *vs. Bloco 1 Grupo Controle; \#vs. Bloco 1 Grupo Estudo (GLM com função de ligação Identidade Normal).

\subsubsection{Variável "T2” - Comparação entre as Fases AQ e TR}

Para esta comparação utilizou-se apenas o último bloco da fase AQ, conforme descrito no item 3.4.3.

Houve diferença entre o último bloco da fase AQ e o primeiro bloco da fase TR, segundo pós teste de Bonferroni $(\mathrm{p}=0,002)$, mas não houve diferença entre $A Q$ e o segundo bloco de TR $(p=1,000)$. Não houve diferença entre os grupos $(p=0,821)$ bem como entre os grupos com relação à curva de desempenho ao longo do tempo $(\mathrm{p}=0,321)$.

Assim, pode-se dizer que o resultado obtido na fase TR foi inferior ao desempenho estabilizado na fase $\mathrm{AQ}$, inferindo que não houve transferência do aprendizado em nenhum dos grupos. Além disso, como relatado anteriormente, com o treino da nova tarefa na fase TR houve redução do tempo de reação (diferenças entre os blocos da fase TR), sendo que ao final da fase TR o resultado foi semelhante ao final da fase AQ. Além disso, o desempenho dos grupos foi semelhante, como demonstra a figura 18. 


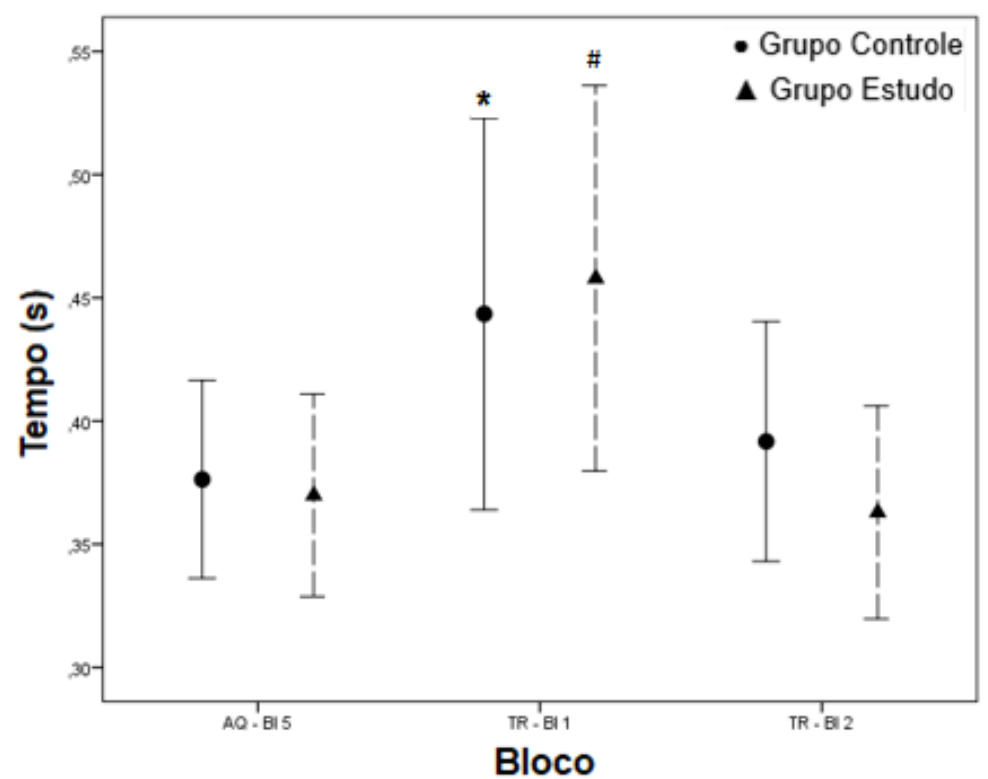

Figura 18. Gráfico das médias e intervalo de confiança de T1 nas fases AQ e TR para cada grupo. Transferência de aprendizado. P<0,05: *vs. Aq-B15 Grupo Controle; \#vs. Aq-B15 Grupo Estudo (GLM com função de ligação Identidade Normal).

\subsubsection{Variável “T2” - Comparação entre as Fases AQ, RET 1 e RET 2}

Para esta comparação utilizou-se apenas o último bloco da fase AQ e o primeiro bloco das fases RET 1 e RET 2, conforme descrito no item 3.4.3.

Não houve diferença entre os blocos $(\mathrm{p}=0,051)$, entre os grupos $(\mathrm{p}=0,815)$ e com relação à curva de desempenho dos grupos ao longo do tempo $(\mathrm{p}=0,370)$.

Assim, pode-se dizer que o resultado obtido na fase AQ foi mantido nas demais fases, inferindo que houve retenção do aprendizado à curto e à longo prazo para os dois grupos, e o desempenho dos grupos foi semelhante, como demonstra a figura 19. 


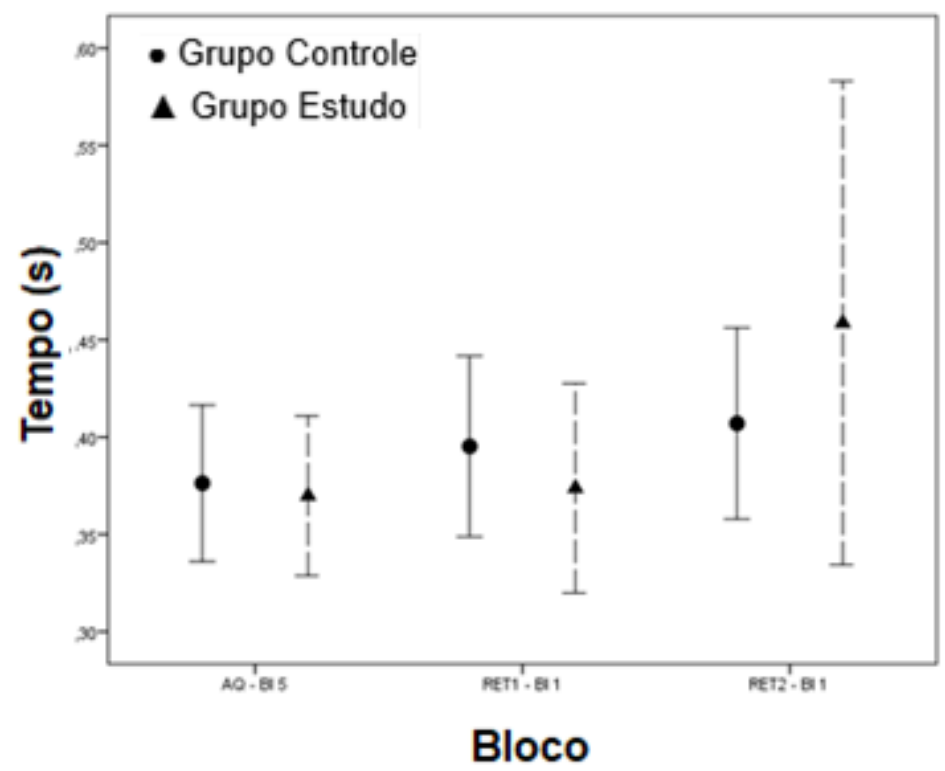

Figura 19. Gráfico de comparação das médias e intervalo de confiança de T2 ao longo das fases AQ, RET 1 e RET 2 para cada grupo. Não foram encontradas diferenças estatisticamente significativas (GLM com função de ligação Identidade Normal).

\subsubsection{VARIÁVEL “T3” OU “TEMPO DE INICIAÇÃO”}

A variável T3 corresponde ao tempo decorrido desde o acendimento da luz até a retirada da barra do suporte de apoio, conforme descrito no item materiais e métodos. Esta variável foi computada a cada tentativa realizada pelo indivíduo.

\subsubsection{Variável "T3” na Fase $A Q$}

Não houve diferença entre os grupos em nenhum bloco da fase AQ ( $p=0,056)$ e entre os grupos com relação à curva de desempenho ao longo de toda a fase AQ $(\mathrm{p}=0,450)$. Porém, houve diferença significativa entre os blocos desta fase $(\mathrm{p}<0,001)$ e, a partir do teste de Bonferroni, verificou-se que a diferença ocorre somente entre o bloco 1 em relação aos demais blocos para os dois grupos $(\mathrm{p}<0,001)$.

Assim, pode-se dizer que houve redução do tempo entre os blocos 1 e 2 da fase AQ seguida de estabilização em ambos os grupos, sendo o desempenho semelhante entre os grupos, como demonstra a figura 20. 


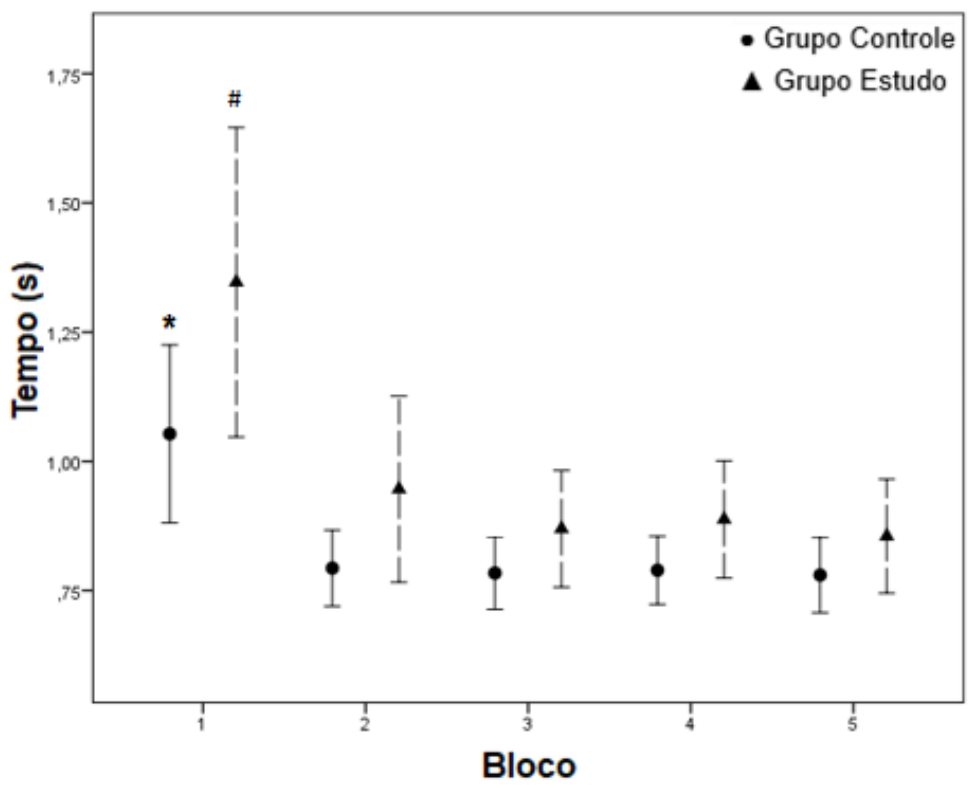

Figura 20. Gráfico das médias e intervalo de confiança de T3 em cada bloco da fase AQ para cada grupo. $\mathrm{P}<0,05: * v s$. Blocos 2-5 Grupo Controle; \#vs. Blocos 2-5 Grupo Estudo (GLM com função de ligação log Gama).

\subsubsection{Variável “T3” na Fase RET 1 (memória motora de curto prazo)}

Não houve diferença entre os grupos ao longo da fase RET 1 ( $\mathrm{p}=0,590)$, entre os dois blocos desta fase para os dois grupos $(\mathrm{p}=0,687)$ e entre os grupos com relação à curva de desempenho ao longo de toda a fase RET $1(\mathrm{p}=0,055)$.

Portanto, não houve redução do tempo ao longo da fase RET 1 e o desempenho foi semelhante entre os grupos, como demonstra a figura 21.

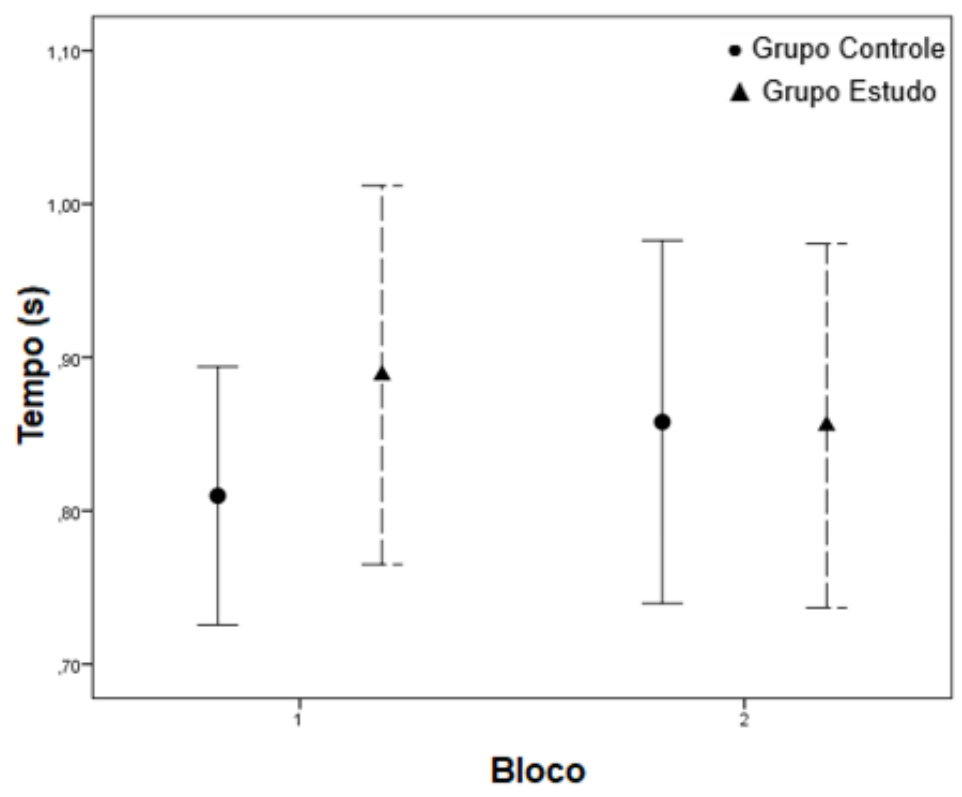


Figura 21. Gráfico das médias e intervalo de confiança de T3 em cada bloco da fase RET1 para cada grupo. Não foram encontradas diferenças estatisticamente significativas (GLM com função de ligação Identidade Normal).

\subsubsection{Variável “T3” na Fase RET 2 (memória motora de longo prazo)}

Não houve diferença entre os grupos nos dois blocos da fase RET $2(p=0,209)$ e entre os grupos com relação à curva de desempenho ao longo de toda a fase RET 2 $(\mathrm{p}=0,229)$. Entretanto, houve diferença significativa entre os blocos desta fase $(\mathrm{p}=0,001)$.

Assim, houve melhora do resultado entre os blocos da fase RET 2 para ambos os grupos, sendo o desempenho dos grupos semelhante como demonstra a figura 22.

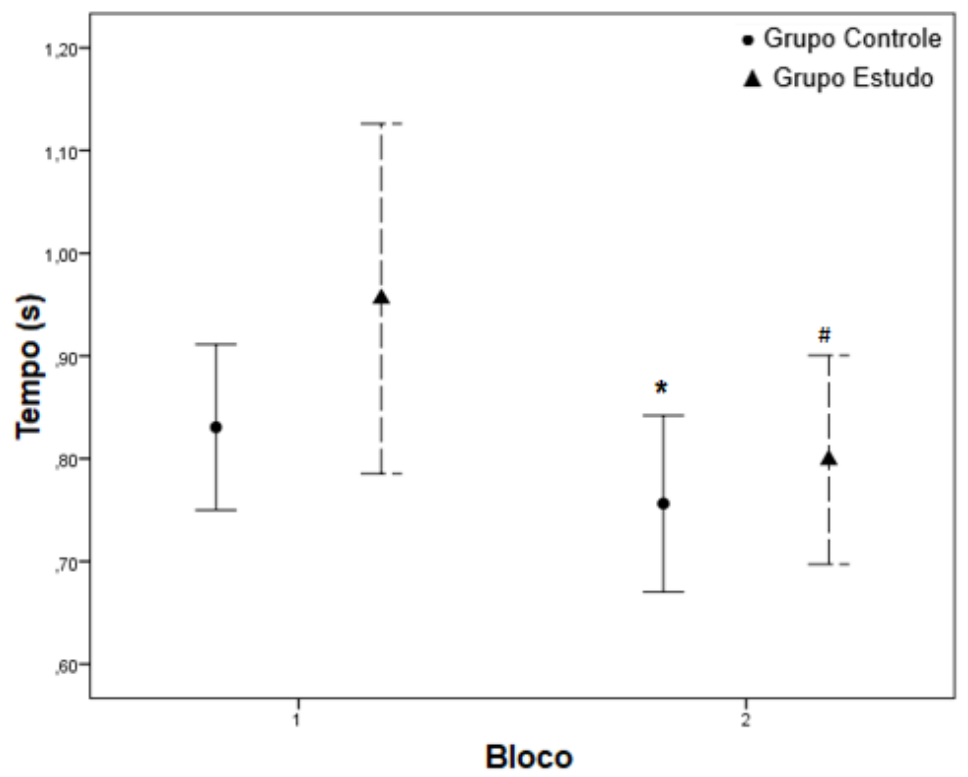

Figura 22. Gráfico das médias e intervalo de confiança de T3 em cada bloco da fase RET 2 para cada grupo. P<0,05: *vs. Bloco 1 Grupo Controle; \#vs. Bloco 1 Grupo Estudo (GLM com função de ligação Identidade Normal).

\subsubsection{Variável "T3” na Fase TR}

Não houve diferença entre os grupos nos dois blocos da fase TR ( $p=0,220)$ e entre os grupos com relação à curva de desempenho ao longo de toda a fase TR $(p=0,320)$. Houve diferença entre os dois blocos desta fase $(\mathrm{p}<0,001)$.

Então, houve redução de tempo entre os blocos da fase TR para ambos os grupos, sendo o desempenho dos grupos semelhante, como demonstra a figura 23. 


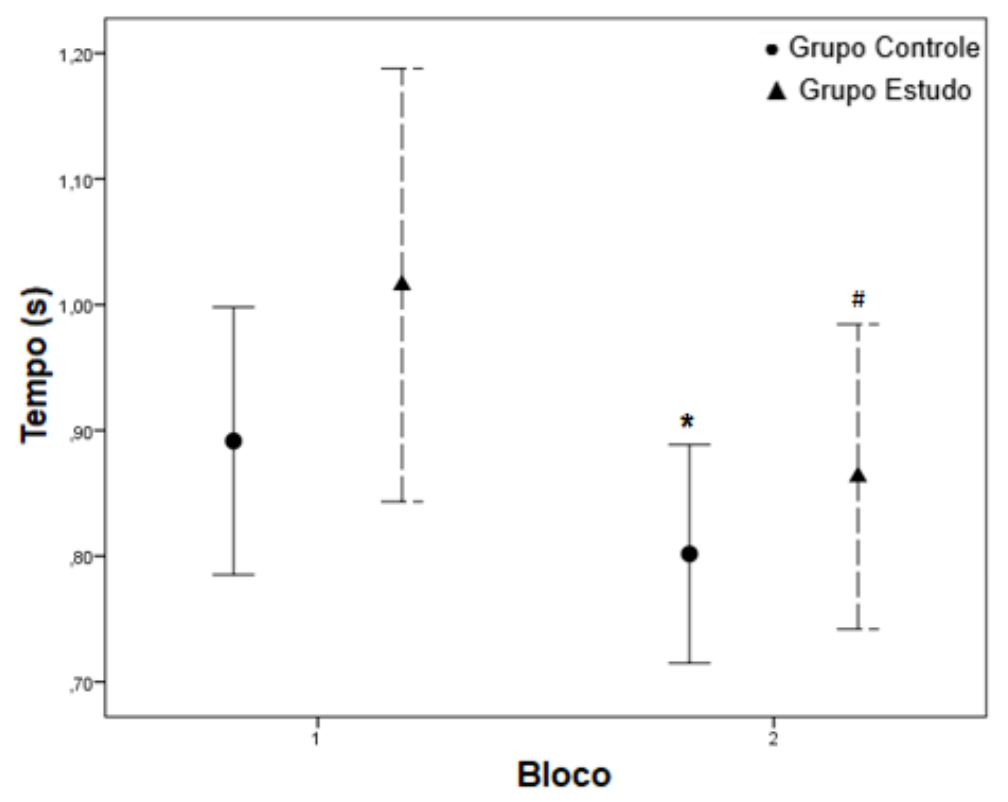

Figura 23. Gráfico das médias e intervalo de confiança de T3 em cada bloco da fase TR para cada grupo. $\mathrm{P}<0,05$ : * vs. Bloco 1 Grupo Controle; \# vs. Bloco 1 Grupo Estudo (GLM com função de ligação Identidade Normal).

\subsubsection{Variável "T3" - Comparação entre as Fases AQ e TR}

Para esta comparação utilizou-se apenas o último bloco da fase AQ, conforme descrito nos materiais e métodos.

Houve diferença entre o último bloco da fase AQ e o primeiro bloco da fase TR, segundo teste de Bonferroni ( $\mathrm{p}<0,001)$, mas não houve diferença entre AQ e o segundo bloco de TR $(\mathrm{p}=1,000)$. Não houve diferença entre os grupos $(\mathrm{p}=0,204)$ e com relação à curva de desempenho dos grupos ao longo do tempo $(\mathrm{p}=0,546)$.

Portanto, o resultado obtido na fase TR foi inferior ao estabilizado na fase AQ, denotando que não houve transferência do aprendizado em nenhum dos grupos. Além disso, como relatado anteriormente, com o treino da nova tarefa na fase TR houve melhora do desempenho (diferenças entre os blocos da fase TR), sendo que ao final da fase TR os tempos foram semelhante aos do final da fase AQ, como demonstra a figura 24. 


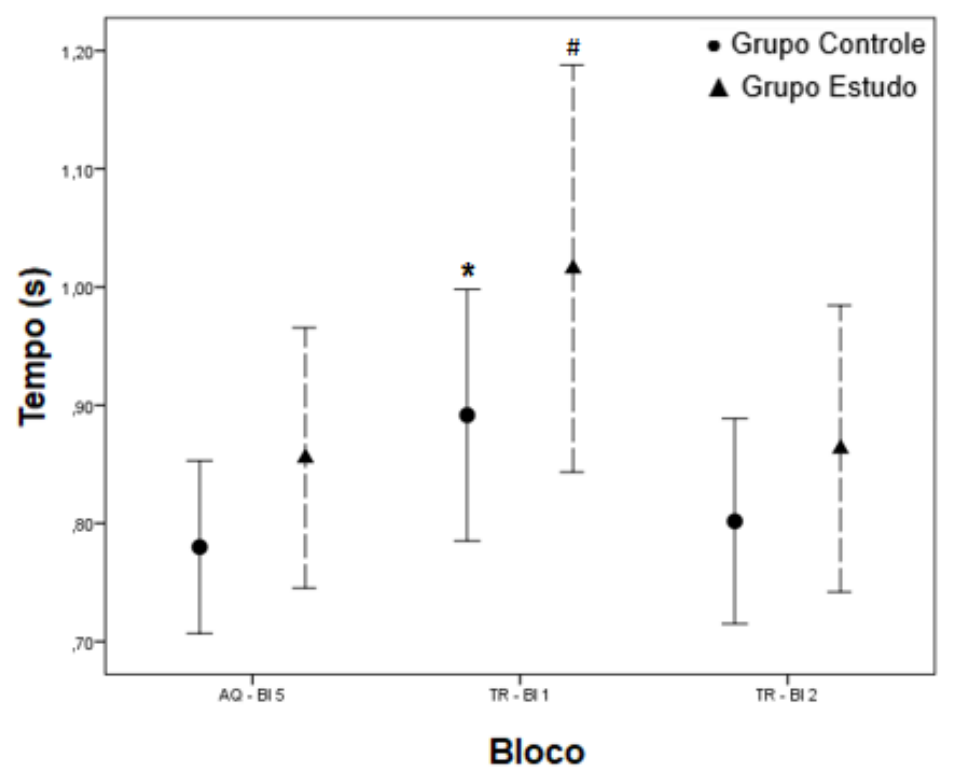

Figura 24. Gráfico das médias e intervalo de confiança de T3 nas fases AQ e TR para cada grupo. Transferência de aprendizado. P<0,05: *vs. Aq-B15 Grupo Controle; \# vs. Aq-B15 Grupo Estudo (GLM com função de ligação Identidade Normal).

\subsubsection{Variável “T3”-Comparação entre as Fases AQ, RET 1 e RET 2}

Para esta comparação utilizou-se apenas o último bloco da fase AQ e o primeiro bloco das fases RET 1 e RET 2, conforme demonstrado no item 3.4.3.

Não houve diferença entre AQ e RET $1(\mathrm{p}=0,071)$, mas houve diferença significativa entre AQ e RET 2 ( $\mathrm{p}=0,040)$, segundo o pós teste de Bonferroni. Não houve diferença significativa entre os grupos $(\mathrm{p}=0,160)$, bem como, em relação à curva de desempenho dos grupos ao longo do tempo $(\mathrm{p}=0,716)$.

Podemos dizer que o resultado obtido na fase AQ foi mantido na fase RET 1, havendo retenção do aprendizado à curto prazo, que não foi mantido na fase RET 2, inferindo que não houve aprendizado à longo prazo para os dois grupos, sendo o desempenho semelhante entre os grupos, como demonstra a figura 25. 


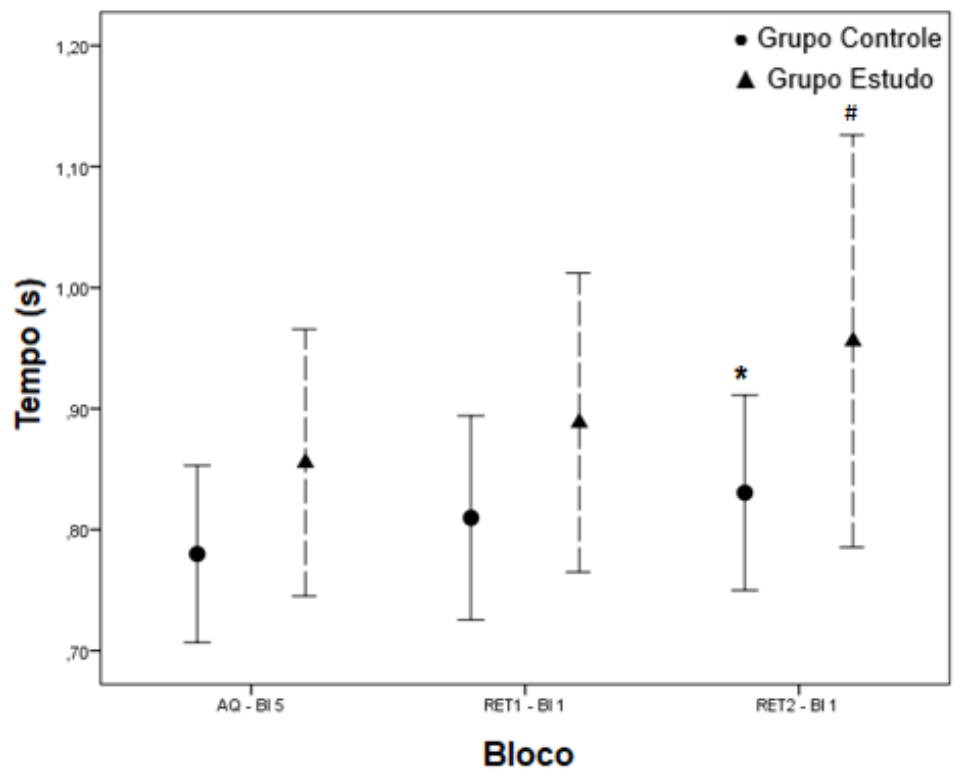

Figura 25. Gráfico de comparação das médias e intervalo de confiança de T3 ao longo das fases AQ, RET 1 e RET 2 para cada grupo. P<0,05: *vs.Aq-B15 Grupo Controle; \#vs.Aq-B15 Grupo Estudo (GLM com função de ligação Identidade Normal).

\subsubsection{VARIÁVEL “T4” OU “TEMPO MÃO-BARRA”}

A variável T4 corresponde ao tempo decorrido desde a retirada da mão do sensor até a retirada da barra do suporte de apoio, conforme descrito nos materiais e métodos. Esta variável foi computada a cada tentativa realizada pelo indivíduo.

\subsubsection{Variável "T4” na Fase $A Q$}

Houve diferença entre os grupos em todos os blocos da fase AQ ( $\mathrm{p}=0,029)$ e entre os blocos desta fase $(\mathrm{p}<0,001)$, sendo que a diferença ocorre somente entre o bloco 1 em relação aos demais blocos para os dois grupos $(\mathrm{p}<0,001)$, segundo pós teste de Bonferroni. Não houve diferença entre os grupos com relação à curva de desempenho ao longo de toda a fase AQ $(\mathrm{p}=0,828)$.

Assim, houve redução do tempo na primeira fase da tarefa, mais relacionada ao planejamento, entre os blocos 1 e 2 da fase AQ, seguida por estabilização do desempenho em ambos os grupos, sendo o GE mais lento que o GC, como demonstra a figura 26. 


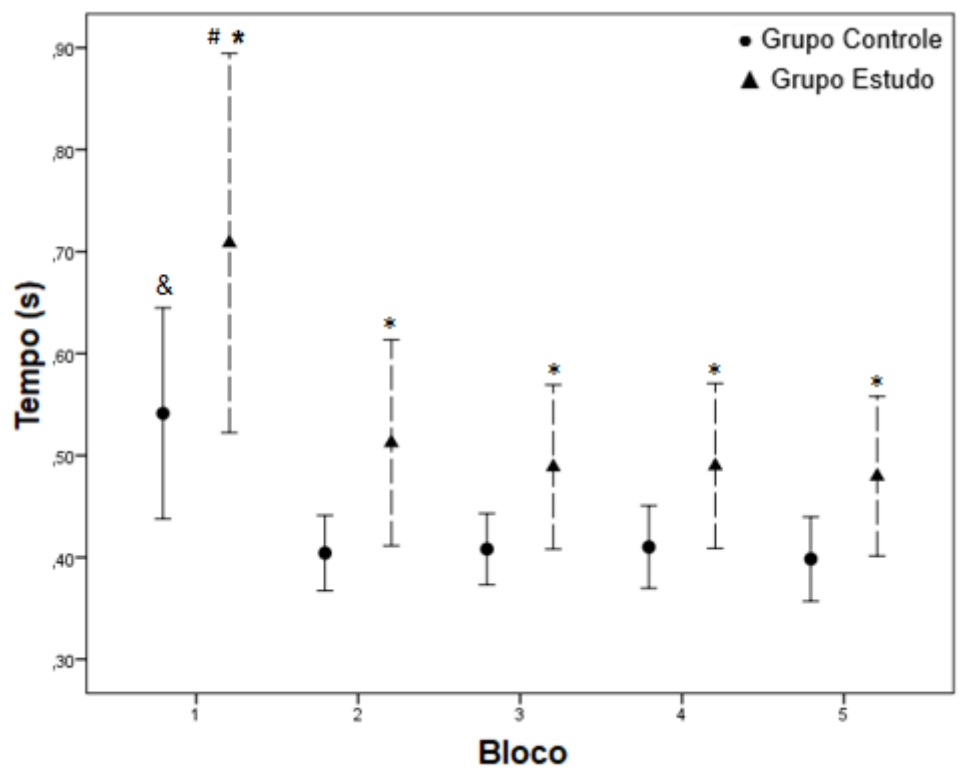

Figura 26. Gráfico das médias e intervalo de confiança de T4 em cada bloco da fase AQ para cada grupo. P<0,05: *vs. Grupo Controle; \& vs. Blocos 2-5 Grupo Controle; \#vs. Blocos 2-5Grupo Estudo (GLM com função de ligação Identidade Normal).

4.2.4.2 Variável “T4” na Fase RET 1 (memória motora de curto prazo)

Houve diferença entre os grupos ao longo da fase RET 1 ( $\mathrm{p}=0,033)$, porém não houve diferença entre os dois blocos desta fase $(\mathrm{p}=0,102)$ e entre os grupos com relação à curva de desempenho ao longo de toda a fase RET $1(\mathrm{p}=0,499)$.

Não houve melhora do desempenho nesta fase, porém o GE foi mais lento que o GC, como demonstra a figura 27. 


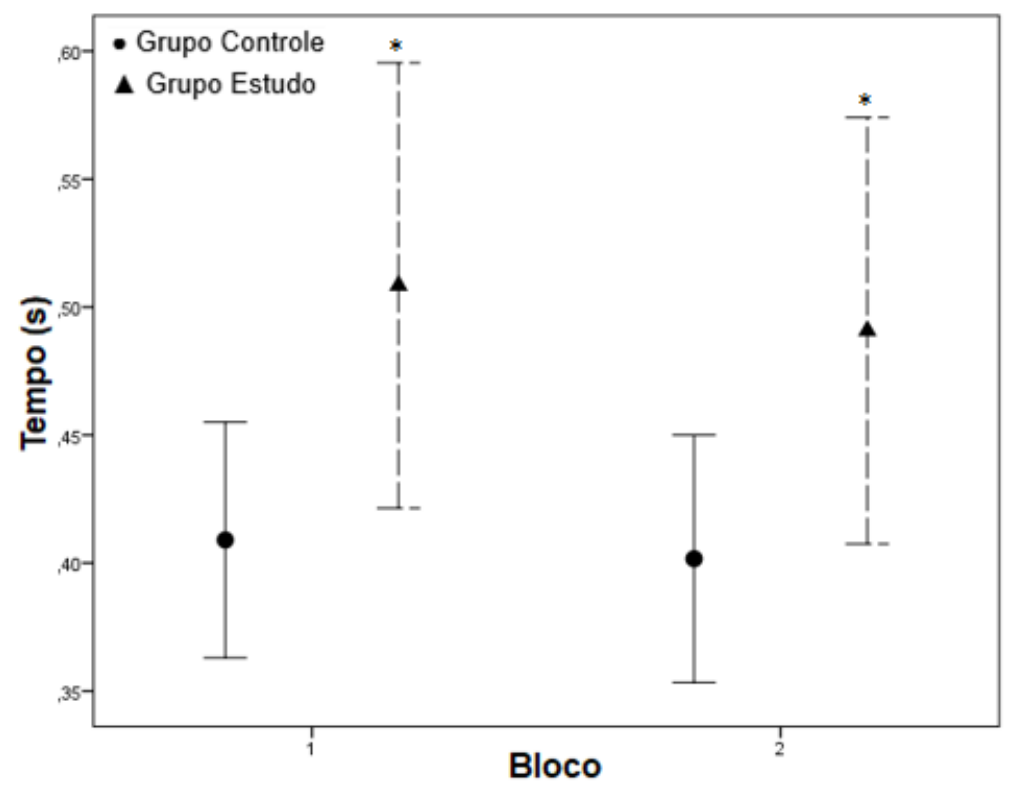

Figura 27. Gráfico das médias e intervalo de confiança de T4 em cada bloco da fase RET1 para cada grupo. $\mathrm{P}<0,05: * v s$. Grupo Controle (GLM com função de ligação Identidade Normal).

\subsubsection{Variável “T4” na Fase RET 2 (memória de longo prazo)}

Não houve diferença entre os grupos nos dois blocos da fase RET $2(p=0,077)$ e entre os grupos com relação à curva de desempenho ao longo de toda a fase RET 2 $(\mathrm{p}=0,802)$. Porém, houve diferença entre os blocos desta fase para os dois grupos $(\mathrm{p}<0,001)$.

Assim, pode-se dizer que houve redução do tempo entre os blocos da fase RET 2 para ambos os grupos, sendo o desempenho dos grupos semelhante, como demonstra a figura 28 . 


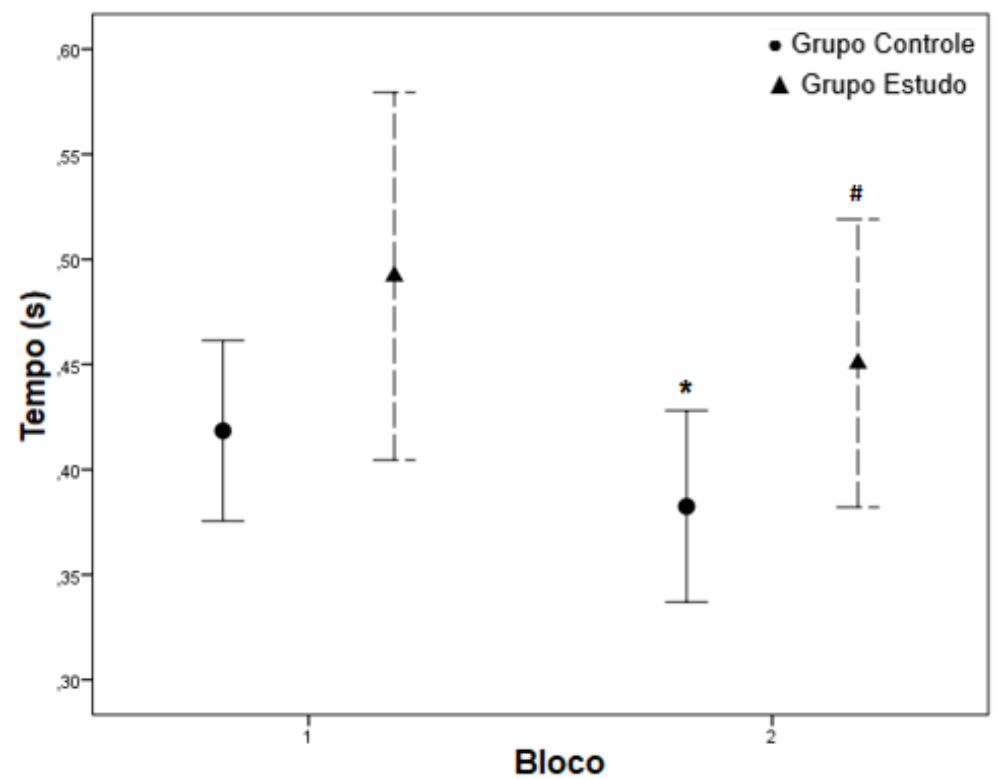

Figura 28. Gráfico das médias e intervalo de confiança de T4 em cada bloco da fase RET 2 para cada grupo. P<0,05: *vs. Bloco 1 Grupo Controle; \#vs. Bloco 1 Grupo Estudo (GLM com função de ligação Identidade Normal).

\subsubsection{Variável "T4" na Fase TR}

Houve diferença entre os grupos nos dois blocos da fase TR $(\mathrm{p}=0,048)$ e entre os dois blocos desta fase $(\mathrm{p}=0,009)$, mas não houve diferença entre os grupos com relação à curva de desempenho ao longo de toda a fase TR $(\mathrm{p}=0,635)$.

É possível dizer, portanto, que houve melhora do desempenho entre os blocos da fase TR para ambos os grupos, sendo o GE mais lento que o GC, como demonstra a figura 29. 


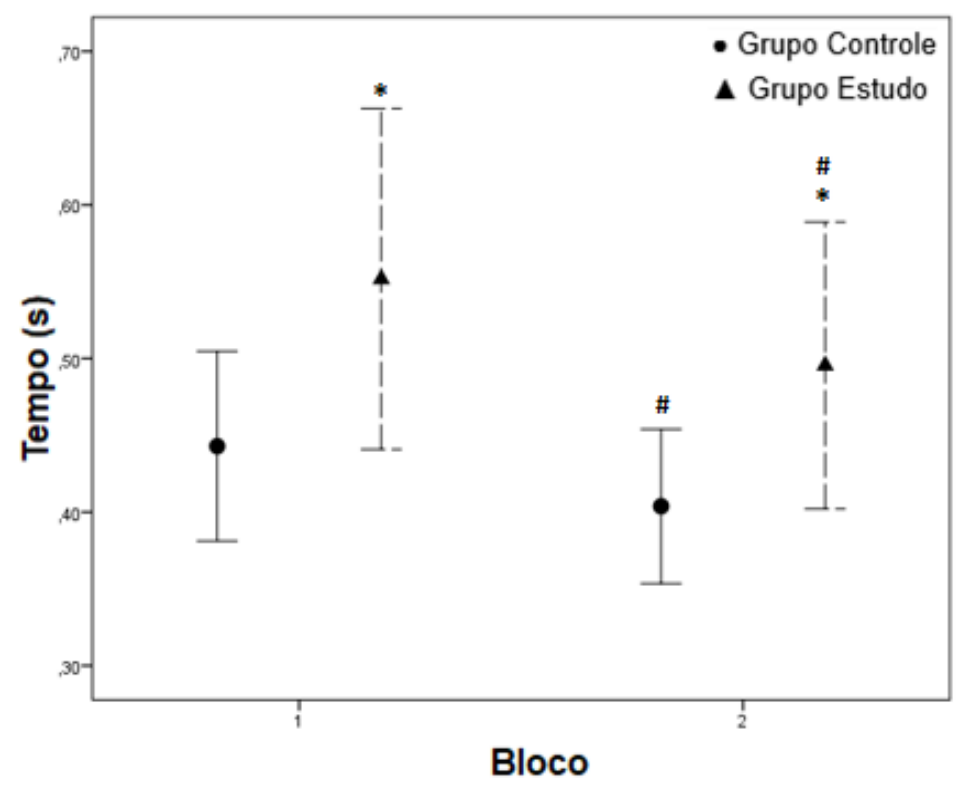

Figura 29. Gráfico das médias e intervalo de confiança de T4 em cada bloco da fase TR para cada grupo. P<0,05: *vs. Grupo Controle; \#vs. Bloco 1 (GLM com função de ligação Identidade Normal).

\subsubsection{Variável "T4” - Comparação entre as Fases AQ e TR}

Para esta comparação utilizou-se apenas o último bloco da fase AQ e os dois blocos da fase TR, conforme descrito nos materiais e métodos.

Houve diferença entre AQ e o primeiro bloco de TR $(\mathrm{p}=0,011)$ e não houve diferença entre AQ e o segundo bloco de TR ( $\mathrm{p}=0,707)$, segundo pós teste de Bonferroni. Houve diferença entre os grupos ( $p=0,042)$, mas não houve diferença entre os grupos com relação à curva de desempenho ao longo do tempo $(\mathrm{p}=0,746)$.

O resultado obtido na fase AQ não foi mantido no primeiro bloco da fase TR, mostrando que não houve transferência de aprendizado. Entretanto, como dito anteriormente, houve redução do tempo ao longo da fase TR, sendo este ao final desta fase semelhante ao obtido em AQ para os dois grupos, embora o GE tenha sido mais lento que o GC, como demonstra a figura 30 . 


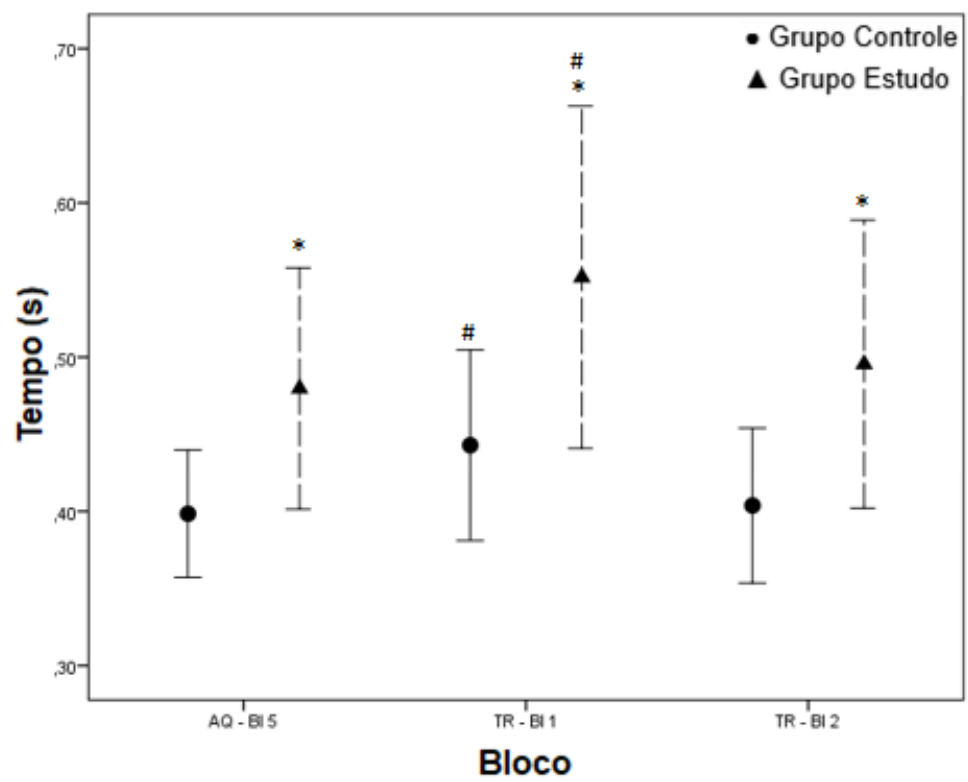

Figura 30. Gráfico de comparação das médias e intervalo de confiança de T4 ao longo das fases AQ e TR para cada grupo. P<0,05: *vs. Grupo Controle; \#vs. Aq-B15 (GLM com função de ligação Identidade Normal).

\subsubsection{Variável "T4" - Comparação entre as Fases AQ, RET 1 e RET 2}

Para esta comparação utilizou-se apenas o último bloco da fase AQ e o primeiro bloco das fases RET 1 e RET 2, conforme descrito no item 3.4.3.

Não houve diferença entre AQ, RET 1 e RET $2(p=0,076)$ e entre os grupos com relação à curva de desempenho ao longo do tempo $(\mathrm{p}=0,558)$. Porém houve diferença entre os grupos $(\mathrm{p}=0,041)$.

O desempenho obtido na fase AQ foi mantido na fase RET 1 e na fase RET 2, mostrando que houve retenção do aprendizado à curto e à longo prazo para os dois grupos, embora GE tenha sido mais lento que o GC, como demonstra a figura 31 . 


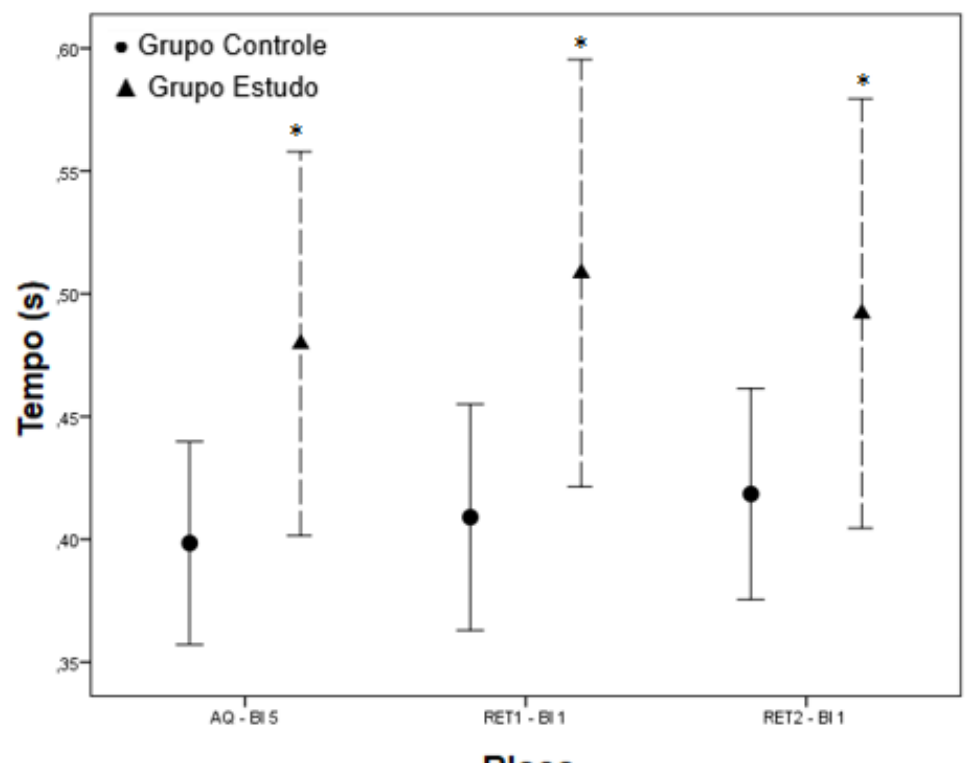

Figura 31. Gráfico de comparação das médias e intervalo de confiança de T4 ao longo das fases AQ, RET 1 e RET 2 para cada grupo. P<0,05: *vs. Grupo Controle (GLM com função de ligação Identidade Normal).

\subsubsection{VARIÁVEL “T5” OU "TEMPO DE FINALIZAÇÃO”}

A variável T5 corresponde ao tempo decorrido desde a retirada da barra do suporte de apoio até o contato com o fundo da caixa, conforme descrito nos materiais e métodos. Esta variável foi computada a cada tentativa realizada pelo indivíduo.

\subsubsection{Variável "T5” na Fase $A Q$}

Houve diferença entre os grupos com relação à curva de desempenho ao longo de toda a fase AQ $(\mathrm{p}=0,020)$. Analisando cada grupo separadamente, encontrou-se que no GC houve diferença entre o primeiro bloco da fase AQ e os demais blocos desta fase ( $\mathrm{p}<0,001$ ). Já no GE houve diferença significativa apenas entre os blocos 1 e 4 da fase AQ $(p=0,028)$. Houve diferença entre os grupos nos blocos $2(p<0,001), 3(p=0,005), 4$ $(\mathrm{p}=0,017)$ e $5(\mathrm{p}=0,001)$ e não houve no bloco $1(\mathrm{p}=0,676)$.

A melhora de desempenho e a estabilização deste foram mais rápidas para GC do que GE, uma vez que GE só apresentou melhora no quarto bloco. Além disso GE foi mais lento em quase toda a fase AQ, como demonstra a figura 32. 


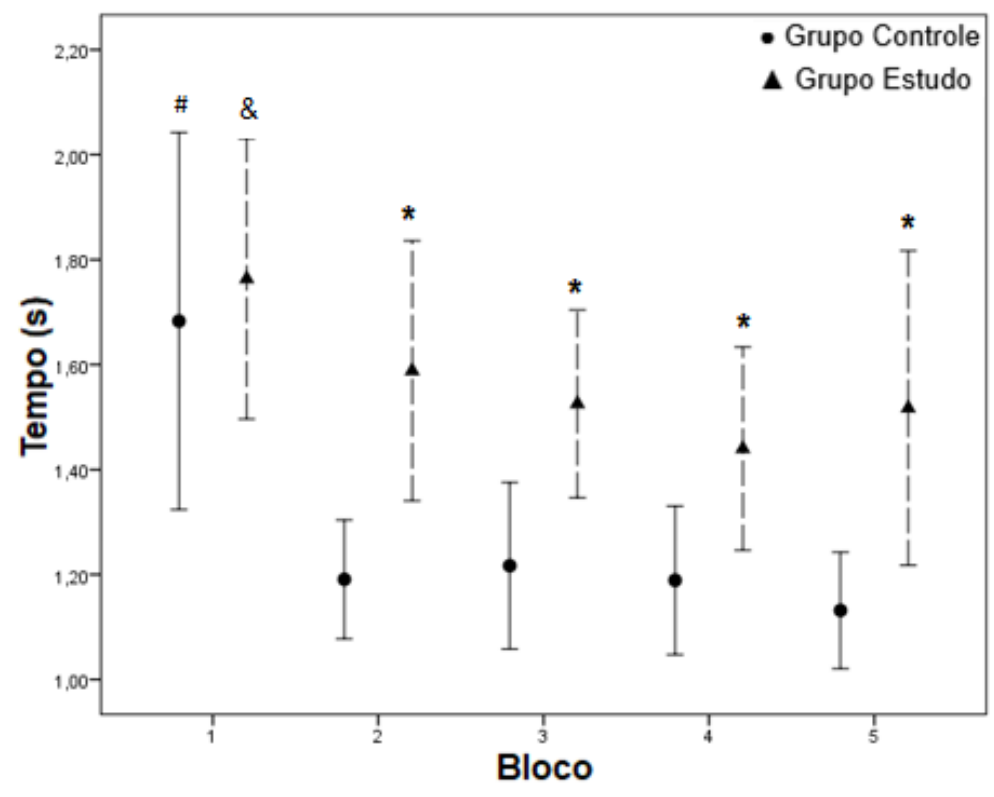

Figura 32. Gráfico das médias e intervalo de confiança de T5 em cada bloco da fase AQ para cada grupo. P<0,05: *vs. Grupo Controle; \#vs. Blocos 2-5 Grupo Controle; \&vs. Bloco 4 Grupo Estudo (GLM com função de ligação log Gama).

\subsubsection{Variável “T5” na Fase RET 1 (memória motora de curto prazo)}

Houve diferença entre os grupos ao longo da fase RET 1 ( $\mathrm{p}=0,023)$, porém não houve entre os dois blocos desta fase $(\mathrm{p}=0,914)$ e entre os grupos com relação à curva de desempenho ao longo de toda a fase RET $1(\mathrm{p}=0,153)$.

Assim, não houve redução dos tempos de finalização nesta fase, sendo GE mais lento que GC, como demonstra a figura 33. 


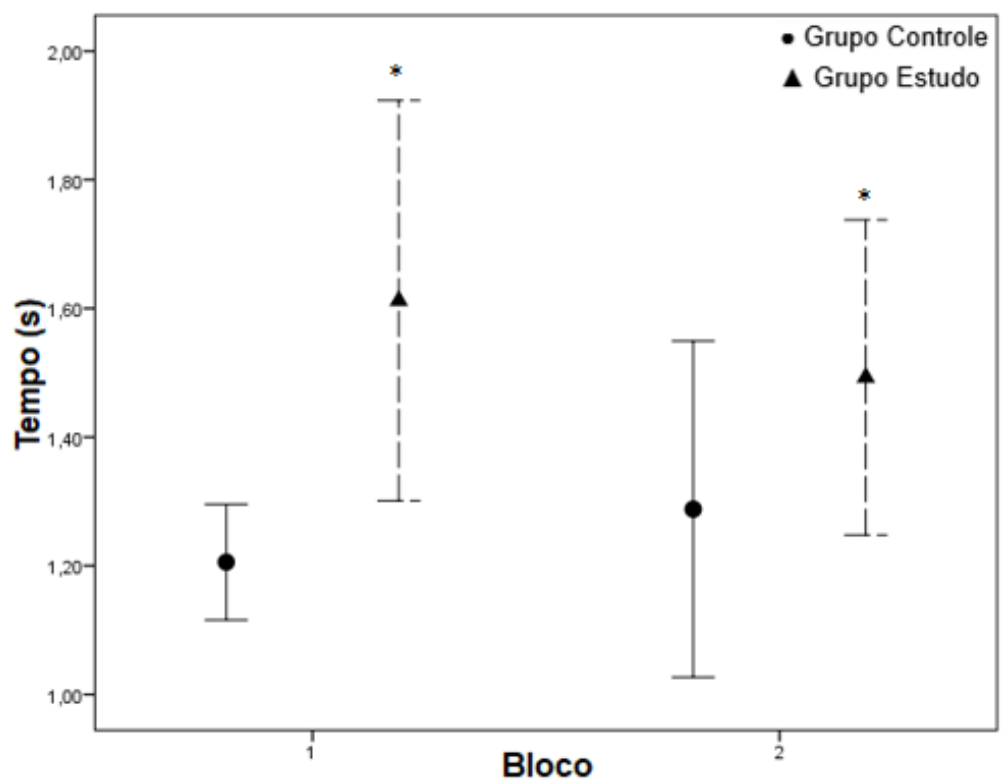

Figura 33. Gráfico das médias e intervalo de confiança de T5 em cada bloco da fase RET1 para cada grupo. $\mathrm{P}<0,05:$ *vs. Grupo Controle (GLM com função de ligação log Gama).

\subsubsection{Variável “T5” na Fase RET 2 (memória motora de longo prazo)}

Houve diferença entre os grupos nos dois blocos da fase RET 2 (p<0,001) bem como entre os blocos desta fase $(\mathrm{p}=0,001)$, porém não houve diferença entre os grupos com relação à curva de desempenho ao longo de toda a fase RET $2(p=0,636)$.

Assim, pode-se dizer que houve melhora do resultado entre os blocos da fase RET 2 para ambos os grupos, sendo o desempenho de GE inferior ao de GC, como demonstra a figura 34 .

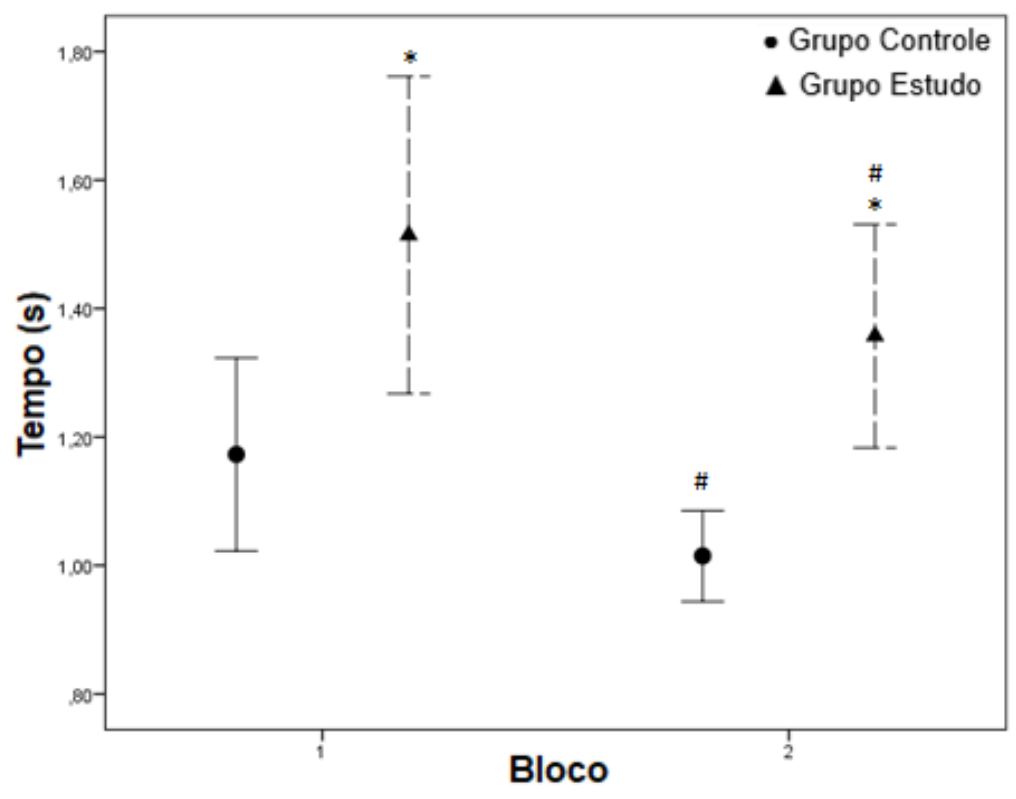


Figura 34. Gráfico das médias e intervalo de confiança de T5 em cada bloco da fase RET 2 para cada grupo. P<0,05: *vs. Grupo Controle; \# vs. Bloco 1 para ambos os grupos (GLM com função de ligação log Gama).

\subsubsection{Variável "T5" na Fase TR}

Houve diferença entre os grupos nos dois blocos da fase TR $(\mathrm{p}=0,006)$ e entre os dois blocos desta fase $(\mathrm{p}=0,008)$, entretanto não houve diferença entre os grupos com relação à curva de desempenho ao longo de toda a fase TR $(\mathrm{p}=0,416)$.

Os dados mostraram que houve redução do tempo de finalização entre os blocos da fase TR para ambos os grupos, sendo o desempenho de GE inferior ao GC, como demonstra a figura 35 .

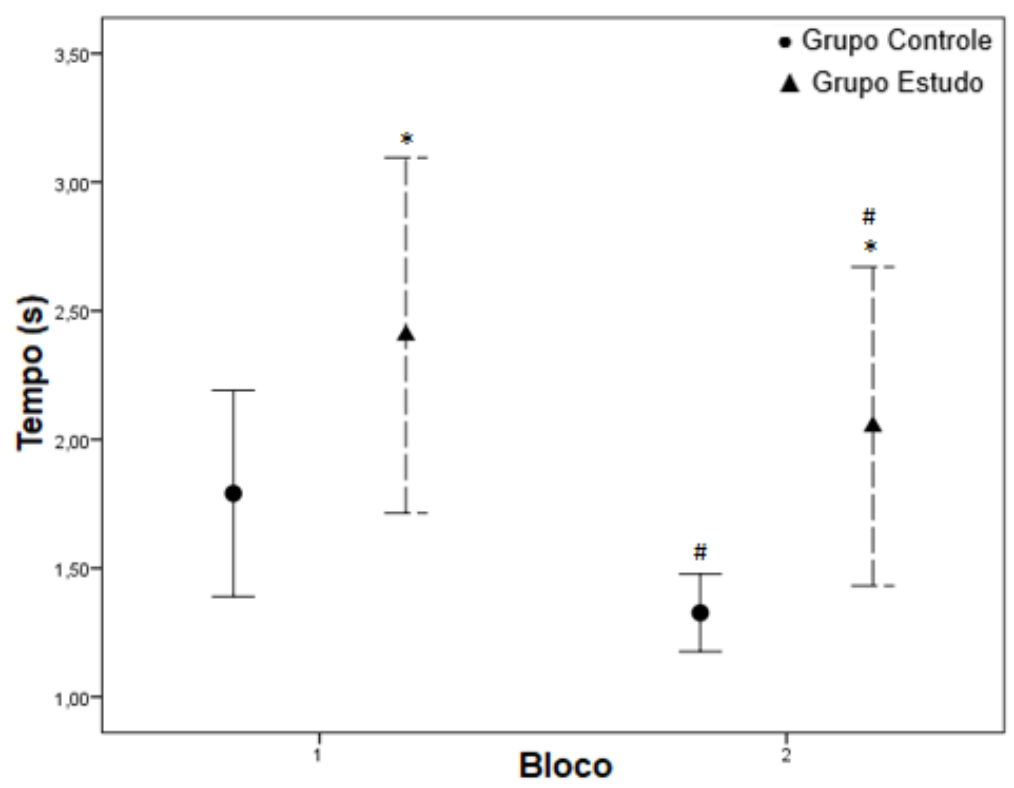

Figura 35. Gráfico das médias e intervalo de confiança de T5 em cada bloco da fase TR para cada grupo. P<0,05: *vs. Grupo Controle; \#vs. Bloco 1 para ambos os grupos (GLM com função de ligação log Gama).

\subsubsection{Variável "T5” - Comparação entre as Fases AQ e TR}

Para esta comparação utilizou-se apenas o último bloco da fase AQ e os dois blocos da fase TR, conforme descrito nos materiais e métodos.

Houve diferença entre AQ e o primeiro bloco de TR $(\mathrm{p}<0,001)$ e entre AQ e o segundo bloco de TR ( $\mathrm{p}=0,003)$, segundo pós teste de Bonferroni. Houve diferença entre os grupos $(\mathrm{p}=0,002)$ e não houve entre os grupos com relação à curva de desempenho ao longo do tempo $(\mathrm{p}=0,501)$. 
O desempenho obtido na fase AQ não foi mantido no primeiro bloco da fase TR, revelando que não houve transferência de aprendizado. Embora tenha ocorrido redução do tempo de finalização ao longo da fase TR, como dito anteriormente, este não se igualou ao desempenho final da fase AQ para os dois grupos. Além disso, GE foi mais lento que o GC, como demonstra a figura 36 .

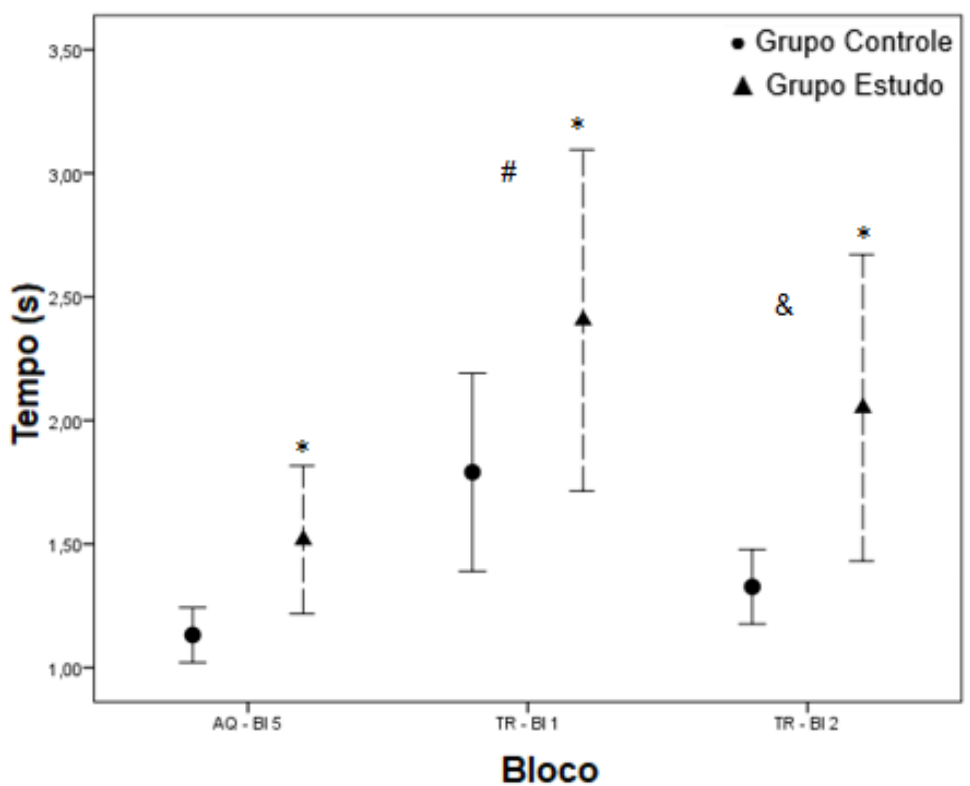

Figura 36. Gráfico de comparação das médias e intervalo de confiança de T5 ao longo das fases AQ e TR para cada grupo. P<0,05: * vs. Grupo Controle; \# vs. Aq-B15 para ambos os grupos; \& vs. Aq-B15 para ambos os grupos (GLM com função de ligação log Gama).

\subsubsection{Variável "T5” - Comparação entre as Fases AQ, RET 1 e RET 2}

Para esta comparação utilizou-se apenas o último bloco da fase AQ e o primeiro bloco das fases RET 1 e RET 2, conforme descrito no item 3.4.3.

Não houve diferença entre AQ, RET 1 e RET 2 ( $p=0,390)$ e entre os grupos com relação à curva de desempenho ao longo do tempo $(\mathrm{p}=0,862)$. Porém, houve diferença entre os grupos $(\mathrm{p}=0,001)$.

O resultado obtido na fase AQ foi mantido nas fases RET 1 e RET 2, inferindo que houve retenção do aprendizado à curto e à longo prazo para os dois grupos, embora o desempenho de GE tenha sido inferior ao GC, como demonstra a figura 37. 


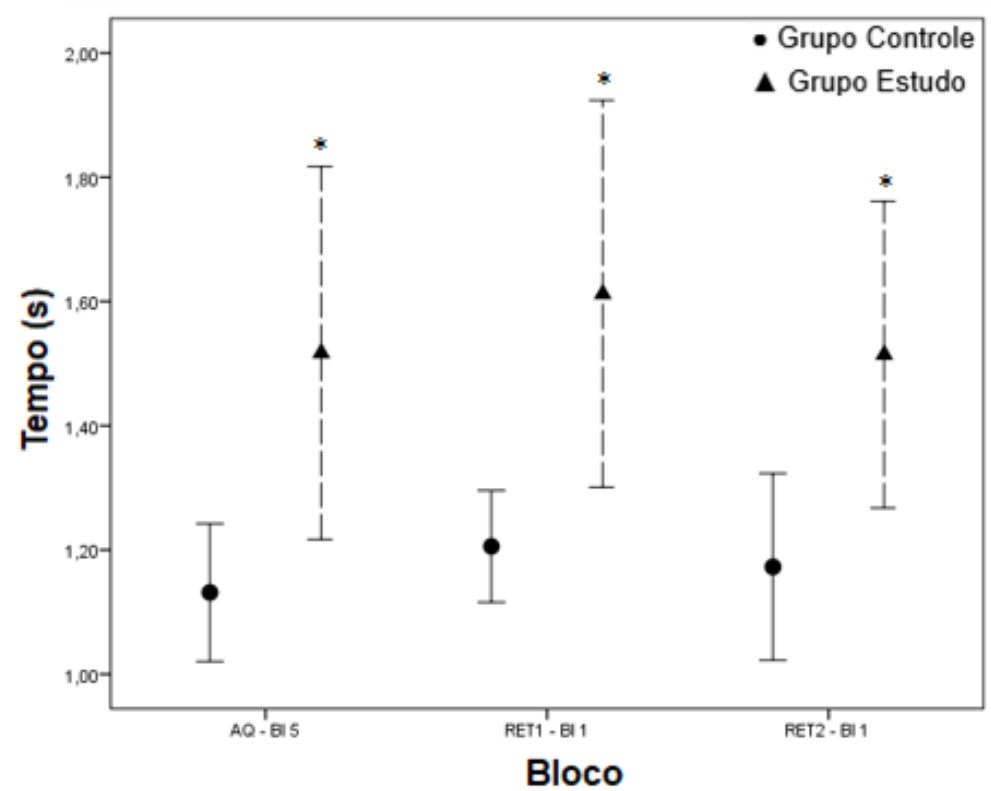

Figura 37. Gráfico de comparação das médias e intervalo de confiança de T5 ao longo das fases AQ, RET 1 e RET 2 para cada grupo. P<0,05: *vs. Grupo Controle (GLM com função de ligação log Gama).

\subsubsection{VARIÁVEL "ERROS”}

A variável "ERROS" corresponde a soma das vezes em que a extremidade da barra tocou a tampa da caixa antes de encaixar no orifício adequado, conforme descrito nos materiais e métodos. Esta variável foi computada a cada tentativa realizada pelo indivíduo.

\subsubsection{Variável "ERROS” na Fase $A Q$}

Não houve diferença entre os grupos em nenhum bloco da fase AQ $(p=0,319)$ entre os blocos desta fase $(\mathrm{p}=0,761)$ ou entre os grupos com relação à curva de desempenho ao longo de toda a fase AQ $(\mathrm{p}=0,812)$.

Não houve, portanto, redução do número de erros com o treino nos dois grupos, sendo o desempenho semelhante entre os grupos, como demonstra a figura 38 . 


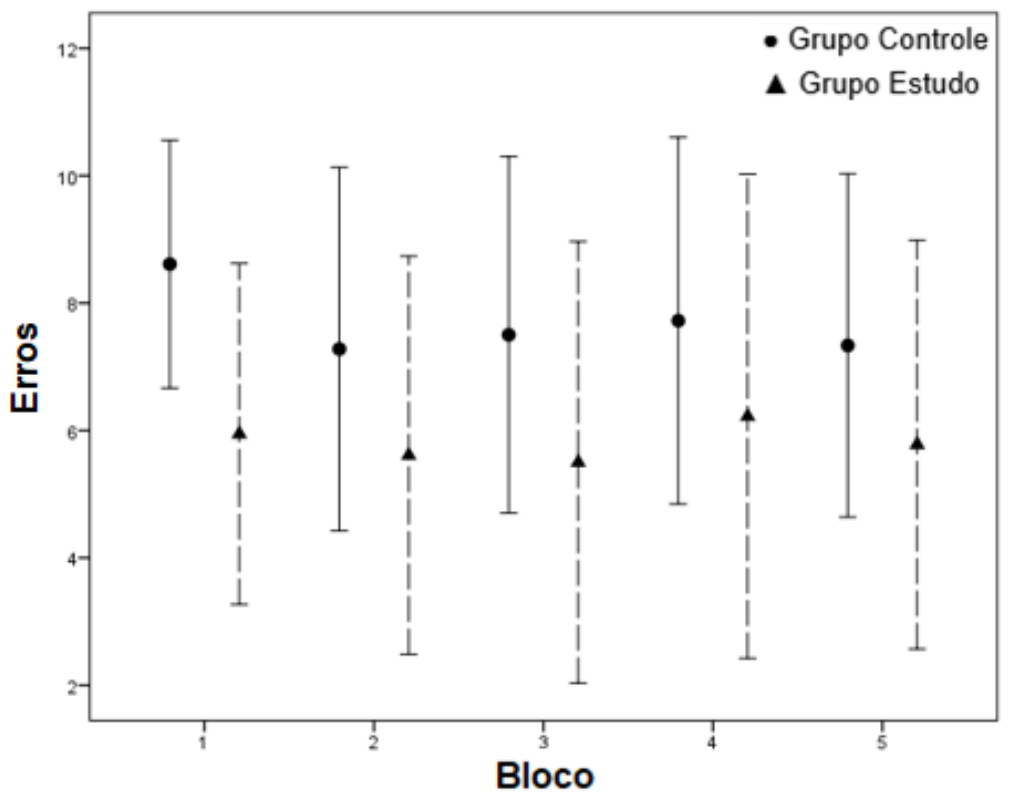

Figura 38. Gráfico das médias e intervalo de confiança de "Erros" em cada bloco da fase AQ para cada grupo. Não foram encontradas diferenças estatisticamente significativas (GLM com função de ligação log Tweedle).

\subsubsection{Variável “ERROS” na Fase RET 1 (memória motora de curto prazo)}

Não houve diferença entre os grupos em nenhum bloco da fase RET $1(p=0,485)$, entre os blocos desta fase $(\mathrm{p}=0,420)$ ou entre os grupos com relação à curva de desempenho ao longo de toda a fase RET $1(\mathrm{p}=0,701)$.

Assim, pode-se dizer que o desempenho foi constante ao longo da fase RET $1 \mathrm{em}$ ambos os grupos, sendo semelhante entre os grupos, como demonstra a figura 39. 


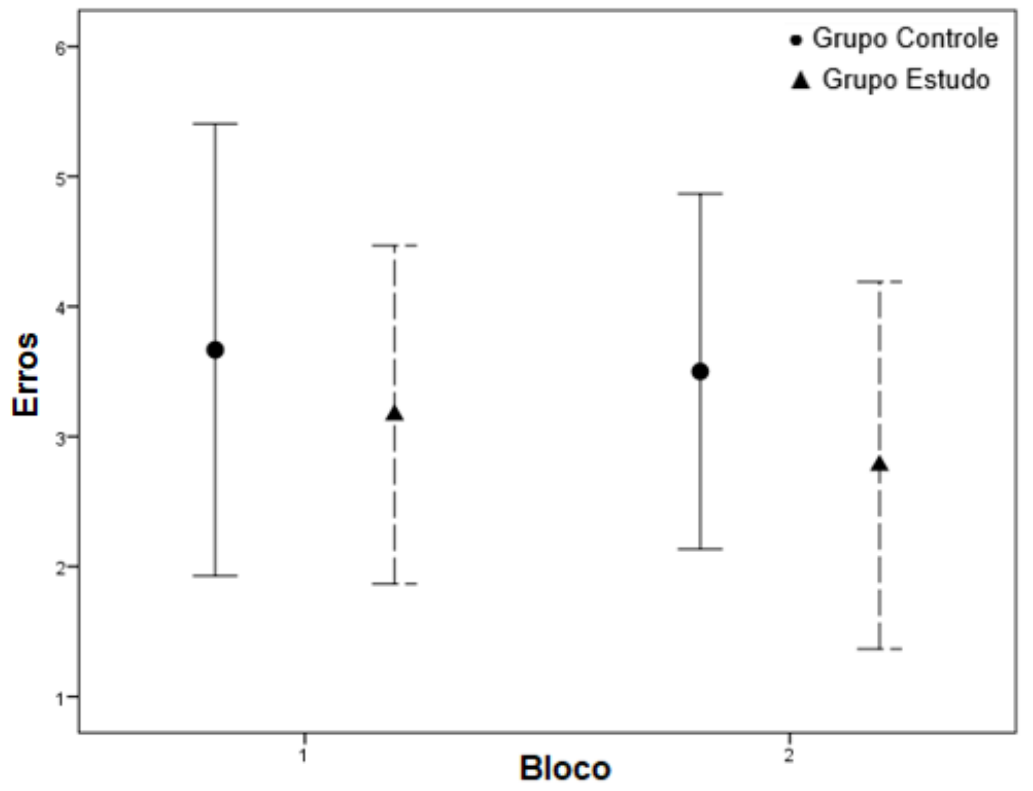

Figura 39. Gráfico das médias e intervalo de confiança de "Erros" em cada bloco da fase RET 1 para cada grupo. Não foram encontradas diferenças estatisticamente significativas (GLM com função de ligação log Tweedle).

4.2.6.3 Variável “ERROS” na Fase RET 2 (memória de longo prazo)

Não houve diferença entre os grupos em nenhum bloco da fase RET $2(p=0,807)$, entre os blocos desta fase $(\mathrm{p}=0,658)$ ou entre os grupos com relação à curva de desempenho ao longo de toda a fase RET $2(\mathrm{p}=0,658)$, sendo o desempenho constante ao longo da fase RET 2 em ambos os grupos e semelhante entre os grupos, como demonstra a figura 40 .

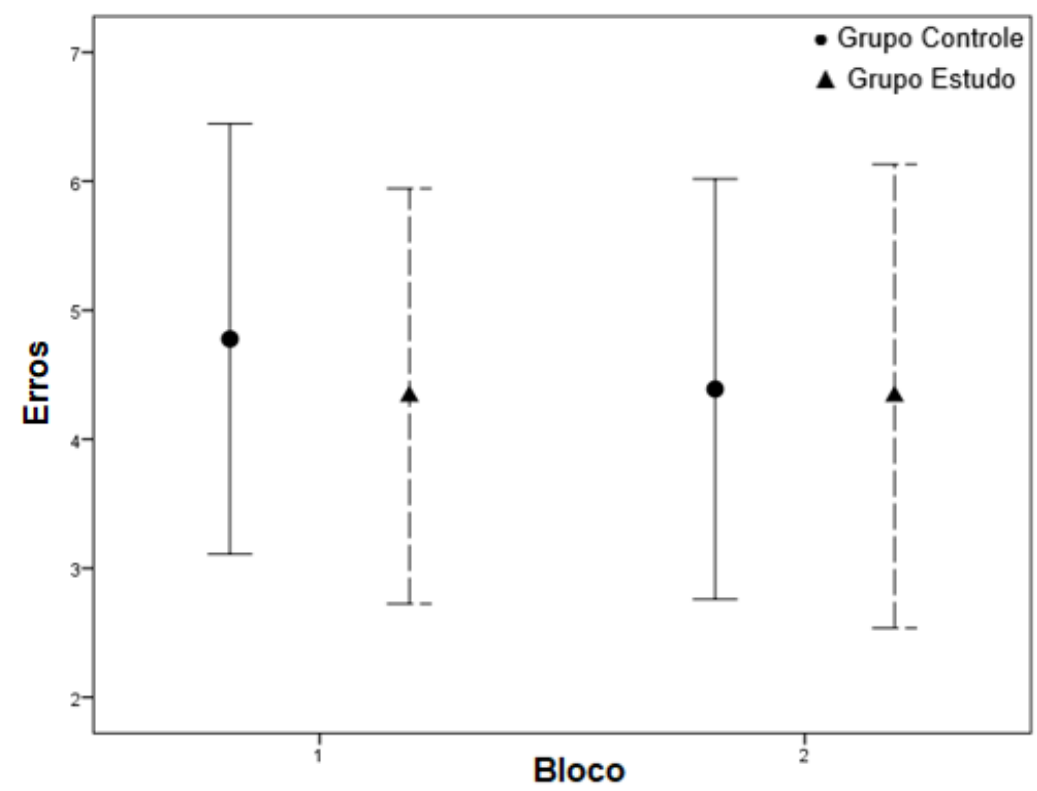


Figura 40. Gráfico das médias e intervalo de confiança de "Erros" em cada bloco da fase RET 2 para cada grupo. Não foram encontradas diferenças estatisticamente significativas (GLM com função de ligação log Gama).

\subsubsection{Variável "ERROS” na Fase TR}

Não houve diferença entre os grupos em nenhum bloco da fase TR $(\mathrm{p}=0,513)$ ou entre os grupos com relação à curva de desempenho ao longo de toda a fase $\mathrm{TR}(\mathrm{p}=0,107)$. Porém, houve diferença entre os blocos desta fase $(\mathrm{p}<0,001)$, demonstrando que houve melhora do desempenho em ambos os grupos ao longo da fase TR, sendo semelhante entre os grupos, como demonstrado na figura 41.

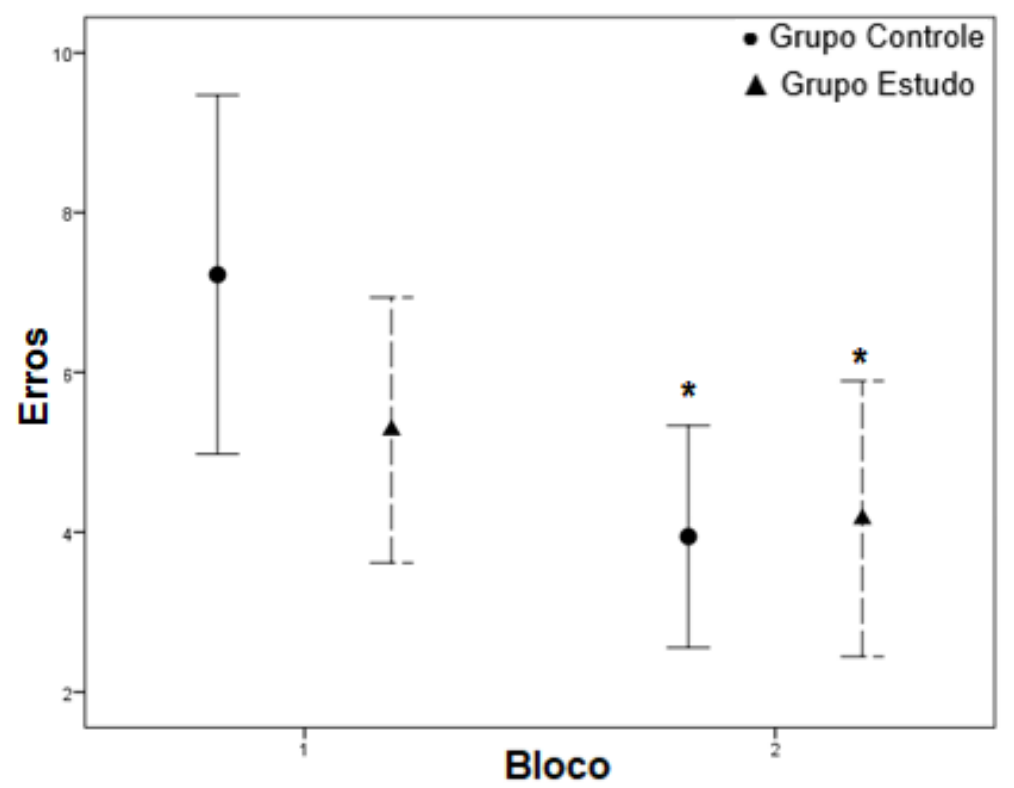

Figura 41. Gráfico das médias e intervalo de confiança de "Erros" em cada bloco da fase TR para cada grupo. P<0,05: *vs. B1 (GLM com função de ligação log Tweedle).

\subsubsection{Variável "ERROS” - Comparação entre as Fases AQ e TR}

Para esta comparação utilizou-se apenas o último bloco da fase AQ, conforme descrito nos métodos.

Não houve diferença entre os grupos $(\mathrm{p}=0,447)$ ou no comportamento dos grupos ao longo do tempo $(\mathrm{p}=0,166)$. Não foram encontradas diferenças significativas entre AQ e o primeiro bloco de TR $(\mathrm{p}=1,000)$, entretanto verificou-se diferença entre o último bloco AQ e o segundo bloco de TR, de acordo com o pós teste de Bonferroni ( $\mathrm{p}=0,002)$. 
O desempenho obtido com o treino realizado na fase AQ se manteve no primeiro bloco da fase TR para ambos os grupos, inferindo que houve transferência de aprendizado motor para a nova tarefa. Além disso, houve melhora com o treino da tarefa (diferença entre os blocos da fase TR), sendo que o desempenho no final da fase TR foi superior ao desempenho na fase AQ para ambos os grupos, como demonstra a figura 42.

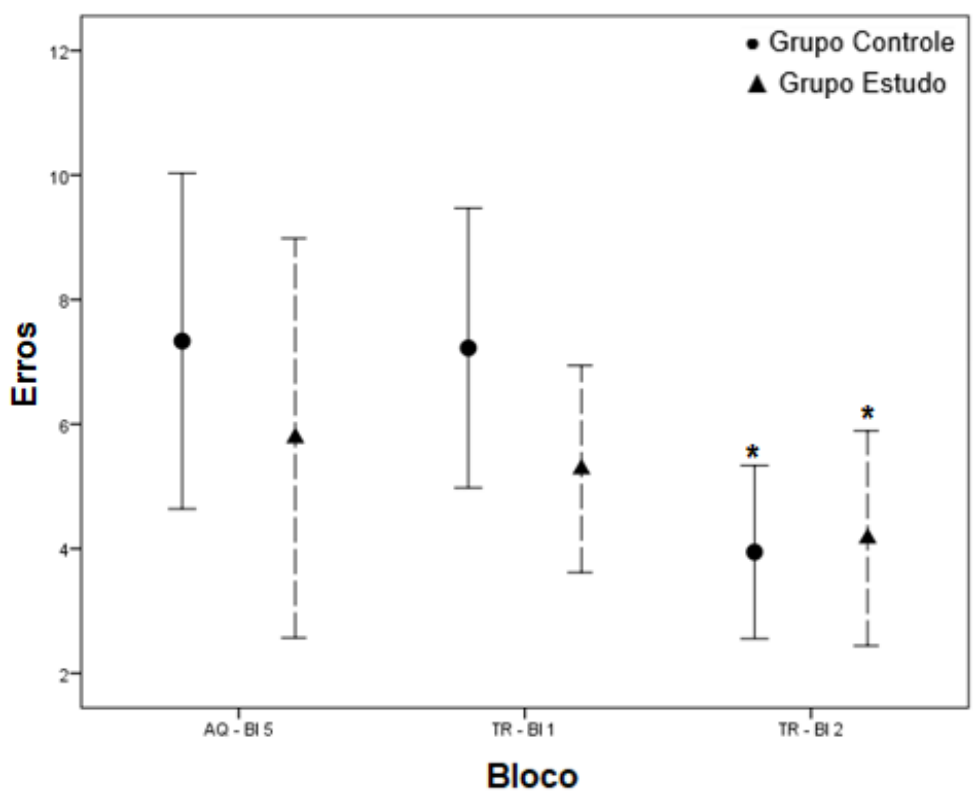

Figura 42. Gráfico das médias e intervalo de confiança de "Erros" nas fases AQ e TR para cada grupo. Transferência de aprendizado. P<0,05: *vs.Aq-B15 (GLM com função de ligação log Tweedle).

\subsubsection{Variável "ERROS” - Comparação entre as Fases AQ, RET 1 e RET 2}

Para esta comparação utilizou-se apenas o último bloco da fase AQ e o primeiro bloco das fases RET 1 e RET 2, conforme descrito no item 3.4.3.

Houve diferença entre AQ e RET 1 (p<0,001) e entre AQ e RET 2 (p=0,026), segundo o teste de Bonferroni. Não houve diferença entre os grupos $(\mathrm{p}=0,510)$ ou entre os grupos com relação à curva de desempenho ao longo do tempo $(\mathrm{p}=0,767)$.

Assim, o desempenho nas fases RET 1 e RET 2 foi superior ao obtido em AQ, inferindo que houve retenção do aprendizado à curto e à longo prazo para os dois grupos, como demonstra a figura 43. 


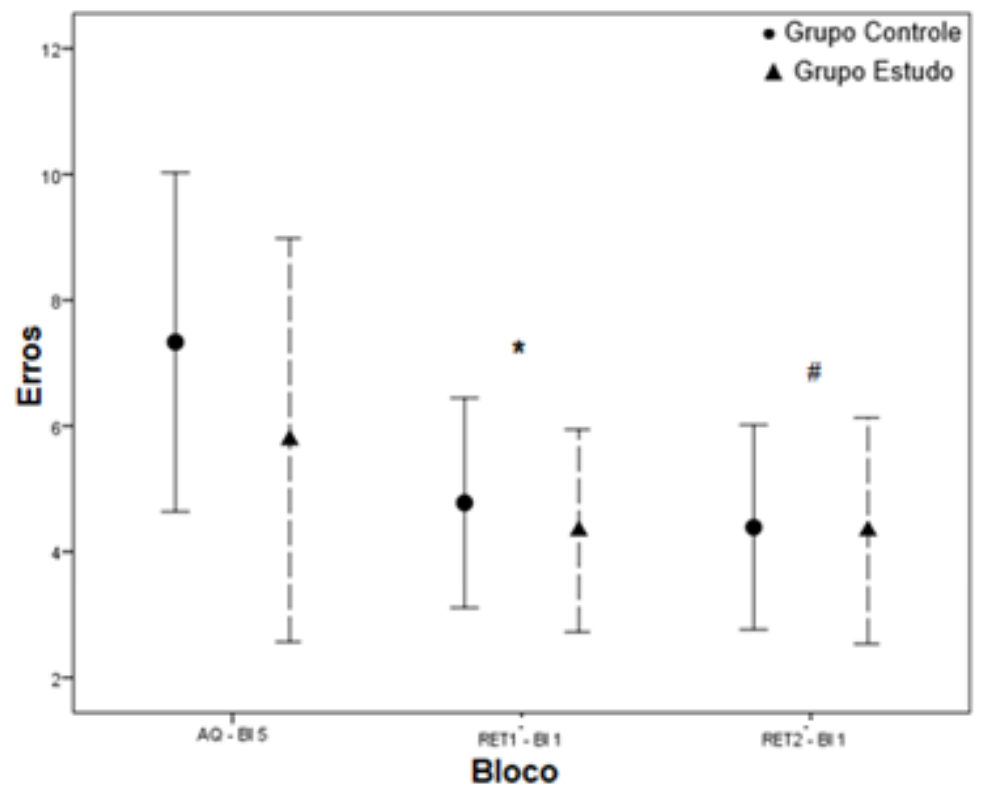

Figura 43. Gráfico de comparação das médias e intervalo de confiança de "Erros" ao longo das fases AQ, RET 1 e RET 2 para cada grupo. P<0,05:*vs.Aq-B15 para ambos os grupos; \# vs.Aq-B15 para ambos os grupos (GLM com função de ligação log Tweedle).

\subsubsection{VARIÁVEL "RETIRADA ANTECIPADA DA MÃO”}

A variável "RETIRADA ANTECIPADA DA MÃO” corresponde à soma das vezes em que o indivíduo retirou a mão do suporte antes do acendimento da luz, ou seja, antes do comando de início da tarefa, conforme descrito. Esta variável foi computada a cada tentativa realizada pelo indivíduo.

\subsubsection{Variável "RETIRADA ANTECIPADA DA MÃO” na Fase AQ}

Não houve diferença entre os grupos em todos os blocos da fase AQ ( $p=0,317)$ ou com relação à curva de desempenho dos grupos ao longo de toda a fase AQ ( $\mathrm{p}=0,813)$. Houve diferença entre os blocos desta fase $(p=0,003)$ e, a partir do pós teste de Bonferroni, verificou-se que a diferença ocorre somente entre o bloco 1 em relação aos blocos 4 e 5 para os dois grupos $(\mathrm{p}=0,012$ e $\mathrm{p}=0,004)$.

Portanto, o número de retiradas antecipadas foi maior no início da fase AQ em relação ao final da mesma, conforme a figura 44. 


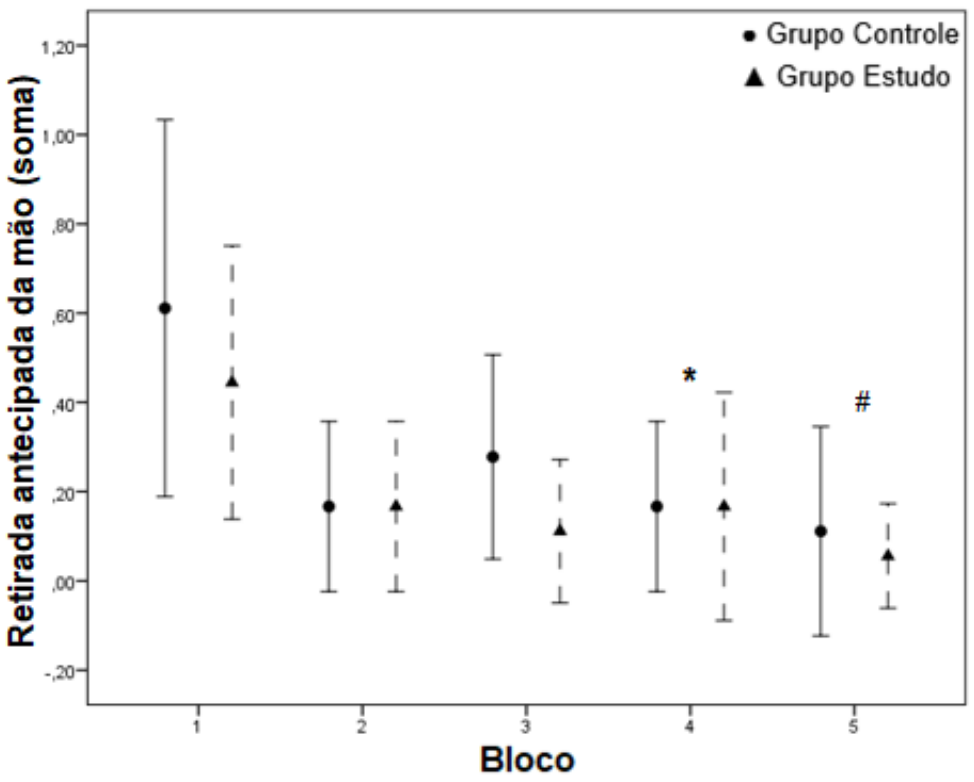

Figura 44. Gráfico das médias e intervalo de confiança de "RETIRADA ANTECIPADA DA MÃO” em cada bloco da fase AQ para cada grupo. P<0,05: *vs. Bloco 1 para ambos os grupos; \#vs. Bloco 1 para ambos os grupos (GLM com função de ligação Identidade Linear).

4.2.7.2 Variável "RETIRADA ANTECIPADA DA MÃO” na Fase RET 1 (memória motora de curto prazo)

Não houve diferença entre os grupos ao longo da fase RET $1(\mathrm{p}=1,000)$, entre os dois blocos desta fase $(\mathrm{p}=0,303)$ ou entre os grupos com relação à curva de desempenho ao longo de toda a fase RET 1 ( $\mathrm{p}=0,303)$, mostrando que não houve diferença no desempenho entre os grupos, como demonstra a figura 45 . 


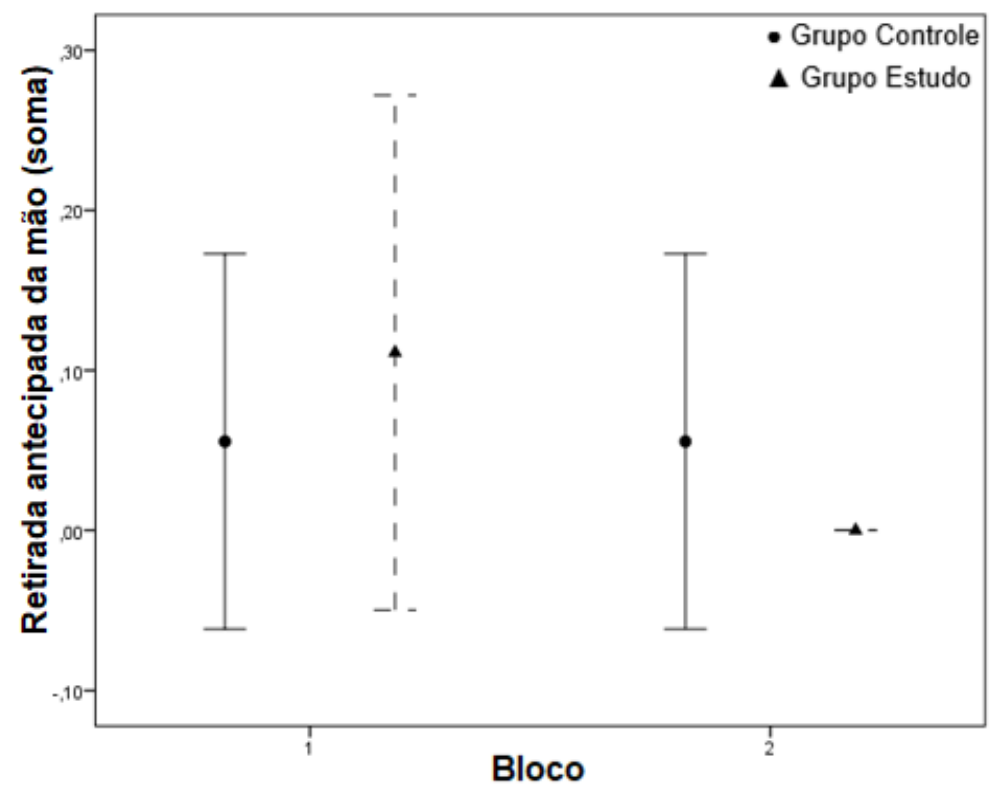

Figura 45. Gráfico das médias e intervalo de confiança de "RETIRADA ANTECIPADA DA MÃO” em cada bloco da fase RET1 para cada grupo. Não foram encontradas diferenças estatisticamente significativas (GLM com função de ligação Identidade Linear).

4.2.7.3 Variável "RETIRADA ANTECIPADA DA MÃO” na Fase RET 2 (memória motora de longo prazo)

Não houve diferença entre os grupos nos dois blocos da fase RET $2(\mathrm{p}=0,717)$ ou em relação à curva de desempenho dos grupos ao longo de toda a fase RET $2(\mathrm{p}=0,717)$. Entretanto, houve diferença entre os blocos desta fase para ambos os grupos $(p=0,011)$.

Assim, houve melhora do desempenho entre os blocos da fase RET 2 para ambos os grupos, como demonstra a figura 46. 


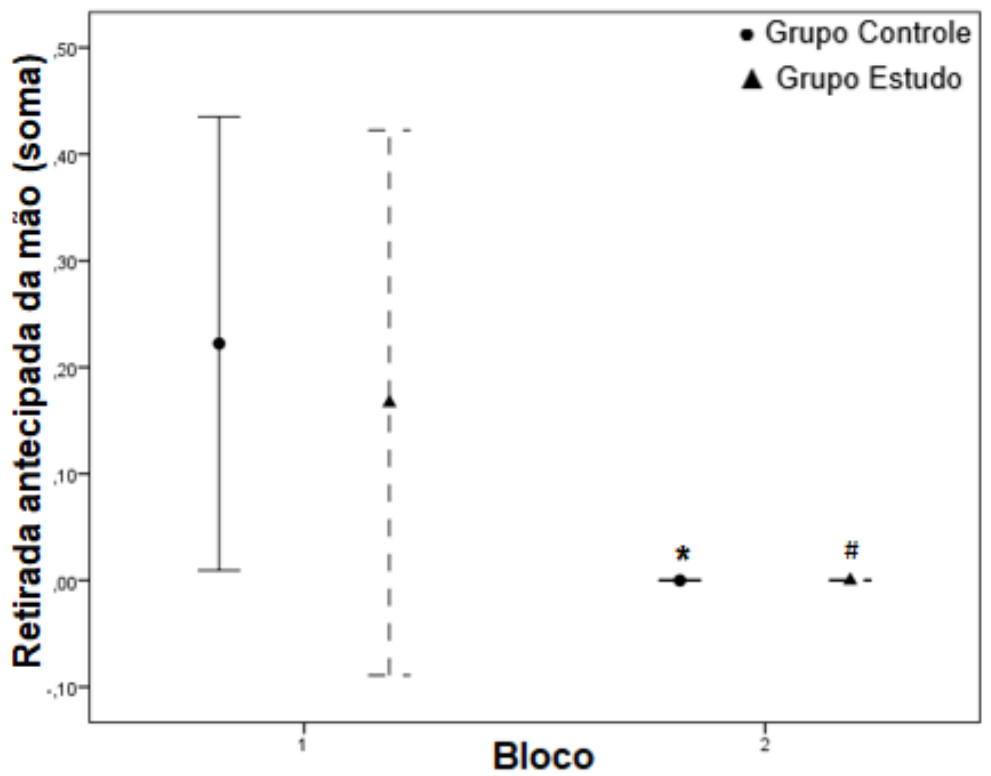

Figura 46. Gráfico das médias e intervalo de confiança de "RETIRADA ANTECIPADA DA MÃO" em cada bloco da fase RET2 para cada grupo. P<0,05: *vs. Bloco 1 Grupo Controle; \#vs. Bloco 1 Grupo Estudo (GLM com função de ligação Identidade Linear).

\subsubsection{Variável “RETIRADA ANTECIPADA DA MÃO” na Fase TR}

Não houve diferença entre os grupos nos dois blocos da fase TR $(p=0,508)$ ou com relação à curva de desempenho dos dois grupos ao longo de toda a fase TR $(\mathrm{p}=0,796)$. Porém, houve diferença entre os dois blocos desta fase $(\mathrm{p}=0,001)$, denotando melhora do desempenho entre os blocos da fase TR para ambos os grupos, como demonstra a figura 47. 


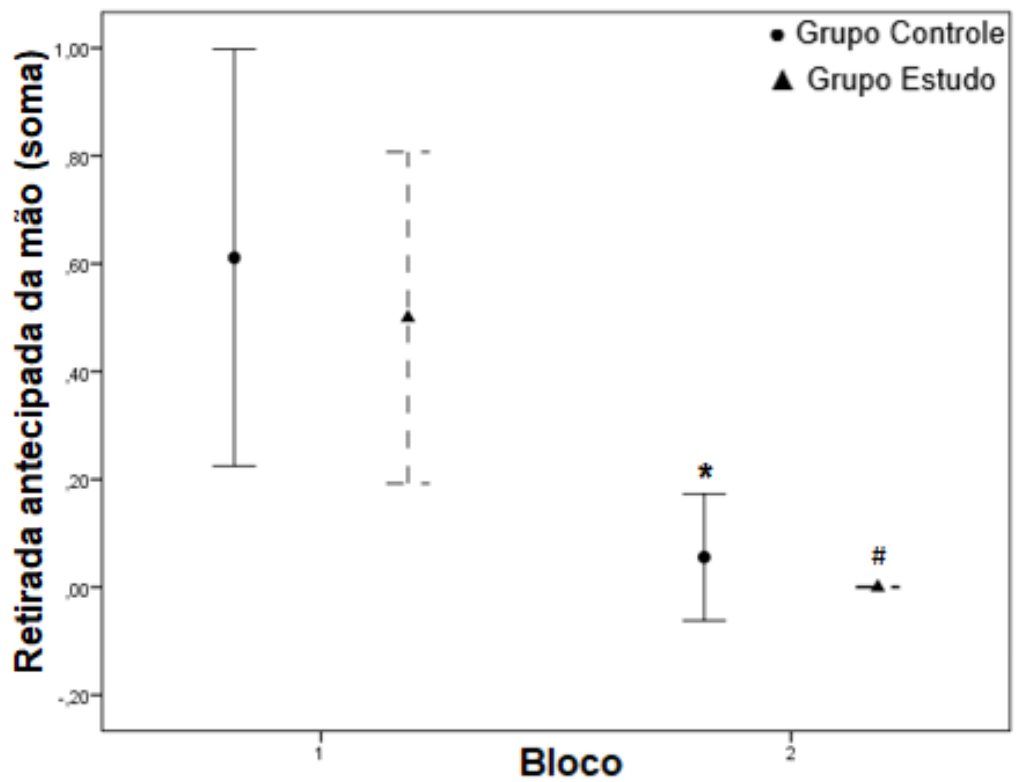

Figura 47. Gráfico das médias e intervalo de confiança de "RETIRADA ANTECIPADA DA MÃO” em cada bloco da fase TR para cada grupo. P<0,05: *vs. Bloco 1 Grupo Controle; \#vs. Bloco 1 Grupo Estudo (GLM com função de ligação Identidade Linear).

\subsubsection{Variável "RETIRADA ANTECIPADA DA MÃO” - Comparação entre as Fases AQe $T R$}

Para esta comparação utilizou-se apenas o último bloco da fase AQ, conforme descrito nos materiais e métodos.

Houve diferença entre o último bloco da fase AQ e o primeiro bloco da fase TR ( $\mathrm{p}=0,000)$, entre o último bloco da fase AQ e o segundo bloco da fase TR $(\mathrm{p}=0,437)$ e entre os dois blocos da fase TR $(\mathrm{p}<0,001)$, segundo teste de Bonferroni. Não houve diferença entre os grupos $(\mathrm{p}=0,490)$ ou com relação à curva de desempenho dos grupos ao longo do tempo $(\mathrm{p}=0,967)$.

O desempenho obtido na fase TR foi inferior ao desempenho estabilizado na fase $\mathrm{AQ}$, inferindo que não houve transferência do aprendizado em nenhum dos grupos. Além disso, com o treino da nova tarefa na fase TR houve melhora do desempenho (diferenças entre os blocos da fase TR), sendo o resultado do último bloco de TR superior ao de AQ nos dois grupos, como demonstra a figura 48 . 


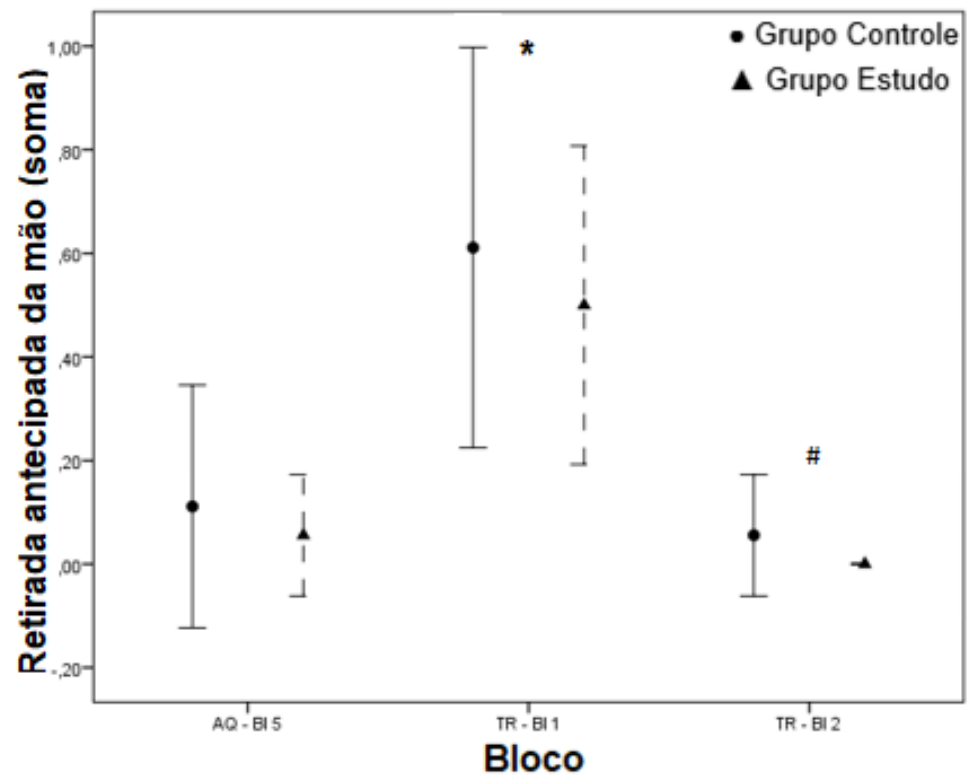

Figura 48. Gráfico das médias e intervalo de confiança de "RETIRADA ANTECIPADA DA MÃO" nas fases AQ e TR para cada grupo. Transferência de aprendizado. P<0,05: *vs. Bloco 1 Grupo Controle; \#vs. Bloco 1 Grupo Estudo (GLM com função de ligação Identidade Linear).

4.2.7.6 Variável “RETIRADA ANTECIPADA DA MÃO” - Comparação entre as Fases AQ, RET 1 e RET 2

Para esta comparação utilizou-se apenas o último bloco da fase AQ e o primeiro bloco das fases RET 1 e RET 2, conforme descrito no item 3.4.3.

Não houve diferença entre os blocos $(p=0,432)$, entre os grupos $(p=0,791)$ e com relação à curva de desempenho dos grupos ao longo do tempo $(\mathrm{p}=0,735)$.

O desempenho obtido na fase AQ foi mantido nas demais fases, sugerindo que houve retenção do aprendizado à curto e à longo prazo para os dois grupos, como demonstra a figura 49. 


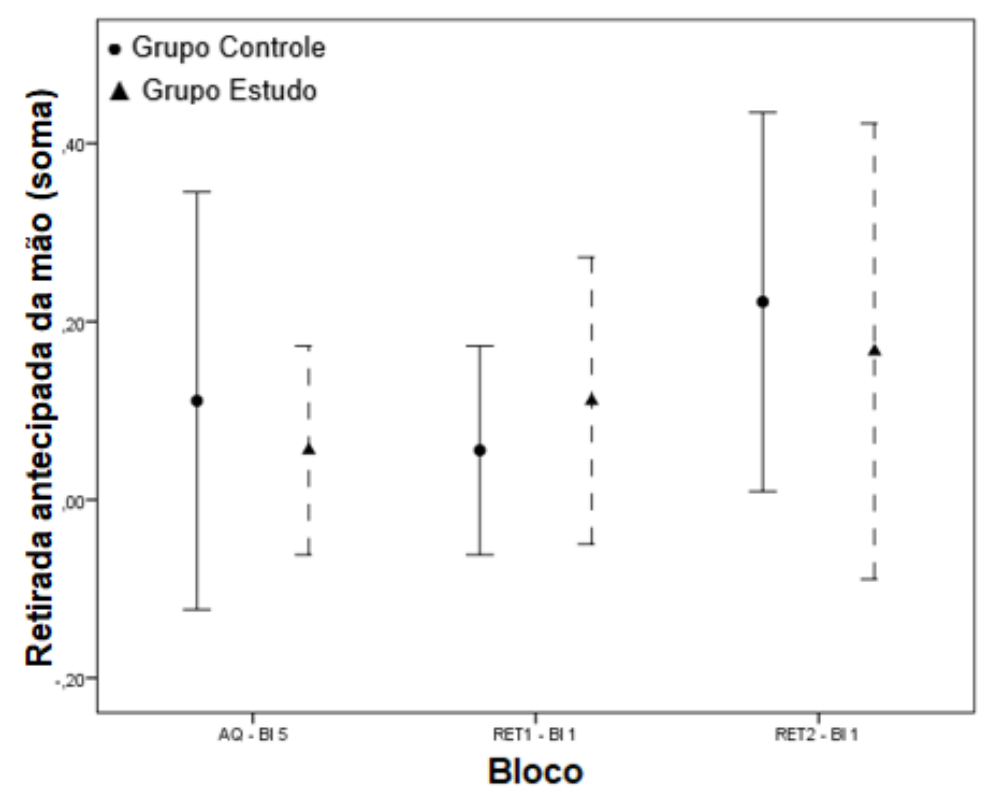

Figura 49. Gráfico de comparação das médias e intervalo de confiança de "RETIRADA ANTECIPADA DA MÃO" ao longo das fases AQ, RET 1 e RET 2 para cada grupo. Não foram encontradas diferenças estatisticamente significativas (GLM com função de ligação Identidade Linear).

\subsubsection{ANÁLISE POR TAXA DE APRENDIZAGEM}

Conforme descrito nos materiais e métodos foi realizada análise das variáveis temporais e erros por taxa de aprendizagem, levando em consideração características individuais da amostra.

Para análise na fase AQ foram utilizados o primeiro e último blocos e para a comparação entre as fases AQ e TR e AQ, RET1 e RET2 utilizou-se apenas o último bloco da fase AQ e o primeiro bloco das demais fases, tal como realizado na análise por médias e IC e descrito nos métodos.

A normalidade dos dados foi testada e, para casos de dados paramétricos, foi utilizado o teste T de Student, enquanto para os não paramétricos utilizou-se o teste MannWhitney.

Para a variável T1 não foram encontradas diferenças nas taxas de aprendizagem entre os grupos ao longo da fase de aquisição $(\mathrm{p}=0,662)$, em relação à sua capacidade de transferência $(\mathrm{p}=0,963)$, de retenção à curto prazo $(\mathrm{p}=0,897)$ ou à longo prazo $(\mathrm{p}=0,884)$.

Para a variável T2 não foram encontradas diferenças nas taxas de aprendizagem entre os grupos ao longo da fase de aquisição $(\mathrm{p}=0,124)$, em relação à sua capacidade de transferência $(\mathrm{p}=0,424)$, de retenção à curto prazo $(\mathrm{p}=0,376)$ ou à longo prazo $(\mathrm{p}=0,584)$. 
Para a variável T3 não foram encontradas diferenças nas taxas de aprendizagem entre os grupos ao longo da fase de aquisição $(\mathrm{p}=0,150)$, em relação à sua capacidade de transferência $(p=0,938)$, de retenção à curto prazo $(p=0,964)$ ou à longo prazo $(p=0,507)$.

Para a variável T4 não foram encontradas diferenças nas taxas de aprendizagem entre os grupos ao longo da fase de aquisição $(\mathrm{p}=0,385)$, em relação à sua capacidade de transferência $(\mathrm{p}=0,628)$, de retenção à curto prazo $(\mathrm{p}=0,387)$ ou à longo prazo $(\mathrm{p}=0,735)$.

Para a variável T5 não foram encontradas diferenças nas taxas de aprendizagem entre os grupos ao longo da fase de aquisição $(\mathrm{p}=0,134)$, em relação à sua capacidade de transferência $(\mathrm{p}=0,791)$, de retenção à curto prazo $(\mathrm{p}=0,916)$ ou à longo prazo $(\mathrm{p}=0,308)$.

Para a variável ERROS não foram encontradas diferenças nas taxas de aprendizagem entre os grupos ao longo da fase de aquisição $(\mathrm{p}=0,823)$, em relação à sua capacidade de transferência $(\mathrm{p}=0,918)$, de retenção à curto prazo $(\mathrm{p}=0,473)$ ou à longo prazo $(\mathrm{p}=0,580)$.

\subsection{ANÁLISE QUALITATIVA DOS VÍDEOS}

Todos os participantes foram filmados nos planos sagital e transverso ao longo de toda a execução da tarefa manual.

Foi realizada análise visual qualitativa dos padrões motores, de forma a verificar as estratégias mais utilizadas para a execução da tarefa ao longo do processo de aprendizagem motora.

Os vídeos foram avaliados alternando os grupos experimental e controle, de modo a minimizar viés metodológico. Foram selecionados alguns momentos da tarefa para esta análise, a saber: primeiro e segundo blocos da fase AQ e primeiro bloco das fases RET1, RET 2 e TR.

A análise baseou-se na análise geral do movimento do membro superior dominante, do membro superior contralateral e do tronco. Além disso foram consideradas questões relacionadas ao entendimento da tarefa.

Observou-se que os dois grupos realizam poucas modificações em seu padrão de movimento ao longo da execução da tarefa, sendo que as maiores modificações ocorrem na fase $\mathrm{AQ}$ e são mais relacionadas a manter ou retirar o apoio do membro superior contralateral, sendo que a maioria dos participantes realizou a alternância destes padrões 
em diversos momentos do teste. Apenas dois indivíduos, um de cada grupo, optou por alterar o posicionamento da cadeira em relação à mesa.

Com relação ao padrão de movimento do membro superior dominante, observouse que a maioria dos indivíduos realizou o alcance, a preensão e o encaixe de forma semelhante, realizando a preensão da barra por seu meio. No entanto, sete indivíduos optaram por segurar a barra pela extremidade, sendo seis do GE e um do GC. Dois indivíduos do GC fizeram uso de apoio do quinto dedo do membro superior dominante para facilitar o encaixe. Um indivíduo de cada grupo tentou auxiliar o encaixe na fase TR utilizando o membro superior contralateral.

O tronco geralmente iniciou encostado para ambos os grupos e se manteve assim para a maioria dos indivíduos ao longo de toda a tarefa. Quando ocorreu a anteriorização do tronco, esta foi discreta e comumente apenas ao final da tarefa, já no momento do encaixe. Observou-se ainda que a anteriorização do tronco foi maior na fase TR. Importante observar que os indivíduos do GE apresentaram uma tendência a manter um adequado posicionamento do tronco, enquanto alguns indivíduos do GC apresentaram posturas de abandono na cadeira, com apoio do tronco e retroversão pélvica.

As maiores modificações de padrão de movimento ocorrem com relação ao apoio do membro superior contralateral, os indivíduos geralmente iniciam a tarefa com ele apoiado e alternam ao longo das tentativas, ainda assim predomina o encosto deste membro ao longo do teste para ambos os grupos.

Em relação à compreensão da tarefa durante a execução da primeira tentativa foi observada importante dificuldade, sendo notória a demora na percepção do acendimento da luz, especialmente no GE e a necessidade de pensar sobre as exigências da tarefa antes de dar início à retirada da mão ou à retirada da barra. Observando a fase inicial da tarefa, um indivíduo do GE tentou retirar a lâmpada ao invés da barra. Na observação da fase de encaixe da barra, três participantes tentaram retirar a tampa ao invés de encaixar a barra através dela, sendo dois do GE e um do GC e nota-se que sete indivíduos não perceberam a necessidade de verticalização da mesma e tentaram encaixá-la horizontalmente; tal fato ocorreu quatro vezes no GC e três vezes no GE.

Nota-se ainda que no GE houveram duas ocorrências de indivíduos que deixavam a barra rolar no pedestal antes de retirá-la, o que dificulta o posicionamento ideal da barra em momentos prévios ao encaixe e favorece erros, fato que não ocorreu no GC. Além disso, quatro participantes do GE e três do GC não notaram a inversão do posicionamento 
da barra na fase TR apenas após a retirada da barra do pedestal e em alguns casos apenas quando a primeira tentativa de encaixe não foi concretizada.

Um dado interessante a ser considerado é o fato de que a superfície de encaixe da barra tratava-se de uma cruz cujas extremidades possuíam espessuras diferentes, permitindo ou não o encaixe. Observou-se que 8 indivíduos do GC e 4 do GE ao reposicionar a barra na posição inicial perceberam essa característica da barra e ou fizeram comentários a respeito ou, deliberadamente, posicionaram a barra deixando-a pronta para o encaixe seguinte, minimizando erros. Isso não significa que outros participantes não tenham percebido este detalhe, mas sim que apenas nestes casos foi percebida claramente a intenção do indivíduo. 


\section{DISCUSSÃO}

Nesta pesquisa foram estudados diversos componentes do fenômeno de AM, tendo por objetivo principal a análise deste processo em indivíduos com EMRR e comparação com indivíduos sem a doença. Foram avaliadas variáveis temporais e de erros relacionadas a cada fase do processo, considerando variáveis motoras, bem como variáveis relacionadas à atenção e planejamento.

O fenômeno da aprendizagem motora constitui-se de um processo que inicia com a aquisição da nova habilidade, segue com a capacidade de armazenamento das informações adquiridas e sua reprodução à curto e à longo prazo. Portanto, a capacidade de armazenamento e recrutamento da memória motora deverá culminar com a capacidade de transferência, ou seja, de realizar uma nova habilidade de características semelhantes à treinada (MALHEIROS et al., 2015). Esse processo pode ser visualizado através de uma curva gráfica a qual demonstre cada uma das fases previamente descritas. Para considerar que houve aprendizado motor, esse gráfico deve indicar variabilidade de performance na fase inicial da fase AQ, seguida de estabilização do desempenho e manutenção deste nas fases RET1, RET2 e TR (MALHEIROS et al., 2015). Neste estudo, realizou-se duas formas de análise destas curvas, uma por médias das variáveis e outra levando em consideração resultados individuais e, assim, a taxa de evolução dos indivíduos. Independentemente da análise realizada, verificou-se que o comportamento das curvas foi semelhante entre os grupos na maioria das variáveis, o que indica que os processos de aprendizagem motora em indivíduos com EMRR, de baixa incapacidade motora e com até dez anos de diagnóstico, ocorrem de forma muito semelhante aos de indivíduos sem a doença. Tal fato é de grande implicação na reabilitação física, uma vez que a melhora funcional é dependente das capacidades de aquisição de novas habilidades motoras, bem como da memória, para que tal aprendizado possa ser funcional, em momentos pós-treino, garantindo as atividades de vida diárias dos indivíduos (FLING, B. W.; GERA, D. G.; HORAK, F. B., 2015).

Houve um único momento em que as curvas de aprendizagem dos dois grupos foram distintas; para a variável T5 ao longo da fase AQ, os dois grupos apresentaram melhora, porém esta ocorreu de forma antecipada no GC. Este grupo reduziu o tempo necessário para o encaixe já no bloco 2 e em seguida estabilizou o desempenho, mantendo 
o mesmo tempo até o final desta fase, enquanto o GE só apresentou redução deste tempo no bloco 4. Essa diferença existente entre os grupos com relação ao momento de estabilização da performance indica a necessidade de maior número de repetições da mesma tarefa no GE para a aquisição da habilidade. Diversas teorias que embasam a reabilitação motora trazem a importância da "repetição sem repetição", ou seja, sugerem que uma mesma habilidade seja trabalhada de formas diferentes ao longo das terapias (SCHMIDT, 1975; SCHMIDT e WRISBERG, 2001), porém, o resultado encontrado neste estudo traz um questionamento sobre estas teorias aplicadas à essa população. Para pessoas com EMRR, talvez haja maior benefício em repetir diversas vezes a mesma tarefa, nas mesmas condições, até que a habilidade possa ser de fato estabilizada para posteriormente inserir a variabilidade da tarefa. É importante enfatizar que a variável T5 corresponde ao final da tarefa, ou seja, ao momento do encaixe. Tal etapa exige planejamento da melhor posição da barra, habilidade motora para realizar os ajustes necessários da barra na mão, assim como habilidade visuo-espacial e percepção sobre a posição da barra em relação à superfície de encaixe, especialmente, habilidade de encaixar a barra adequadamente por dentro do orifício. Assim, é necessário que o indivíduo tenha boa habilidade manual fina, boa coordenação e visão aguçadas para que o encaixe ocorra de forma correta e na maior velocidade possível. Na falta destas, o indivíduo demanda maior tempo para realizar o encaixe. Além disso, caso o planejamento inicial da posição da barra não tenha ocorrido de forma correta, o indivíduo precisará realizar este planejamento no momento final da tarefa, ou seja, o momento do encaixe, que deveria exigir apenas habilidades motoras, passa a requerer habilidades cognitivas. Levando-se em conta os déficits comumente apresentados por indivíduos com EM e que os indivíduos do GE não foram testados previamente quanto às suas capacidades motoras finas, pode-se considerar que a demora para a estabilização do comportamento motor do GE em T5 em comparação ao outro grupo seja devido a questões motoras e não à AM (LATIMERCHEUNG et al., 2013).

A fase AQ é o momento de treinamento da tarefa, ou seja, ao realizar a primeira tentativa o indivíduo entra em contato com a tarefa proposta e tem que compreender qual a ação a ser realizada e buscar as melhores estratégias para a realização da mesma. Foi observado que, apesar da orientação de que a tarefa deveria ser realizada o mais rápido possível, nas primeiras tentativas os voluntários de ambos os grupos não se preocuparam com o tempo gasto na realização da tarefa, mas sim com o entendimento da tarefa em si, 
dessa forma observa-se uma demora acentuada na realização da primeira tentativa seguida de redução deste tempo ao longo das repetições. Nesta fase, espera-se que os indivíduos utilizem o maior número de estratégias motoras, entretanto neste estudo foram observadas poucas modificações dos padrões de postura e movimento nos dois grupos, embora tais estratégias tenham tido maior variação na fase AQ em relação às demais fases. Talvez o número reduzido de estratégias se justifique por se tratar de um movimento relativamente simples, que engloba poucas articulações e poucos eixos de movimento. A maior variedade se deu com relação ao apoio do membro contralateral, predominando o apoio deste membro em relação ao não uso do mesmo. Duas questões podem estar relacionadas à preferência pelo apoio. A primeira trata de necessidade biomecânica de apoio do maior número de seguimentos corpóreos, a fim de favorecer a agilidade e a destreza do membro superior em teste, sobretudo em indivíduos com alteração do movimento e da postura como os com lesão do SNC. A segunda trata da necessidade cognitiva inerente à tarefa, ou seja, quanto maior a necessidade de planejamento para o movimento, maior a tendência do corpo se fixar em posturas que demandem pouco controle e atenção (SHUMWAY-COOK e WOOLLACOTT, 2003). À medida que o indivíduo se sente mais confiante em relação à sua capacidade motora e sobre os componentes da tarefa é esperado que o mesmo experiencie novas possibilidades de posturas, as quais possam favorecer a execução da tarefa. Sendo assim, o corpo passa a ser explorado e podem acontecer modificações como as vistas neste estudo, tais como alternância do apoio do membro superior não dominante, anteriorização do tronco e modificações do assento em relação à mesa. Notou-se que a postura do tronco dos indivíduos do GE foi mais correta do que do outro grupo, o qual muitas vezes se deixou ficar em "posturas de abandono" no assento, com excessivo apoio de tronco e retroversão pélvica, assim como redução da base de apoio nos pés. Tais posturas podem ser indicadores de que, quanto mais seguro e confortável o indivíduo está com a tarefa proposta e consigo mesmo, menos ele se preocupa com a postura e com as estratégias utilizadas, o que poderia ser um erro, pois, ao negligenciar questões biomecânicas, estes indivíduos poderiam ter uma performance pior (SHUMWAY-COOK e WOOLLACOTT, 2003), o que não aconteceu com os indivíduos do GC.

Observa-se ainda na fase AQ o quanto as questões cognitivas têm implicações importantes na realização de tarefas motoras. Os dois grupos, mas especialmente o GE, tiveram muitas dificuldades com relação à compreensão da tarefa. Assim, muito tempo foi investido na primeira tentativa para a identificação dos componentes da tarefa, e tal fato se destaca na análise dos movimentos que indicou alguns casos de percepção tardia do 
acendimento da luz, retirada da lâmpada ao invés da barra, manutenção da barra em sua posição horizontal ao invés da verticalização e retirada da tampa ao invés do encaixe adequado. Importante destacar que essa dificuldade de entendimento da tarefa se deu mesmo com a descrição prévia feita pela examinadora, o que pode reforçar os achados de Sarabandi (2017), de que o treino da tarefa motora associada a descrições da tarefa pode não ser o mais indicado para o aprendizado motor, uma vez que ouvir a descrição da tarefa a ser realizada não trouxe grandes compreensões sobre o ato a ser executado, enquanto que a percepção visual e tátil do aparelho e a repetição da tarefa favoreceram a aquisição da habilidade (SARABANDI, 2017).

Ressaltamos que para todas as variáveis temporais (T1 a T5) e para a variável "retirada antecipada da mão" o comportamento dos grupos foi semelhante na fase AQ, havendo melhora progressiva, seguida de estabilização do desempenho, conforme indicado na literatura (MALHEIROS et al., 2015). Já com relação à variável “erros”, a curva da fase AQ não indica melhora, ou seja, os indivíduos dos dois grupos seguiram com uma performance variável, ora acertando, ora errando o encaixe, ao longo de toda a fase. Duas hipóteses foram aventadas para justificar essa anormalidade na curva de aprendizagem: 1- o comando e os reforços periódicos dados pela examinadora enfatizaram as questões temporais e não a necessidade de acerto do encaixe e 2- questões antecipatórias relacionadas à posição da barra, sendo que ambas são inter-relacionadas.

Ao enfatizar a necessidade de que a tarefa fosse realizada na maior velocidade possível, os indivíduos podem ter negligenciado a importância de acertar o encaixe direto, ou seja, sem tocar a tampa. Para que a tarefa pudesse ser executada de forma rápida, os indivíduos podem não ter se planejado quanto à melhor maneira ou o melhor momento de posicionar a barra na mão e prepará-la para o encaixe, o que culminou na repetição dos toques da barra na tampa e na realização dos ajustes após erros recorrentes, esse efeito da ênfase na velocidade causou os mesmos efeitos em uma pesquisa de AM na paralisia cerebral (CABRAL-SEQUEIRA, A. S.; COELHO, D. B.; TEIXEIRA, L. A, 2016). A superfície de encaixe da barra apresentava formato de cruz e suas extremidades tinham dimensões diferentes, sendo que, a depender da posição da barra na mão do indivíduo, o encaixe poderia ser facilitado ou dificultado. Ao retornar a barra no pedestal ao final de uma tentativa, o indivíduo poderia posicioná-la estrategicamente de forma a facilitar o acerto do encaixe na tentativa seguinte. Entretanto, a partir da análise dos vídeos observou-se que poucos indivíduos demonstraram perceber esse detalhe do encaixe e consequentemente não planejaram o posicionamento correto da barra no pedestal de forma 
a facilitar a tentativa seguinte. Apesar da semelhança dos resultados entre os grupos, aparentemente a percepção e o planejamento do GC em relação ao posicionamento do encaixe foi superior ao outro grupo, uma vez que alguns indivíduos utilizaram o quinto dedo como guia no momento do encaixe e quase metade deste grupo demonstrou entendimento das dimensões da barra através da fala ou do posicionamento da barra deliberadamente de forma a facilitar o encaixe. O GE, além de não ter se utilizado destas estratégias, ainda apresentou mais casos de pegada pela extremidade da barra ao invés do centro, o que claramente não favorece o encaixe. A EM apresenta sintomas motores e cognitivos, sendo que é consenso na literatura que aspectos cognitivos afetam diretamente a atividade motora (PAPAPETROPOULOS et al., 2004). É sabido que a EM pode afetar questões de planejamento e percepção, o que justifica a pobreza das estratégias utilizadas neste sentido (MOTL e MCAULEY, 2010).

No momento de idealização do projeto, não constava a variável "Retirada antecipada da mão", esta foi incorporada à medida em que a avaliadora percebeu que o primeiro indivíduo avaliado apresentou erros no processo de inicialização da tarefa, retirando a mão antecipadamente em relação ao acendimento da luz, passando assim a computar essa variável. Como dito anteriormente, os resultados desta variável na fase AQ foram semelhantes entre os grupos, porém é importante ressaltar que só houve estabilização deste comportamento a partir do quarto bloco desta fase, ou seja, os dois grupos necessitaram de mais da metade da fase de treino para aprender que estavam se antecipando à tarefa. Uma vez que todos os voluntários tinham clara a obrigatoriedade de esperar o acendimento da luz antes de iniciar a tarefa, pode-se atribuir este erro de timing à ansiedade e/ou falta de atenção, ou seja, na ânsia de realizar a tarefa rapidamente, negligenciaram a importância da espera pelo sinal de inicialização. Além disso, verificouse que boa parte dos voluntários sequer percebeu que havia retirado a mão da plataforma antes do acendimento da luz, o que demonstra mais uma vez a dificuldade na atenção, para ambos os grupos. Obviamente, se não há percepção do erro a correção do mesmo fica prejudicada, o que pode justificar a demora para a estabilização dos resultados na fase AQ. Caso o projeto tivesse considerado esta variável, poderiam ter sido aplicados testes de ansiedade e de atenção, os quais poderiam ser correlacionados à esta variável.

Após a fase de treino, os voluntários tiveram dez minutos para descanso, nos quais poderiam caminhar, conversar, realizar outras tarefas motoras ou mesmo escolher realizar a prática mental da tarefa. Na sequência, foram conduzidos novamente à sala de testes e submetidos à mesma tarefa, chamada nesta pesquisa de fase RET 1 e composta 
por dois blocos ininterruptos da tarefa. Esta fase pode ser analisada comparando os seus próprios blocos, considerando-a, assim, mais uma etapa de treino. Não foi observada melhora entre os blocos desta fase para nenhum grupo, o que se justifica pelo fato da habilidade já ter sido estabilizada na fase anterior. O mais importante nesta fase é compará-la com a fase anterior (AQ) de modo a verificar se houve retenção da habilidade motora a curto prazo, fato verificado para todas as variáveis temporais e para os dois grupos. Com relação aos "erros" nessa fase, observou-se melhora na fase RET 1 em relação à AQ. Aqui deve-se lembrar que esta variável não foi devidamente estabilizada na fase AQ, portanto, a fase RET1 serviu como mais um período de treino para os dois grupos. Sendo assim, esta pesquisa demonstrou que os indivíduos com EMRR são capazes de reter a informação motora a curto prazo corroborando com a literatura (MANCINI et al., 2009).

Após uma semana sem treino, os voluntários retornaram para realizar a fase RET2, a qual traz informações sobre a memória de longo prazo. Da mesma forma que em RET 1, pode-se analisar os resultados dentro da fase e também compará-la com a fase AQ. Sendo assim, observou-se melhora entre os blocos da fase RET2 para a maioria das variáveis, exceto "erros", o que demonstra que, mesmo com a habilidade estabilizada na fase AQ, após uma semana sem treino, os indivíduos foram capazes de apresentar melhora da performance, o que pode ser explicado pelos mecanismos da memória, especialmente a partir do sono. Além disso, quando os resultados são comparados à fase $A Q$, observa-se que houve retenção a longo prazo para a maioria das variáveis, exceto para T3, variável que engloba o tempo de iniciação da tarefa após o acendimento da luz e a retirada da barra do pedestal. Como a variável T2 mostrou que houve retenção a longo prazo, pode-se inferir que, na realidade, o planejamento relacionado à retirada da barra do pedestal (T3) é que apresentou déficit à longo prazo.

Dois fatos merecem destaque: os indivíduos com EM necessitaram de mais repetições que o GC para estabilizar a variável T5 e ambos os grupos tiveram limitações na retenção à longo prazo da variável T3. As duas variáveis apresentam fortes componentes motores, tanto para a retirada da barra, quanto para o encaixe, bem como exigem planejamento adequado para a execução correta e agilidade na tarefa. Não foram detectadas dificuldades na aquisição ou na retenção da habilidade quando avaliamos as variáveis de reação e que associam planejamento, motricidade e reação. Assim sendo, pode ser interessante pensar em estratégias terapêuticas mais específicas para o planejamento motor e não somente para a execução da tarefa por si só, estratégias estas 
que poderiam inclusive associar a liberação de neurotrofinas, tais como o BDNF. Esse estudo não objetivou estudar intervenções que pudessem favorecer ainda mais a retenção. Porém, tendo em vista os bons resultados encontrados na memória de curto e longo prazo e o fato dos voluntários terem ficado livres durante o período de descanso, seria interessante que novas pesquisas fossem realizadas no intuito de investigar se $o$ treinamento de outras tarefas de forma intervalada, a realização de exercício aeróbio e/ou a prática mental da tarefa poderiam favorecer a memorização ou resultar em melhora da performance nas fases RET1 e RET2, sobretudo nos indivíduos com EM, que mostrou necessidade de maior repetição da tarefa com relação à variável T5.

A fase TR, corresponde aos testes de transferência do aprendizado motor, ou seja, é o momento em que se verifica a capacidade do indivíduo de realizar tarefas semelhantes à treinada. Tal capacidade é de extrema importância no dia-a-dia dos indivíduos, pois a partir dela é possível que os indivíduos sejam capazes de realizar atividades sem treino específico, como por exemplo, um músico que aprendeu a tocar violão é capaz de tocar outros instrumentos de corda. Considerando a reabilitação motora, poderíamos entender a transferência como algo positivo dado que, por exemplo, a partir do treino terapêutico do levantar-se de um tablado elevado e rígido, o paciente seria capaz de melhorar o levantarse a partir do sofá baixo e macio que possui em sua casa sem a necessidade deste treino específico. Levando-se em conta a importância desta capacidade, esta pesquisa propôs-se a avaliar a transferência da habilidade manual, variando o posicionamento da extremidade de encaixe na mão dos participantes. Segundo Schimidt (1975), os movimentos a serem realizados após as modificações da tarefa devem pertencer à mesma classe de movimentos da tarefa treinada, para que se possa testar a capacidade de transferência de determinada habilidade motora (SCHIMIDT, 1975).

A princípio imaginamos que a troca de posicionamento da barra poderia resultar em um viés metodológico importante, uma vez que, mesmo com os olhos fechados, poderiam supor que foi realizada a inversão, o que facilitaria o planejamento motor. Para nossa surpresa, poucos indivíduos demonstraram perceber a inversão da barra antes de vêla invertida e isso se deu para os dois grupos. Muitos, inclusive, só perceberam tal alteração na hora de realizar o encaixe, fato ocorrido com maior frequência no GE.

Nossa hipótese inicial era que o GE teria maior dificuldade de transferir o aprendizado motor em comparação ao GC, porém verificamos que não houve transferência para nenhum dos grupos, ou seja, o AM seguiu percurso similar. Os testes foram semelhantes aos aplicados por Torriani-Pasin (2010), sendo que ela avaliou esta 
habilidade em indivíduos pós acidente vascular encefálico (AVE) e encontrou manutenção parcial dos resultados dos testes de transferência tanto para o grupo pós-AVE quanto no grupo saudável (TORRIANI-PASIN, 2010). Importante ressaltar que, nos testes de Torriani-Pasin, 26 indivíduos (tanto do GC quanto do GE) realizaram a tarefa com a mão esquerda e 10 (exclusivamente do GE) utilizaram a mão direita; e que a pegada da barra nas fases AQ, RET1 e RET2 foi realizada pela parte de baixo da barra, ou seja, o movimento realizado pelo antebraço foi de supinação para neutro e na fase TR a pegada foi feita por cima da barra e o movimento foi de pronação para neutro para a maioria dos indivíduos. Em nossa pesquisa, 35 indivíduos realizaram a tarefa com o membro superior direito e ficaram livres para escolher a pegada manual, sendo que todos os indivíduos o fizeram por cima da barra em todas as fases de teste, realizando um movimento de pronação para neutro em AQ, RET1 e RET2, mas devido a inversão da barra em TR, o encaixe exigiu que os indivíduos realizassem também rotação interna de ombro. Assim, nos testes de Torriani-Pasin, o padrão de movimento se manteve o mesmo para todas as fases, enquanto em nossa pesquisa houve a incorporação de um novo movimento bem como o uso de mais uma articulação, o ombro, na fase TR.

Podemos supor que o teste escolhido pode não ser adequado para a avaliação da transferência de aprendizado motor, pois seria esperado que indivíduos sem lesão encefálica apresentassem essa capacidade. Acreditamos que o movimento realizado na fase TR nesta pesquisa não pertenceu à mesma classe de movimentos da tarefa treinada, conforme exigido na tese de Schimidt (SCHIMIDT, 1975) e, talvez, por este motivo, não houve transferência de aprendizado em nenhum dos grupos. Assim, sugerimos que nova pesquisa seja realizada, mantendo os parâmetros de movimento, de forma a verificar se, nesta condição, o grupo com EMRR demonstraria capacidade de transferência.

Outro ponto importante a ser discutido é a questão do desempenho dos grupos no que diz respeito à velocidade de execução e quantidade de erros. Estudos prévios que avaliaram a destreza manual na EM demonstraram maior lentidão na tarefa em comparação a indivíduos sem a doença (BONZANO et al., 2011; TOMASSINI et al., 2011; ALMUKLASS et al.,2017) e pobre performance motora. Conforme visto nos métodos, nesta pesquisa, a tarefa foi dividida em cinco momentos, desmembrando variáveis de maior demanda cognitiva das relacionadas à maior demanda motora. Dessa forma foi possível verificar diferenças no desempenho do GE de acordo com a demanda exigida pela tarefa. 
Assim, com relação ao tempo de reação (T2) o desempenho dos grupos foi igual ao longo de todo o processo, portanto, em uma variável que não exige muitos componentes de planejamento e cuja execução motora é simples, o desempenho entre os grupos foi semelhante, como já havia sido demonstrado em estudo prévio (ZAHIRI et al., 2017)

No tempo de iniciação (T3), de maior demanda cognitiva (planejamento), também não houve diferença entre os grupos.

Entretanto, com relação às variáveis de motricidade (T4 e T5) bem como no tempo total (T1), o desempenho do GE foi inferior ao GC, exceto em T1 de RET1 e T4 de RET2, nas quais o GE atingiu o mesmo nível de desempenho do GC. Dessa forma, podese inferir que os indivíduos com EMRR são mais lentos na execução de tarefas motoras, porém podem ser tão rápidos quanto indivíduos sadios, desde que tenham a possibilidade de maior tempo de treino da tarefa, corroborando com a literatura como citado previamente. Sabe-se que a lesão da esclerose múltipla deve-se, em parte, por perda da bainha de mielina dos neurônios do SNC, a qual tem por função principal a velocidade de transmissão dos impulsos nervosos (KANDEL et al., 1997), podendo essa, portanto, ser a principal razão pela qual o GC mostrou-se mais lento na execução das partes motoras da tarefa. Acreditamos que a melhora do desempenho do GE próxima aos níveis do GC, em alguns momentos específicos do teste, deva-se ao desenvolvimento de estratégias compensatórias por parte dos indivíduos com EMRR tais como maior uso das habilidades cognitivas, haja visto o fato deste grupo ter se mostrado mais focado e atento ao longo dos procedimentos. Há de se colocar que estas estratégias compensatórias no GE podem ter sido desenvolvidas em processos de reabilitação física e/ou cognitiva realizadas previamente e que por estarem fora de período de surto, mecanismos de plasticidade cerebelar e do córtex motor podem ter garantido o bom desempenho durante os testes. Importante relembrar que o GE desta pesquisa apesentava baixa incapacidade motora, com EDSS variando entre 0 e 4,5 e média 1,72. Assim, apesar da alta funcionalidade destes indivíduos e de sua motricidade do membro superior avaliado estar íntegra, estes indivíduos foram mais lentos que os do GC, apresentando melhora com o treinamento. Nossos resultados corroboram com a literatura a qual sugere que, independentemente do grau de incapacidade motora e da extensão do comprometimento do SNC, a performance motora de indivíduos com EM após treinamento, bem como os mecanismos de plasticidade, são comparáveis à de indivíduos saudáveis (ZELLER et al., 2010). 
Uma das propostas iniciais desta pesquisa era justamente verificar se a medida em que aumenta a incapacidade motora há alteração nas capacidades de AM. Infelizmente, devido à maior concentração dos indivíduos com EM nas faixas iniciais da EDSS essa estatística não foi possível.

O aparelho e o delineamento dos testes utilizados nesta pesquisa cumpriram seu papel de avaliação dos processos de aprendizagem motora na esclerose múltipla remitente recorrente, embora pequenas modificações no teste de transferência sejam necessárias para garantir que os parâmetros de movimento sejam mais próximos ao da tarefa treinada. Uma modificação simples seria manter a inversão do posicionamento da barra, porém solicitar ao voluntário que fizesse a pegada da barra necessariamente de baixo para cima, ao invés de permitir a livre escolha da pegada manual, garantindo que o movimento fosse realizado com a mesma parametrização. Entretanto a indução do movimento poderia reduzir a avaliação das estratégias motoras bem como do planejamento. Outras possíveis soluções seriam manter a extremidade de encaixe no lado direito do aparato, porém fazer a troca da barra por outra de diferente massa corporal, ou ainda mudar as extremidades de encaixe por outra de dimensões diferentes das utilizadas na fase AQ.

Importante ressaltar que este teste pode ser utilizado não apenas na pesquisa, mas também na clínica, como importante guia de avaliação e acompanhamento destes indivíduos, desde que se leve em conta tempos extensos entre uma aplicação e outra ou pequenas modificações no equipamento entre o teste e o reteste de acompanhamento. No caso de uso clínico, sugere-se a redução do número de tentativas na fase $A Q$, uma vez que foi visto neste estudo, que para este tipo de tarefa, apenas 2 blocos de 10 tentativas seriam mais do que suficientes para estabilizar a habilidade. No mais, as demais fases também poderiam ser reduzidas a apenas 1 bloco de 5 tentativas, pois apenas as primeiras tentativas são consideradas para a avaliação da manutenção do desempenho. 


\section{CONCLUSÃO}

O aprendizado motor pode ser verificado por meio de testes de retenção e transferência, sendo visualizado através de uma curva na qual espera-se que os resultados demonstrem capacidade de memória motora a curto e longo prazo bem como de transferência.

Os resultados encontrados neste estudo demonstraram que os indivíduos com EMRR, de baixa incapacidade motora e com até 10 anos de diagnóstico, apresentam a mesma curva de aprendizado motor que indivíduos sem a doença, demonstrando assim, a capacidade de aprendizagem motora destes indivíduos. Algumas particularidades encontradas nesta população indicam a necessidade de repensar as estratégias terapêuticas utilizadas neste grupo, como por exemplo, a maior repetição da mesma tarefa. Também é necessário ter em mente que a velocidade de execução da tarefa nestes indivíduos pode ser mais lenta, apesar da capacidade de aprendizagem estar íntegra.

Sugerimos que novas pesquisas sejam realizadas a fim de verificar as estratégias terapêuticas e os momentos mais adequados para a realização das mesmas, a fim de aprimorar as habilidades motoras desta população e facilitar a reabilitação da mesma. 


\section{CONSIDERAÇÕES FINAIS SOBRE O PROCESSO DA PÓS-GRADUAÇÃO}

Ao longo desses quase três anos de mestrado vivi muitas experiências que vão além da sala de aula, da bancada do laboratório ou do experimento com os pacientes, elas transbordam para o campo emocional e fazem parte do processo de crescimento pessoal até mais do que profissional.

Há muitos anos tinha a ideia de seguir na área acadêmica, porém enquanto fisioterapeuta, decidi primeiramente me desenvolver na clínica, fator pelo qual escolhi esta profissão. Considerei que com maior capacidade técnica teria maior capacidade para formar fisioterapeutas, bem como uma visão mais criteriosa no desenvolvimento de pesquisas que tivessem implicações reais na clínica e no tratamento dos pacientes.

Antes mesmo de definir a orientação e o projeto de pesquisa houveram questões éticas que me fizeram questionar a seriedade da pesquisa brasileira e dos profissionais envolvidos. Foram momentos difíceis e que quase me fizeram abdicar do meu propósito. Infelizmente, um tempo depois tive o desprazer de me deparar com colegas vivendo situações parecidas, ou ainda piores!

A pesquisa teve início com o desenvolvimento e construção do equipamento de coleta, com a colaboração de um engenheiro de automação, foi possível elaborar um aparato capaz de captar e armazenar os tempos de execução da tarefa de forma automática. Na sequência, veio a coleta dos dados e eu diria que essa foi a fase mais fácil para mim, pois já faz parte da minha experiência diária trabalhar em equipe e atender pacientes com comprometimentos neurológicos.

O projeto de pesquisa era ambicioso e visava a análise conjunta de dados temporais, análise de movimento e análise genética, de forma a contemplar todas as vertentes relacionadas à aprendizagem motora. Talvez tenha sido um projeto muito ambicioso para as possibilidades do mestrado, ainda mais em um país como o Brasil, ainda tão carente de recursos financeiros para ensino, pesquisa e saúde.

O fato é que foi realizada a coleta de vídeos, as quais ambicionava analisar através de software de análise de imagens, porém não foi possível devido à falta de experiência na captação de vídeos e as dificuldades para calibração destas imagens. 
Assim, foi necessário adaptar a forma de análise, a qual passou a ter caráter qualitativo. Apesar da frustração de não ter realizado a análise da forma programada, acredito que essa experiência me fez expandir o meu pensamento e hoje não considero que a pesquisa tenha menor validade, pelo contrário, pude pensar melhor sobre estratégias, funções e planejamentos e talvez através de softwares eu não tivesse chegado às mesmas conclusões que cheguei analisando qualitativamente.

Havíamos programado a investigação sobre a relação do polimorfismo Val66Met na aprendizagem motora e para tal coletei amostras de saliva de todos os indivíduos no segundo dia dos testes utilizando os coletores Oragene-DNA, OG-500, da marca DNA genotek®. Todos os cuidados éticos, de conforto aos indivíduos e conservação das amostras foram tomados. Em uma segunda etapa, no Laboratório de Biomedicina da EACH-USP, realizei a extração do DNA e a partir deste material e através da técnica de eletroforese foi possível confirmar a existência de material genético suficiente nas amostras para a avaliação do polimorfismo Val66Met. Posteriormente seria realizada a técnica Polymerase Chain Reaction (PCR-RFLP) de forma a verificar se na amostra havia algum indivíduo com esta alteração genética e por fim analisar se a mesma interfere negativamente na aprendizagem motora, mais especificamente na retenção à curto e longo prazo, como hipotetizado. Passamos longos meses em busca de colegas que pudessem me ensinar e guiar na realização da técnica, uma vez que fisioterapeutas não possuem formação adequada para trabalhos em laboratório, assim como buscamos financiamentos para a compra de materiais e equipamentos para o desenvolvimento e implantação da técnica no laboratório da EACH. Infelizmente, devido à falta de recursos humanos e financeiros não foi possível realizar esta parte da pesquisa até o presente momento. Devido aos prazos de conclusão da pós-graduação e a dificuldade de realização da técnica pelos motivos supracitados optamos por dar continuidade à essa parte da pesquisa após a conclusão da pós-graduação; aproveito para registrar a intenção da execução dessas análises e publicação dos resultados após a conclusão da pós-graduação.

Apesar de todas as dificuldades e frustrações relatadas acima e que permearam todo o processo da pós-graduação, acredito que saio vitoriosa deste processo, pois se infelizmente não pude executar a pesquisa conforme programado, aprendi a flexibilizar o meu pensamento, o meu planejamento e principalmente o meu tempo. Hoje consigo entender que o mestrado não é o momento de desenvolver as melhores pesquisas ou de concluir tudo o que foi idealizado, mas trata-se de um processo de aprendizado sobre o que é a pesquisa, a docência, a universidade e sobre quem eu sou! Hoje entendo que se 
não concordo com os caminhos que a pesquisa vem trilhando e com as ações que os pesquisadores e docentes têm tomado, devo me esforçar para fazer diferente, para mostrar para as novas gerações que é possível fazer mais e melhor, que é possível levar o conhecimento adiante! E é por isso que tenho orgulho em entregar a minha dissertação e em dizer que pretendo seguir na Academia, progredindo e ajudando a progredir! 


\section{REFERÊNCIAS}

1. ABE, M. et al. Reward improves long term retention of a motor memory through induction of offline memory gains. Current Biology, v. 21, n. 7, p. 557-62, 2011.

2. ASSOCIAÇÃO BRASILEIRA DE ESCLEROSE MÚLTIPLA (ABEM) [homepage on internet]. São Paulo. Available from: <www.abem.org.br/index.php/esclerosemultipla>. Acesso em: 14 nov. 2018.

3. ALMUKLASS, A. M. et al. Peg-manipulation capabilities during a test of manual dexterity differ for persons with multiple sclerosis and healthy individuals. Exp Brain Res, v. 11, p. 3487-3493, 2017.

4. BENSON, L. A. et al. Elevated relapse rates in pediatric compared to adult MS persist for at least 6 years. Mult Scler Relat Disord, v. 3, p. 186-193, mar. 2014.

5. BERGHOFF, S. A. et al. Dietary cholesterol promotes repair of demyelinated lesions in the adult brain. Nature Communications, v. 24 (8), jan. 2017.

6. BONZANO, L. et al. Structural integrity of callosal midbody influences intermanual transfer in a motor reaction-time task. Hum. Brain Mapp, v. 32, p. 218-228, 2011.

7. BROWNE, P. et al. Atlas of Multiple Sclerosis 2013: A growing global problem with widespread inequity. Neurology, v. 83, p. 1022-24, sep. 2014.

8. CABRAL-SEQUEIRA, A. S.; COELHO, D. B.; TEIXEIRA, L. A. Motor imagery training promotes motor learning in adolescents with cerebral palsy: comparison between left and right hemiparesis. Exp Brain Res., v. 234(6), p. 1515-1524, 2016.

9. CARPINELLA, I. et al. Robot Training of Upper Limb in Multiple Sclerosis: Comparing Protocols With or Without Manipulative Task Components. IEEE Trans Neural Syst Rehabil Eng, v. 20 (3), p. 351-60, may. 2012.

10. CATTANEO, D. et al. Head Control: Volitional Aspects of Rehabilitation Training in Patients With Multiple Sclerosis Compared With Healthy Subjects. Arch Phys Med Rehabil, v. 86 (7), p. 1381-86, jul. 2005. 
11. CATTANEO, D.; JONSDOTTIR, J. Sensory impairments in quiet standing in subjects with multiple sclerosis. Mult Scler, v. 15 (1), p. 59-67, jan. 2009.

12. COMPSTON, A.; COLES, A. Multiple sclerosis. Lancet, v. 359, p. 1221-31, apr. 2002.

13. CORREALE, J. et al. Immunomodulatory effects of vitamin D in multiple sclerosis. Brain, v. 132, p. 1146-60, may. 2009.

14. DALGAS, U. et al. Multiple sclerosis and physical exercise: recommendations for the application of resistance-, endurance- and combined training. Mult Scler, v. 14 (1), p. 35-53, jan. 2008.

15. DUNCAN, B. B. et al. Medicina ambulatorial: condutas de atenção primária baseada em evidências. 3 Ed. Porto Alegre: Artmed Editora, 2004. 1976 p.

16. DYMENT, D. A. et al. Genetics of multiple sclerosis. Lancet Neurol, v. 3, p. 104-10, feb. 2004.

17. FILIPPI, M. et al. Brain mapping in multiple sclerosis: Lessons learned about the human brain. NeuroImage, sep. 2017.

18. FLING, B. W.; GERA, D. G.; HORAK, F. B. Functional connectivity underlying postural motor adaptation in people with multiple sclerosis. Neuroimage Clin, v. 6 (8), p. 281-289, may. 2015.

19. FOLSTEIN, M. F. et al. "Mini-mental state". A practical method for grading the cognitive state of patients for the clinician. J Psychiatr Res, v. 3, p. 189-98, nov. 1975.

20. GERA, G. et al. Postural Motor Learning Deficits in People With MS in Spatial but Not Temporal Control of Center of Mass. Neurorehabil Neural Repair, v. 30(8), p. 722-30, sep. 2016.

21. HAFLER, D. A. et al. Risk alleles for multiple sclerosis identified by a genomewide study. N Engl J Med, v. 357 (9), p. 851-62, aug. 2007.

22. HALLETT, M. Neuroplasticity and rehabilitation. J Rehabil Res, v. 42 (4), p. 17-22, jul-aug. 2005. 
23. HELDNER, M. R. et al. Coin rotation task: a valid test for manual dexterity in multiple sclerosis. Phys Ther, v. 94 (11), p. 1644-51, nov. 2014.

24. HENNIGAN, A.; O'CALLAGHAN, R. M., KELLY, A. M. Neurotrophins and their receptors: roles in plasticity, neurodegeneration and neuroprotection. Biochem Soc Trans; 35 (2), P. 424-427, apr. 2007.

25. IWANOWSKI, P; LOSY, J. Immunological differences between classical phenothypes of multiple sclerosis. J Neurol Sci, v. 349 (1-2), p. 10-14, feb. 2015.

26. JAGANNATH, V. A. et al. Vitamin D for the management of multiple sclerosis: review. Cochrane Database Syst Ver, v. 12, jun. 2010.

27. JOHNSTON, M. V. Plasticity in the developing brain: implications for rehabilitation. Dev Disabil Res Rev, v. 15 (2), p. 94-101, 2009.

28. KANDEL, E. R.et al. Fundamentos da Neurociência e do Comportamento. $1^{\mathrm{a}}$ ed. Rio de janeiro: Ed. Prentice-Hall do Brasil LTDA, 1997. 591p.

29. KARNI, A. et al. The acquisition of skilled motor performance: fast and slow experience-driven changes in primary motor cortex. Proceedings of the National Academy of Sciences of the USA, v. 95, p. 861-868, 1998.

30. KURTZKE, J. F. Rating neurologic impairment in multiple sclerosis: an expanded disability status scale (EDSS). Neurology, v. 33 (11), p. 1444-52, nov. 1983.

31. KURTZKE, J. F.; PAGE W. F. Epidemiology of multiple sclerosis in US veterans: VII. Risk factors for MS. Neurology, v. 48 (1), p. 204-13, jan. 1997.

32. LAROCCA, N. G. Impact of walking impairment in multiple sclerosis: perspectives of patients and care partners. Patient, v. 4 (3), p. 189-201, oct. 2011.

33. LATIMER-CHEUNG, A. E. et al. Effects of exercise training on fitness, mobility, fatigue, and health-related quality of life among adults with multiple sclerosis: a systematic review to inform guideline development. Arch Phys Med Rehabil, v. 94 (9), p. 1800-28, sep. 2013.

34. LEOCANI, L. et al. Impaired short-term motor learning in multiple sclerosis: evidence from virtual reality. Neurorehabil Neural Repair, v. 21 (3), p.273-78, may-jun. 2007. 
35. LEVIN, L. I. et al. Multiple sclerosis and Epstein-Barr virus. JAMA, v. 289, p. 15336, mar. 2003.

36. MAGGIL, R. A. Aprendizagem motora: conceitos e aplicações. São Paulo: Edgar Bucher, 2000. 369p.

37. MALHEIROS, R. P. M. et al. Aprendizagem motora em pessoas com distrofias musculares: tarefa de labirinto no computador. In: MONTEIRO, C. B. M. et al. Realidade Virtual em distrofias musculares. $1^{a}$ ed. São Paulo: Ed. Plêiade, 2015. 282p.

38. MANCINI, L. et al., Short-term adaptation to a simple motor task: A physiological process preserved in multiple sclerosis. NeuroImage, v. 45, p. 500-511, 2009.

39. MATSUDA, P.N. et al. Falls in multiple sclerosis. Pm, v. 3 (7), p. 624-32, jul. 2011.

40. MC GOWAN, K. et al. Short-Term Motor Learning and Retention During Visually Guided Walking in Persons With Multiple Sclerosis. Neurorehabil Neural Repair, v. 31(7), p. 648-56, jul. 2017.

41. MILO, R; KAHANA, E. Multiple sclerosis: geoepidemiology, genetics and the environment. Autoimmun Ver, v. 9 (5), p. 387-94, mar. 2010.

42. MOTL, R. W.; MCAULEY, E. Symptom cluster and quality of life: preliminar evidence in multiple sclerosis. J Neurosci Nurs, v. 42, p. 212-6, aug. 2010.

43. NEWELL, M. K. Schema Theory (1975): retrospectives and prospective. Researcher Quarterly for Exercise and Sports, v. 74, n. 4, p.383- 88, 2003.

44. NOWAK, D. A. et al. Interhemispheric competition after stroke: brain stimulation to enhance recovery of function of the affected hand. Neurorehabil Neural Repair, v. 23 (7), p. 642-56, sep. 2009.

45. PAPAPETROPOULOS, S. et al. A registry-based, case-control investigation of Parkinson's disease with and without cognitive impairment. Eur J Neurol, v. 11(5), p. 347-351, may. 2004.

46. PETERSON, D. S. et al. Corpus Callosum Structural integrity is associated with postural control improvement in persons with multiple sclerosis who have minimal disability. Neurorehabil and neural repair, v. 31(4), p. 343-53, apr. 2017. 
47. REIS, J. et al. Noninvasive cortical stimulation enhances motor skill acquisition over multiple days through an effect on consolidation. PNAS, v. 106, n.5, p.1590-95, 2009.

48. REJDAK, K. et al. Multiple sclerosis: a practical overview for clinicians. Br Med Bull, v. 95 , p. 79-104, jul. 2010.

49. RICHARDS, R. G. et al. A review of the natural history and epidemiology of multiple sclerosis: implications for resource allocation and health economic models. Health Technol Assess, v. 6, p. 1-73, 2002.

50. ROBERTSON, E. M.; COHEN, D. A. Understanding consolidation through the architecture of memories. Neuroscientist, v. 12, n.3, p. 261-71, 2006.

51. ROBERTSON, E.M. et al. Current concepts in procedural consolidation. Neuroscience, v. 5, p. 1-7, 2004.

52. RUMPF, J. J. et al. Compromised tDCS-induced facilitation of motor consolidation in patients with multiple sclerosis. J Neurol, v. 265(10), p. 2302-2311, oct. 2018.

53. SARABANDI, M. A Comparison of Implicit and Explicit Motor Sequence Learning in Patients with Relapsing-Remitting Multiple Sclerosis. Sports (Basel), v. 5(2), jun. 2017.

54. SCHMIDT, R. A. A schema theory of discrete motor skill learning. Psychological Review, v. 82, n. 4, july. 1975.

55. SCHMIDT, R. A.; WRISBERG, C. A. Aprendizagem e performance motora: uma abordagem da aprendizagem baseada no problema. Porto Alegre: Artmed, 2001, 352p.

56. SCHUMWAY-COOK, A.; WOOLLACOTT, M. H. Controle motor: teorias e aplicações práticas. São Paulo: Manole, 2003. 592p.

57. SHERWOOD, D. E.; LEE, T. D. Schema theory: critical review and implications for the role of cognition in a new theory of motor learning. Research Quarterly for Exercise and Sport, v. 74, n. 4, p.376-82, 2003.

58. SOCIE, M. J.; SOSNOFF, J. J. Gait variability and multiple sclerosis. Mult Scler Int, mar. 2013. 
59. TACHINNO, A. et al. Selective impairments of motor sequence learning in multiple sclerosis patients with minimal disability. Brain res, v. 585, p. 91-98, oct. 2014.

60. TEIXEIRA, L. A. Aprendizagem de habilidades motoras na ginástica artística. In: Nunomura M,Nista-Piccolo VL. Compreendendo a ginástica artística. São Paulo: Phorte, 2004.

61. TOMASSINI, V. et al. Preservation of motor skill learning in patients with multiple sclerosis. M.S.J., v. 17 (1), p. 103-115, jul. 2010.

62. TORRIANI-PASIN, C. Aprendizagem de uma habilidade motora com demanda de planejamento em pacientes pós-acidente vascular encefálico em função do lado da lesão. 2010. 172 f. Tese (doutorado em Educação Física) - Faculdade de Educação Física e Esporte, Universidade de São Paulo, São Paulo, 2010.

63. VAN MIER, H.I.; PETERSEN, S.E. Intermanual transfer effects in sequential tactuomotor learning: evidence for effector independent coding. Neuropsychologia, v.44, p. 939-49, 2006.

64. WITT, K. et al. G. Sleep consolidates the effector-independent representation of a motor skill. Neuroscience, v.171, p. 227-34, 2010.

65. YOUNG, J. A.; TOLENTINO, M. Neuroplasticity and its applications for rehabilitation. Am J Ther, v. 18 (1), p. 70-80, jan. 2011.

66. ZAHIRI, N. et al. Interference effect of prior explicit information on motor sequence learning in relapsing-remitting multiple sclerosis patients. Malays J. Med. Sci, v. 24 (1), p. 69-80, mar. 2017.

67. ZATORRE, R. J. Plasticity in gray and white: neuroimaging changes in brain structure during learning. Nat Neurosci, v. 15 (4), p. 528-36, mar. 2012.

68. ZELLER, D. et al. Rapid-onset central motor plasticity in multiple sclerosis. Neurology, v. 74, p. 728-35, mar. 2010.

69. ZWIBEL, H. L. Contribution of impaired mobility and general symptoms to the burden of multiple sclerosis. Adv Ther, v. 26 (12), p. 1043-57, dec. 2009. 


\section{ANEXOS}

\section{Anexo I}

Parecer do Comitê de Ética em Pesquisa com Seres Humanos- EACH USP

\section{USP - ESCOLA DE ARTES, CIÊNCIAS E HUMANIDADES DA UNIVERSIDADE DE SÃO} Plotoforma

\section{PARECER CONSUBSTANCLADO DO CEP}

\section{DADOS DO PROJETO DE PESQUISA}

Titulo da Pesqulsa: Aprendizado Motor na Esclerose Moltipla

Pesqulasdor: Michele Schuitz

Area Tematica: Genetica Humana:

(Trata-6e de pesquisa envolvendo Genetca Humana que năo necesslta de anallse

Versac: 3 etca por parte da CONEP; :

CAAE: 60189716.6 .0000 .5390

Institulç:o Proponente: Escola de Artes, Clenclas e Humanidades

Patrocinador Principal: Financlamento Proprio

\section{DADOS DO PARECER}

Nümero do Parecer: 1.947 .155

\section{Apreeentaça do Projeto:}

A Esclerose Multipla (EM), doença auto-Imune desmielinizante, e a principal causa de deficiencla neurologica náo traumatica em acuitos jovens, causando distunçbes sensorials, cogritivas e motoras, sendo recomendada a reallzaçăo de fisloterapla. Um dos principals objettvos da tsioterapla na reabilltaçăo de Indlviduos com lesరles neurologlcas e promover aprendizado motor (AM), fenomeno relacionado a neuroplasticidade e 30 Brain-dentived neurotrophic factor (BDNF), entretanto sabe-se que entre $20-30 \%$ da populaçăo geral apresenta uma mułaçăo genetca, corhedida por pollmortismo Val-66Met (Val66Met SNP). a qual œcasiona atteraçfo no transporte intracelular e secreçalo do BDNF, podendo resultar en alteraçbes do aprendlzado motor. Objetivo: Avallar aspectos do AM na EM. Como objetivos secundarios tem-se alnda correlacionar aspectos do AM com Val65 Met SNP e correlacionar aspectos do AM com a Incapacidade motora segundo $0 s$ crtterios de Kurtzke. Metodos: Aproximadamente 50 Indlviduos dlagnosticados com EM comporăo o grupo expertmental (GE) e 50 Individuos saudávels comporăo o grupo controle (GC). Ambos 05 grupos serdo submetdos a avallaçbes cogritivas, avallaçbes motoras e coleta de sallva para genotipagem e Identiflcaçắo do Val66 Met SNP, as coletzs serăo realzadas na Associaçăo Brasleira de Esclerose Muitpla (ABEM) pos analse do Conite de Ettica em Pesquisa (CEP)

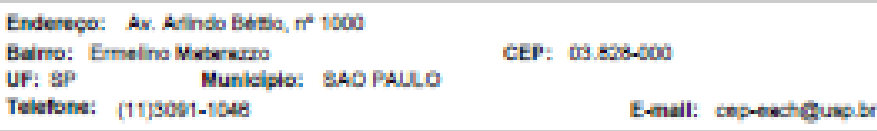


USP - ESCOLA DE ARTES, CIÊNCIAS E HUMANIDADES

DA UNIVERSIDADE DE SÃO

Platoforma
Braril

Corthuacha to Pamoer 1987.19

Objetlivo da Pesqulsa:

Objettvo Principa:

- Avaliar aspectos do aprendizado motor (aquisıçăo, retençăo e transfertencla) na esclerose mütipla.

Objettvos Secundarios

- Correladonar aspectos do aprendizado motor com o poimortsmo Val6eMet.

- Correlacionar aspectos do aprendizado motor com a incapacidade motora segundo os criterios de Kurtzke38.

Avallaçao dos Flacos $\theta$ Benencios:

Considerado risco minimo para realizaçafo da pesquisa e especificado o beneficio relacionado a malor compreensăo dos fenomenos relacionados ao aprendizado motor, visando a melhorla do processo de reabilitaçăo dos indlviduos portadores de esclerose mulitipla.

Comentarios $\theta$ Consideraç0es sobre a Pesqulsa:

Pesquisa de interesse para a area de saude, bem deserhada metodologicamente, com objetvos passivels de serem alcançados. Os preceltos eticos forarr considerados no projeto para futura reallzaçăo da mesma.

Consideraç0 sob sobre 08 Termos de apresentaçà obrigatorla:

Todos 05 termos obrigatorios foram devidamente apresentados.

Recomendaços:

N5̆o ha.

Conclusbes ou Pendenclas $\theta$ Llata de Inadequaçoes:

N55o ha.

Consideraços Finals a criterio do CEP:

Este parecer fol elaborado bseasdo nos documentos abalxo relacionados:

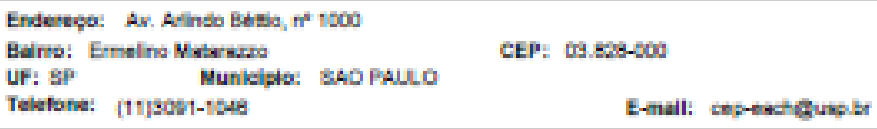


USP - ESCOLA DE ARTES,

CIÊNCIAS E HUMANIDADES

DA UNIVERSIDADE DE SÃO

Platoforma

grasil

Corthacks to Pawoer 1907.198

\begin{tabular}{|c|c|c|c|c|}
\hline Tipo Documento & Arquivo & Postagem & Altor & Situaç̧50 \\
\hline $\begin{array}{l}\text { Intormaçes Eds/cass } \\
\text { do Proleto }\end{array}$ & 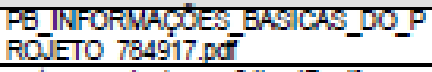 & $\begin{array}{c}2401 / 2017 \\
18: 43: 04\end{array}$ & & Acerio \\
\hline Qutros & carta_ressubmissao_24j|an17_por' & $\begin{array}{c}24 / 01 / 2017 \\
18: 42: 18\end{array}$ & Michele Schútz & Acelio \\
\hline $\begin{array}{l}\text { TCLE / Termos de } \\
\text { Assentlmento / } \\
\text { Justiflicativa de } \\
\text { Ausencla }\end{array}$ & TCLE_experimental_CEP.docx & $\begin{array}{c}24 / 01 / 2017 \\
18: 40: 33\end{array}$ & Michele Schultz & Aceltio \\
\hline $\begin{array}{l}\text { TCLE / Termos de } \\
\text { Assentlmento / } \\
\text { Justifncativa de } \\
\text { Ausencla }\end{array}$ & TCLE_cortrole_CEP.dOCX & $\begin{array}{c}24 / 01 / 2017 \\
18: 40: 23\end{array}$ & Michele Schultz & Aceltio \\
\hline $\begin{array}{l}\text { Declaracta de } \\
\text { Instituçasoe } \\
\text { intrastutura }\end{array}$ & carta_ABEM_pd" & $\begin{array}{c}08 / 11 / 2016 \\
17: 15: 59\end{array}$ & Michele Schưtz & Aceltio \\
\hline $\begin{array}{l}\text { Projeto Detalhado / } \\
\text { Erochura } \\
\text { Investigador }\end{array}$ & proj]eto_final_cep_O8Bnov $16 . d 0 \mathrm{C}$ & $\begin{array}{c}08 / 11 / 2016 \\
17: 15: 07\end{array}$ & Michele Schuitz & Acelito \\
\hline Outros & carta_cep_08nov16.pd" & $\begin{array}{c}08 / 11 / 2016 \\
17: 14: 06 \\
\end{array}$ & Michele Schultz & Acelito \\
\hline Qutros & carta_protocolo_cep.pdí & $\begin{array}{c}08 / 11 / 2016 \\
17: 13: 41 \\
\end{array}$ & Michele Schu'tz & Aceltio \\
\hline Foha de Fosto & Tolna_rosto_assinaca por & $\begin{array}{c}14 / 09 / 2016 \\
10: 05: 21 \\
\end{array}$ & Michee Schuitz & Acerio \\
\hline
\end{tabular}

sltuaçao do Parecer:

Aprovado

Necesalta Apreclaç:o da CONEP:

Náo

SAO PAULO, 03 de Março de 2017

Assinado por:

Rosa Yuka sato Chubacl

(Coordenador)

\footnotetext{
Endertęo: Av. Athato Bdsia, $\pi^{*} 160$

CEP: 여 : $5280-000$

Telefore: (11)govi-10e 
Anexo II- Escala Expandida do Estado de Incapacidade (EDSS)

\section{ESCALA EXPANDIDA DO ESTADO DE INCAPACIDADE - EDSS}

\begin{tabular}{|c|c|c|}
\hline Escore & Características & e Total \\
\hline 0 & $\begin{array}{l}\text { Exame neurológico normal (todos os SF } \\
\text { grau 0; cerebral, grau } 1 \text { aceitável) }\end{array}$ & \\
\hline 1,0 & Sem incapacidade (1 SF grau 1) & \\
\hline 1,5 & Sem incapacidade (2 SF grau 1) & \\
\hline 2,0 & $\begin{array}{l}\text { Incapacidade mínima em } 1 \mathrm{SF} \text { (1 SF } \\
\text { grau 2, outros grau } 0 \text { ou } 1)\end{array}$ & \\
\hline 2,5 & $\begin{array}{l}\text { Incapacidade minima em } 2 \mathrm{SF} \text { ( } 2 \mathrm{SF} \\
\text { grau 2, outros grau } 0 \text { ou } 1 \text { ) }\end{array}$ & \\
\hline 3,0 & $\begin{array}{l}\text { Incapacidade moderada em } 1 \mathrm{SF} \text { ( } 1 \mathrm{SF} \\
\text { grau 3, outros grau } 0 \text { ou } 1 \text { ) ou incapacidade } \\
\text { discreta em } 3 \text { ou } 4 \mathrm{SF} \text { (3/4 SF grau } 2 \text {, outros grau } \\
0 \text { ou 1). } \\
\text { Deambulando plenamente. }\end{array}$ & \\
\hline 3,5 & $\begin{array}{l}\text { Deambulação plena, com incapacidade } \\
\text { moderada em 1SF (1 SF grau 3) e } 1 \text { ou } 2 \mathrm{SF} \text { grau } \\
\text { 2; ou 2SF grau 3; ou } 5 \mathrm{SF} \text { grau } 2 \text { (outros } 0 \text { ou } 1)\end{array}$ & \\
\hline 4,0 & $\begin{array}{l}\text { Deambulação plena, até } 500 \mathrm{~m} \text { sem } \\
\text { ajuda ou descanso (1 SF grau 4, outros } 0 \text { ou } 1)\end{array}$ & \\
\hline 4,5 & $\begin{array}{l}\text { Deambulação plena, até } 300 \mathrm{~m} \text { sem } \\
\text { ajuda ou descanso. Com alguma limitação da } \\
\text { atividade ou requer assistência mínima (1 SF grau }\end{array}$ & \\
\hline
\end{tabular}




\begin{tabular}{|c|c|c|}
\hline & 4, outros 0 ou 1 ) & \\
\hline 5,0 & $\begin{array}{l}\text { Deambulação até } 200 \mathrm{~m} \text { sem ajuda ou } \\
\text { descanso. Limitação nas atividades diárias ( } \\
\text { equivalentes são } 1 \text { SF grau } 5 \text {, outros } 0 \text { ou } 1 \text {; ou } \\
\text { combinação de graus menores excedendo o } \\
\text { escore 4.0) }\end{array}$ & \\
\hline 5,5 & $\begin{array}{l}\text { Deambulação até } 100 \mathrm{~m} \text { sem ajuda ou } \\
\text { descanso. Incapacidade impedindo atividades } \\
\text { plenas diárias (equivalentes são } 1 \mathrm{SF} \text { grau } 5 \text {, } \\
\text { outros } 0 \text { ou 1; ou combinações de graus menores } \\
\text { excedendo o escore } 4.0 \text { ) }\end{array}$ & \\
\hline 6,0 & $\begin{array}{l}\text { Assistência intermitente ou com auxilio } \\
\text { unilateral constante de bengala, muleta ou suporte } \\
\text { (equivalentes são mais que } 2 \mathrm{SF} \text { graus } 3+\text { ) }\end{array}$ & \\
\hline 6,5 & $\begin{array}{l}\text { Assistência bilateral (equivalentes são } \\
\text { mais que } 2 \text { SF graus } 3+\text { ) }\end{array}$ & \\
\hline 7,0 & $\begin{array}{l}\text { Não anda } 5 \mathrm{~m} \text { mesmo com ajuda. } \\
\text { Restrito a cadeira de rodas. Transfere da cadeira } \\
\text { para cama (equivalentes são combinações com } \\
\text { mais que } 1 \mathrm{SF} 4+\text {, ou piramidal grau } 5 \\
\text { isoladamente) }\end{array}$ & \\
\hline 7,5 & $\begin{array}{l}\text { Consegue apenas dar poucos passos. } \\
\text { Restrito á cadeira de rodas. Necessita ajuda para } \\
\text { transferir-se (equivalentes são combinações com } \\
\text { mais que } 1 \mathrm{SF} \text { grau 4+) }\end{array}$ & \\
\hline 8,0 & $\begin{array}{r}\text { Restrito ao leito, mas pode ficar fora da } \\
\text { cama. Retém funções de autocuidado; bom uso }\end{array}$ & \\
\hline
\end{tabular}




\begin{tabular}{|c|c|}
\hline & $\begin{array}{l}\text { dos braços (equivalentes são combinações de } \\
\text { vários SF grau 4+) }\end{array}$ \\
\hline 8,5 & $\begin{array}{l}\text { Restrito ao leito constantemente. Retém } \\
\text { algumas funções de autocuidade e dos braços } \\
\text { (equivalentes são combinações de vários SF grau } \\
\text { 4+) }\end{array}$ \\
\hline 9 & $\begin{array}{l}\text { Paciente incapacitado no leito. Pode } \\
\text { comunicar, não come, não deglute (equivalentes é } \\
\text { a maioria de SF grau 4+) }\end{array}$ \\
\hline 9,5 & $\begin{array}{l}\text { Paciente totalmente incapacitado no } \\
\text { leito. Não comunica, não come, não deglute } \\
\text { (equivalentes são quase todos de SF grau 4+) }\end{array}$ \\
\hline 10 & Morte por esclerose múltipla \\
\hline TOTA & \\
\hline
\end{tabular}

*** SISTEMA FUNCIONAIS (SF) PARA A ESCALA EXPANDIDA DO ESTADO DE INCAPACIDADE

\section{Funções Piramidais}

1. Normal

2. Sinais anormais sem incapacidade motora

3. Incapacidade mínima

4. Discreta ou moderada paraparesia ou hemiparesia; monoparesia grave

5. Paraparesia ou hemiparesia acentuada; quadriparesia moderada; ou monoplegia

6. Paraplegia, hemiplegia ou acentuada quadriparesia

7. Quadriplegia

\section{Desconhecido}

\section{Funções Cerebelares}

1. Normal

2. Sinais anormais sem incapacidade

3. Ataxia discreta em qualquer membro

4. Ataxia moderada do tronco ou de membros

5. Incapaz de realizar movimentos coordenados devido á ataxia 


\section{Desconhecido}

\section{Funções do Tronco Cerebral}

1. Normal

2. Somente sinais anormais

3. Nistagmo moderado ou outra incapacidade leve

4. Nistagmo grave, acentuada paresia extraocular ou incapacidade moderada de outros cranianos

5. Disartria acentuada ou outra incapacidade acentuada

6. Incapacidade de deglutir ou falar

\section{Desconhecido}

\section{Funções Sensitivas}

1. Normal

2. Diminuição de sensibilidade ou estereognosia em 1-2 membros

3. Diminuição discreta de tato ou dor, ou da sensibilidade posicional, e/ou diminuição moderada da vibratória ou estereognosia em 1-2 membros; ou diminuição somente da vibratória em 3-4membros

4. Diminuição moderada de tato ou dor, ou posicional, e/ou perda da vibratória em 1-2 membros; ou diminuição discreta de tato ou dor, e/ou diminuição moderada de toda propriocepção em 3-4 membros

5. Diminuição acentuada de tato ou dor, ou perda da propriocepção em 1-2 membros, ou diminuição moderada de tato ou dor e/ou diminuição acentuada da propriocepção em mais de 2 membros

6. Perda da sensibilidade de 1-2 membros; ou moderada da diminuição de tato ou dor e/ou perda da propriocepção na maior parte do corpo abaixo da cabeça

\section{Desconhecido}

\section{Funções Vesicais}

1. Normal

2. Sintomas urinários sem incontinência

3. Incontinência \{ou igual uma vez por semana

4. Incontinência \}ou igual uma vez por semana

5. Incontinência diária ou mais que 1 vez por dia

6. Caracterização contínua

7. Grau para bexiga e grau 5 para disfunção retal

\section{Desconhecido}

\section{Funções intestinais}

1. Normal

2. < obstipação diária e sem incontinência

3. Obstipação diária sem incontinência

4. Obstipação < uma vez por semana

5. Incontinência > uma vez por semana mas não diária

6. Sem controle de esfíncter retal

7. Grau 5 para bexiga e grau 5 para disfunção retal

\section{Desconhecido}

\section{Funções Visuais}

1. Normal

2. Escotoma com acuidade visual (AV) igual ou melhor que 20/30

3. Pior olho com escotoma e AV de 20/30 a 20/59

4. Pior olho com grande escotoma, ou diminuição moderada dos campos, mas com AV de 20/60 a 20/99

5. Pior olho com diminuição acentuada dos campos e AV de 20/100 a 20/200; ou grau 3 com AV do melhor olho igual ao menor que $20 / 60$ 
6. Pior olho com AV menor que 20/200; ou grau 4 com AV do melhor olho igual ao menor que 20/60

7. Grau 5 com AV do melhor olho igual ou menor que 20/60

\section{Desconhecido}

\section{Funções mentais}

1. Normal

2. Alterações apenas do humor

3. Diminuição discreta da mentação

4. Diminuição normal da mentação

5. Diminuição acentuada da mentação (moderada síndrome cerebral crônica)

6. Demência ou grave síndrome cerebral crônica

\section{Desconhecido}

Outras funções

1. Nenhuma

2. Qualquer outro achado devido à EM

3. Desconhecido

\section{ferência:}

Kurtzke. Neurology 1983; 33:1444-52. 


\section{Anexo III}

Mini-exame do Estado Mental (MEEM)

1. Orientação temporal (1 ponto por cada resposta correta)

Que dia é hoje?

Em que mês estamos?

Em que ano estamos?

Em que dia da semana estamos?

Qual a hora aproximada?

(considere a variação de mais ou menos uma hora)

Nota:

Orientação espacial (1 ponto por cada resposta correta)

Em que local nós estamos? (apontando para o chão)

Que local é este aqui? (apontando ao redor, em sentido mais amplo)

Em que bairro nós estamos ou qual o nome de uma rua próxima?

Em que cidade nós estamos?

Em que Estado nós estamos?

Nota:

2. Memória imediata (contar 1 ponto por cada palavra corretamente repetida na $1^{\mathrm{a}} \mathrm{vez}$ )

"Eu vou dizer três palavras e você irá repeti-las a seguir:

Carro

Vaso

Tijolo

Nota:

3. Atenção e Cálculo (1 ponto por cada resposta correta. Se der uma resposta errada, mas depois continuar a subtrair bem e/ou auto-corrigir-se, consideram-se as respostas subseqüentes como corretas. Parar ao fim de 5 respostas)

"Agora lhe peço que me diga quantos são 100-7; 93-7; 86-7; 79-7; 72-7; 65 ".

Nota:

4. Evocação (1 ponto por cada resposta correta)

"Veja se consegue dizer as três palavras que pedi há pouco para decorar".

Carro

Vaso

Tijolo 
Nota:__ 5. Linguagem (1 ponto por cada resposta correta)

a. "Como se chama isto? Mostrar os objetos:

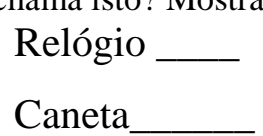

Caneta

Nota:

b. "Preste atenção, vou the dizer uma frase e quero que você repita depois de mim: Nem aqui, nem ali, nem lá" (considere 1 ponto somente de a repetição for perfeita)

Nota:

C. "Quando eu the der esta folha de papel, pegue nela com a mão direita, dobre-a ao meio e coloque-a no chão"; dar a folha segurando com as duas mãos. Se o sujeito pedir ajuda no meio da tarefa, não dê dicas.

Pega com a mão direita

Dobra ao meio

Coloca onde deve

Nota:

d. "Por favor, faça o que está escrito neste cartão". Mostrar um cartão com a frase bem legível, "FECHE OS OLHOS"; sendo analfabeto lê-se a frase.

Fechou os olhos

Nota:

e. "Escreva uma frase inteira aqui". Deve ter sujeito e verbo e fazer sentido, com começo, meio e fim; os erros gramaticais não prejudicam a pontuação. (1 ponto)

Frase:

Nota:

6. Habilidade Construtiva (1 ponto pela cópia correta)

Deve copiar um desenho. Dois pentágonos parcialmente sobrepostos; cada um deve ficar com 5 lados, dois dos quais intersectados. Não valorizar tremor ou rotação.

Cópia:

Nota:

TOTAL(Máximo 30 pontos): 
Anexo IV

Termos de Consentimento Livre e Esclarecido (TCLE)

TERMO DE CONSENTIMENTO LIVRE E ESCLARECIDO

Grupo Controle - Participantes não portadores de Esclerose Múltipla

DADOS DE IDENTIFICAÇÃO DO PARTICIPANTE DA PESQUISA OU RESPONSÁVEL LEGAL

1.NOME:

DOCUMENTO DE IDENTIDADE.

SEXO : $\mathrm{M} \square \mathrm{F} \square$

DATA NASCIMENTO: .......................

ENDEREÇO

RUA

$\mathrm{N}^{\mathrm{o}}$

APTO:

BAIRRO:

CIDADE:

CEP:

TELEFONE:

DDD ( ..)...

\section{RESPONSÁVEL LEGAL}

NATUREZA (grau de parentesco, tutor, curador etc.)

DOCUMENTO DE IDENTIDADE

SEXO: $\mathrm{M} \square \mathrm{F} \square$

DATA NASCIMENTO.: .....................

ENDEREÇO:

RUA.

$\mathrm{N}^{\mathrm{o}}$

APTO:

BAIRRO:

CIDADE:

.CEP:

TELEFONE: DDD

(.............)....... 
DADOS SOBRE A PESQUISA

1. TÍTULO DO PROTOCOLO DE PESQUISA: Aprendizado Motor na Esclerose Múltipla

\section{PESQUISADORES}

PESQUISADOR 1: Profa. Dra. Michele Schultz

CARGO/FUNÇÃO: Professora da Escola de Artes, Ciências e Humanidades da Universidade de São Paulo e orientadora de mestrado e doutorado pelo programa Neurociências e Comportamento do Instituto de Psicologia da USP.

PESQUISADOR 2: Nádia Baggio Barreto Rodrigues

CARGO/FUNÇÃO: Fisioterapeuta pós-graduanda do programa Neurociências e Comportamento do Instituto de Psicologia da Universidade de São Paulo, nível mestrado.

3. AVALIAÇÃO DO RISCO DA PESQUISA:

$\begin{array}{lll}\text { RISCO MÍNIMO } & \mathbf{X} & \text { RISCO MÉDIO } \\ \text { RISCO BAIXO } & \square & \text { RISCO MAIOR }\end{array}$

4. DURAÇÃO TOTAL DA PESQUISA: 24 meses

Prezado Senhor(a), a Esclerose Múltipla pode trazer alterações motoras as quais podem associar-se a dificuldades de aprendizado motor, interferindo no processo de reabilitação. Por isto, o senhor(a) está sendo convidado(a) a participar desta pesquisa intitulada: "Aprendizado Motor na Esclerose Múltipla”, cujo objetivo é avaliar aspectos do aprendizado motor na esclerose múltipla e relacioná-lo a variáveis como alterações genéticas e grau de incapacidade motora. Ou seja, este estudo visa verificar como o aprendizado motor se comporta frente a esclerose múltipla.

Para tal se faz necessária a comparação com o comportamento do aprendizado motor de participantes não portadores de esclerose múltipla, denominados grupo controle, pareados por idade, sexo e escolaridade aos participantes portadores de esclerose múltipla, denominados grupo experimental, por este motivo, o senhor(a) está sendo convidado (a) a participar desta pesquisa.

O senhor(a) participará de uma avaliação de rastreio e avaliação cognitiva, avaliação do aprendizado motor e será coletada uma amostra da sua mucosa oral e saliva para realizarmos análises genéticas laboratoriais. Todo o procedimento será realizado em dois dias, com duração máxima de 02 horas por dia. 
A avaliação cognitiva será realizada através do teste Mini-exame do Estado Mental-MEEM e faz parte do protocolo de elegibilidade da pesquisa, podendo ser incluído ou não na pesquisa a partir dos resultados desta avaliação. O pesquisador lhe apresentará testes simples relacionados à orientação espacial e temporal, memória, cálculo, linguagem-nomeação, repetição, compreensão, escrita e cópia de desenho.

A avaliação do aprendizado motor consistirá na realização de uma atividade manual simples, na qual o participante estará sentado em uma cadeira confortável e posicionado diante de uma mesa e do aparelho de teste, composto por uma barra de madeira de $17 \mathrm{~cm}$ e peso estimado de $300 \mathrm{~g}$ e caixa de madeira, nas dimensões $13 \times 15 \times 4,5$. Será solicitado ao participante que insira a barra de madeira em um orifício existente na caixa, na maior velocidade possível. A tarefa é composta por quatro fases realizadas em dois dias com intervalo de uma semana entre eles. No primeiro dia serão realizadas as fases de aquisição, na qual o participante realizará 50 repetições da tarefa, fase de retenção 1, na qual serão realizadas 10 repetições da tarefa e fase de transferência, com 10 repetições da mesma. No segundo dia será realizada a fase de retenção 2, com 10 repetições da tarefa. Durante a realização da tarefa os participantes serão filmados nos planos frontal (câmera posicionada à frente do participante) e transversal (câmera posicionada acima do participante), de forma a verificar a existência de movimentos compensatórios nos membros superiores e tronco. Para tanto, serão posicionados marcadores de isopor em pontos específicos do braço e tronco dos participantes, a saber: acrômio (no ombro), olécrano (no cotovelo) e processo estilóide da ulna (no punho) do membro superior dominante, vértebras torácicas e lombares (na coluna vertebral) e espinha ilíaca póstero-superior (no quadril) bilateralmente.

A coleta da amostra de mucosa oral e saliva será realizada no primeiro dia de teste, por profissional capacitado e com materiais e procedimentos adequados; o material utilizado para a coleta será de uso exclusivo do paciente e será imediatamente descartado após sua utilização. A coleta consiste em leve escovação da cavidade oral do participante, sem causar qualquer tipo de lesão. As amostras serão identificadas por códigos e a identidade dos participantes preservada. O material coletado será encaminhado para o laboratório de Biomedicina da Escola de Artes, Ciências e Humanidades da USP, onde será armazenado para posterior análise. Após a utilização das amostras, o conteúdo restante será descartado como resíduo de serviço de saúde (grupo A1) de acordo com as normas vigentes. 
Os riscos aos quais o senhor(a) estará exposto são mínimos e relacionam-se a risco de queda durante o deslocamento na instituição, mínimo desconforto durante a extração de saliva e mínima fadiga muscular ou mental durante a realização dos testes de aprendizado motor. No entanto serão tomadas medidas para que estes sejam diminuídos, como por exemplo, pausas durante os testes e caso o senhor(a) deseje, o procedimento poderá ser interrompido imediatamente. Em caso de eventuais danos o senhor(a) será devidamente indenizado(a).

Os benefícios advindos desta pesquisa relacionam-se a uma maior compreensão dos fenômenos relacionados ao aprendizado motor, podendo contribuir com o processo de reabilitação dos indivíduos portadores de esclerose múltipla. Não haverá benefício imediato, bem como pagamentos ou compensações financeiras.

Ressaltamos que o senhor(a) poderá ter acesso aos seus resultados da pesquisa a qualquer momento e se quiser sair da pesquisa, o seu tratamento na Associação Brasileira de Esclerose Múltipla continuará normalmente. Os resultados individuais de cada participante da pesquisa serão do conhecimento exclusivo dos pesquisadores envolvidos, sendo que as informações obtidas serão analisadas em conjunto com outros participantes e não haverá divulgação da identificação de nenhum participante. Quando os resultados forem publicados em revistas científicas, em congressos ou demais eventos científicos, sua privacidade sempre estará garantida.

Ressaltamos que não há despesas pessoais para o senhor(a) em qualquer fase do estudo, incluindo exames e consultas. Também não há compensação financeira relacionada à sua participação no estudo.

Este projeto foi aprovado pelo Comitê de Ética em Pesquisa (CEP) - Escola de Artes, Ciências e Humanidades Universidade de São Paulo, que tem por finalidade analisar as pesquisas desenvolvidas em seres humanos realizadas por docentes, alunos, técnicos da EACH-USP, sob os aspectos ético e legal (enquadrando-se na legislação vigente para a espécie, especialmente a Resolução n0 196, de 10 de outubro de 1996, do Conselho Nacional de Saúde). Desse modo, se o(a) senhor(a) tiver alguma consideração ou dúvida sobre a ética da pesquisa, entre em contato com o Comitê de Ética em Pesquisa (CEP) - Escola de Artes, Ciências e Humanidades Universidade de São Paulo. Av. Arlindo Béttio, 1000, Ermelino Matarazzo São Paulo - SP. CEP: 03828-000. Sala T14-I1. Telefone: (11) 3091-1046. E-mail: cep-each@usp.br.

O pesquisador responsável por esta pesquisa é a professora Dra. Michele Schultz e a segunda pesquisadora é a aluna de pós-graduação Nádia Baggio Barreto Rodrigues, 
ambas podem ser localizadas na Universidade de São Paulo-Escola de Ciências, Artes e Humanidades (EACH), Av. Arlindo Bettio, 1000, sala 252, Ermelino Matarazzo, 03828000 - São Paulo, SP - Brasil. Telefone: (11) 3091-8123, bem como pelos e-mails: mschultz@usp.br e nadia.baggio@usp.br e pelos telefones pessoais (11) 3091-8830 e (11)96342-5838.

Eu (nome do participante ou responsável),

discuti com a equipe da Profa. Dra. Michele Schultz, sobre a minha decisão em participar nesse estudo. Ficaram claros para mim quais são os propósitos do estudo, os procedimentos a serem realizados, seus desconfortos e riscos, as garantias de confidencialidade e de esclarecimentos permanentes. Ficou claro também que minha participação é isenta de despesas. Concordo voluntariamente em participar deste estudo e poderei retirar o meu consentimento a qualquer momento, antes ou durante o mesmo, sem penalidades, prejuízo ou perda de qualquer benefício que eu possa ter adquirido, ou no meu atendimento na Associação Brasileira de Esclerose Múltipla-ABEM.

Declaro que, após convenientemente esclarecido pelo pesquisador e ter entendido o que me foi explicado, consinto em participar do presente Protocolo de Pesquisa.

Assinatura do paciente/representante legal Data / / 
(Somente para o responsável do projeto)

Declaro que obtive de forma apropriada e voluntária o Consentimento Livre e Esclarecido deste paciente ou representante legal para a participação neste estudo.

Assinatura do responsável pelo estudo Data / /

Nádia Baggio Barreto Rodrigues 
TERMO DE CONSENTIMENTO LIVRE E ESCLARECIDO

Grupo Experimental - Participantes portadores de Esclerose Múltipla

DADOS DE IDENTIFICAÇÃO DO PARTICIPANTE DA PESQUISA OU RESPONSÁVEL LEGAL

1.NOME:

DOCUMENTO DE IDENTIDADE.

SEXO : $M \square F \square$

DATA NASCIMENTO: .......................

ENDEREÇO

RUA

$\mathrm{N}^{\mathrm{o}}$

APTO:

BAIRRO:

CIDADE:

CEP:.

TELEFONE:

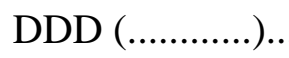

\section{RESPONSÁVEL LEGAL}

NATUREZA (grau de parentesco, tutor, curador etc.)

DOCUMENTO DE IDENTIDADE

SEXO: $\mathrm{M} \square \mathrm{F} \square$

DATA NASCIMENTO.: .....................

ENDEREÇO:

RUA

$\mathrm{N}^{\mathrm{o}}$

APTO: BAIRRO:

CIDADE:

CEP:

TELEFONE: DDD

DADOS SOBRE A PESQUISA 
1. TÍTULO DO PROTOCOLO DE PESQUISA: Aprendizado Motor na Esclerose Múltipla

\section{PESQUISADORES}

PESQUISADOR 1: Profa. Dra. Michele Schultz

CARGO/FUNÇÃO: Professora da Escola de Artes, Ciências e Humanidades da Universidade de São Paulo e orientadora de mestrado e doutorado pelo programa Neurociências e Comportamento do Instituto de Psicologia da USP.

PESQUISADOR 2: Nádia Baggio Barreto Rodrigues

CARGO/FUNÇÃO: Fisioterapeuta pós-graduanda do programa Neurociências e Comportamento do Instituto de Psicologia da Universidade de São Paulo, nível mestrado.

3. AVALIAÇÃO DO RISCO DA PESQUISA:

\section{RISCO MÍNIMO $\mathbf{X}$ RISCO MÉDIO \\ RISCO BAIXO $\quad \square \quad$ RISCO MAIOR}

\section{DURAÇÃO TOTAL DA PESQUISA: 24 meses}

Prezado Senhor(a), a Esclerose Múltipla pode trazer alterações motoras as quais podem associar-se a dificuldades de aprendizado motor, interferindo no processo de reabilitação. Por isto, o senhor(a) está sendo convidado(a) a participar desta pesquisa intitulada: “Aprendizado Motor na Esclerose Múltipla”, cujo objetivo é avaliar aspectos do aprendizado motor na esclerose múltipla e relacioná-lo a variáveis como alterações genéticas e grau de incapacidade motora. Ou seja, este estudo visa verificar como o aprendizado motor se comporta frente a esclerose múltipla.

O senhor(a) participará de uma avaliação de rastreio e avaliação cognitiva, avaliação do aprendizado motor e será coletada uma amostra da sua mucosa oral e saliva para realizarmos análises genéticas laboratoriais. Todo o procedimento será realizado em dois dias, com duração máxima de 02 horas por dia.

A avaliação cognitiva será realizada através do teste Mini-exame do Estado Mental-MEEM e faz parte do protocolo de elegibilidade da pesquisa, podendo ser incluído ou não na pesquisa a partir dos resultados desta avaliação. O pesquisador lhe apresentará testes simples relacionados à orientação espacial e temporal, memória, cálculo, linguagem-nomeação, repetição, compreensão, escrita e cópia de desenho.

A avaliação do aprendizado motor consistirá na realização de uma atividade manual simples, na qual o participante estará sentado em uma cadeira confortável e posicionado diante de uma mesa e do aparelho de teste, composto por uma barra de 
madeira de $17 \mathrm{~cm}$ e peso estimado de $300 \mathrm{~g}$ e caixa de madeira, nas dimensões $13 \times 15 \times 4,5$. Será solicitado ao participante que insira a barra de madeira em um orifício existente na caixa, na maior velocidade possível. A tarefa é composta por quatro fases realizadas em dois dias com intervalo de uma semana entre eles. No primeiro dia serão realizadas as fases de aquisição, na qual o participante realizará 50 repetições da tarefa, fase de retenção 1, na qual serão realizadas 10 repetições da tarefa e fase de transferência, com 10 repetições da mesma. No segundo dia será realizada a fase de retenção 2, com 10 repetições da tarefa. Durante a realização da tarefa os participantes serão filmados nos planos frontal (câmera posicionada à frente do participante) e transversal (câmera posicionada acima do participante), de forma a verificar a existência de movimentos compensatórios nos membros superiores e tronco. Para tanto, serão posicionados marcadores de isopor em pontos específicos do braço e tronco dos participantes, a saber: acrômio (no ombro), olécrano (no cotovelo) e processo estilóide da ulna (no punho) do membro superior dominante, vértebras torácicas e lombares (na coluna vertebral) e espinha ilíaca póstero-superior (no quadril) bilateralmente.

A coleta da amostra de mucosa oral e saliva será realizada no primeiro dia de teste, por profissional capacitado e com materiais e procedimentos adequados; o material utilizado para a coleta será de uso exclusivo do paciente e será imediatamente descartado após sua utilização. A coleta consiste em leve escovação da cavidade oral do participante, sem causar qualquer tipo de lesão. As amostras serão identificadas por códigos e a identidade dos participantes preservada. O material coletado será encaminhado para o laboratório de Biomedicina da Escola de Artes, Ciências e Humanidades da USP, onde será armazenado para posterior análise. Após a utilização das amostras, o conteúdo restante será descartado como resíduo de serviço de saúde (grupo A1) de acordo com as normas vigentes.

Os riscos aos quais o senhor(a) estará exposto são mínimos e relacionam-se a risco de queda durante o deslocamento na instituição, mínimo desconforto durante a extração de saliva e mínima fadiga muscular ou mental durante a realização dos testes de aprendizado motor. No entanto serão tomadas medidas para que estes sejam diminuídos, como por exemplo, pausas durante os testes e caso o senhor(a) deseje, o procedimento poderá ser interrompido imediatamente. Em caso de eventuais danos o senhor(a) será devidamente indenizado(a).

Os benefícios advindos desta pesquisa relacionam-se a uma maior compreensão dos fenômenos relacionados ao aprendizado motor, podendo contribuir com o processo de 
reabilitação dos indivíduos portadores de esclerose múltipla. Não haverá benefício imediato, bem como pagamentos ou compensações financeiras.

Ressaltamos que o senhor(a) poderá ter acesso aos seus resultados da pesquisa a qualquer momento e se quiser sair da pesquisa, o seu tratamento na Associação Brasileira de Esclerose Múltipla continuará normalmente. Os resultados individuais de cada participante da pesquisa serão do conhecimento exclusivo dos pesquisadores envolvidos, sendo que as informações obtidas serão analisadas em conjunto com outros participantes e não haverá divulgação da identificação de nenhum participante. Quando os resultados forem publicados em revistas científicas, em congressos ou demais eventos científicos, sua privacidade sempre estará garantida.

Ressaltamos que não há despesas pessoais para o senhor(a) em qualquer fase do estudo, incluindo exames e consultas. Também não há compensação financeira relacionada à sua participação no estudo.

Este projeto foi aprovado pelo Comitê de Ética em Pesquisa (CEP) - Escola de Artes, Ciências e Humanidades Universidade de São Paulo, que tem por finalidade analisar as pesquisas desenvolvidas em seres humanos realizadas por docentes, alunos, técnicos da EACH-USP, sob os aspectos ético e legal (enquadrando-se na legislação vigente para a espécie, especialmente a Resolução n0 196, de 10 de outubro de 1996, do Conselho Nacional de Saúde). Desse modo, se o(a) senhor(a) tiver alguma consideração ou dúvida sobre a ética da pesquisa, entre em contato com o Comitê de Ética em Pesquisa (CEP) - Escola de Artes, Ciências e Humanidades Universidade de São Paulo. Av. Arlindo Béttio, 1000, Ermelino Matarazzo São Paulo - SP. CEP: 03828-000. Sala T14-I1. Telefone: (11) 3091-1046. E-mail: cep-each@usp.br.

O pesquisador responsável por esta pesquisa é a professora Dra. Michele Schultz e a segunda pesquisadora é a aluna de pós-graduação Nádia Baggio Barreto Rodrigues, ambas podem ser localizadas na Universidade de São Paulo-Escola de Ciências, Artes e Humanidades (EACH), Av. Arlindo Bettio, 1000, sala 252, Ermelino Matarazzo, 03828000 - São Paulo, SP - Brasil. Telefone: (11) 3091-8123, bem como pelos e-mails: mschultz@usp.br e nadia.baggio@usp.br e pelos telefones pessoais (11) 3091-8830 e (11)96342-5838. 
Eu (nome do participante ou responsável),

discuti com a equipe da Profa. Dra. Michele Schultz, sobre a minha decisão em participar nesse estudo. Ficaram claros para mim quais são os propósitos do estudo, os procedimentos a serem realizados, seus desconfortos e riscos, as garantias de confidencialidade e de esclarecimentos permanentes. Ficou claro também que minha participação é isenta de despesas. Concordo voluntariamente em participar deste estudo e poderei retirar o meu consentimento a qualquer momento, antes ou durante o mesmo, sem penalidades, prejuízo ou perda de qualquer benefício que eu possa ter adquirido, ou no meu atendimento na Associação Brasileira de Esclerose Múltipla-ABEM.

Declaro que, após convenientemente esclarecido pelo pesquisador e ter entendido o que me foi explicado, consinto em participar do presente Protocolo de Pesquisa.

Assinatura do paciente/representante legal Data / /

(Somente para o responsável do projeto)

Declaro que obtive de forma apropriada e voluntária o Consentimento Livre e Esclarecido deste paciente ou representante legal para a participação neste estudo.

Assinatura do responsável pelo estudo Data / / 